\title{
Alimentação no primeiro semestre de vida de crianças com risco para o desenvolvimento de asma e/ou atopia. Projeto Chiado
}

\author{
Rafael de Carvalho Cacavallo
}

Dissertação apresentada ao Programa de Pós-Graduação em Saúde Pública da Faculdade de Saúde Pública da Universidade de São Paulo para obtenção do título de Mestre em Saúde Pública

Área de Concentração: Epidemiologia Orientador: Profa. Dra. Maria Regina Alves Cardoso 


$$
4583912005 \text { dor. }
$$

Autorizo exclusivamente para fins acadêmicos e científicos a reprodução total ou parcial desta dissertação por processos fotocopiadores. Ao usá-la, cite a fonte.

Autor: Raluel de C Cacuvallo

Data: $04 / 03 / 05$ 


\section{AGRADECIMENTOS}

A todos aqueles que considerem terem colaborado, de alguma forma, para a realização deste trabalho.

À Coordenadoria de Aperfeiçoamento de Pessoal de Nivel Superior (CAPES) pela doação concedida. 


\section{RESUMO}

Cacavallo RC. Alimentação no primeiro semestre de vida de crianças com risco para o desenvolvimento de asma e/ou atopia - ProjeTo ChIADo. São Paulo; 2005. [Dissertação de Mestrado - Faculdade de Saúde Pública - USP].

Objetivo Nutrição ideal e boa alimentação de recém-nascidos e lactentes são fatores determinantes para sua saúde, crescimento e desenvolvimento, outrossim, o destaque para o aleitamento materno como fator protetor contra inúmeras doenças. Propöe-se descrever e caracterizar o padrão alimentar e o crescimento de crianças no primeiro semestre de vida, participantes do estudo "Poluição ambiental urbana e outros fatores relacionados à ocorrência de chiado na infância: um estudo de coorte na cidade de São Paulo, Brasil - ProJeto CHIADO". Método Utilizaram-se de dados de uma coorte de recém-nascidos em andamento na cidade de São Paulo. Estudaram-se variáveis sócio-econômicas; alimentares, com proposta de classificaçāo do padrāo alimentar envolvendo aspectos fundamentais da alimentação infantil para diagnóstico da condição alimentar da criança; e antropométricas, para cálculo dos índices de interesse e comparação com o padrão de referência do NCHS. Resultados Das 174 crianças com informação disponível no início do estudo, 103 completaram 6 meses de vida. Observou-se duração média do aleitamento materno de 96,32 dias (13,76 semanas), sendo a duração mediana de 91,2 dias (13 semanas) e duração média do aleitamento materno exclusivo (AME) de 60,26 dias (8,6 semanas), sendo a duração mediana de 30,4 dias (4,34 semanas). Quanto ao crescimento (estado nutricional), verificou-se prevalência de pesolestatura < -2dp $[\mathrm{WHZ}<-2 d p]$, aos 6 meses de vida, de 1,32\% e 9,21\% para peso/estatura > +2dp $[\mathrm{WHZ}>+2 \mathrm{dp}$ ]. A prevalência de retardo de crescimento (déficit estatural) [HAZ<-2dp] foi de 2,63\% e não se observaram casos de baixo peso para idade [WAZ< -2dp] ao final do seguimento. Em relação ao padrão NCHS e ao grupo "não AME", as crianças em aleitamento materno exclusivo (AME) apresentaram desempenho de crescimento menos satisfatório, confirmando a inadequação do referido padrão para a avaliação do crescimento de crianças nessa condição alimentar. Conclusão Embora com desempenho geral de crescimento satisfatório, a população estudada, apesar do intenso seguimento com orientação nutricional, apresentou prática alimentar com adequação muito aquém das recomendações atuais.

Palavras chave: alimentação infantil, estado nutricional, coorte, chiado. 


\section{ABSTRACT}

Cacavallo RC. Feeding in the first 6 months of life of infants at risk for asthma/atopy development - Projeto ChIADo. São Paulo; 2005. [Master degree - Faculdade de Saúde Pública - USP].

Objective Optimum nutrition and good feeding of infants and young children determine their health, growth and development, furthermore the hole of breastfeeding as a protective factor against a large sorts of diseases. This study aims to characterize and describe the feeding pattern and growth of infants in the first 6 months of life who are included in the study "Urban air pollution and other factors related with the occurrence of wheezing in childhood: a birth cohort in the city of Sao Paulo, Brazil - Projeto ChIADo". Methods Data of a birth cohort ongoing at the city of Sao Paulo were used. Socio-economic variables; feeding practices variables, with the proposal of a feeding pattern classification that enable the assessment of the infant's feeding status; and anthropometrical variables, for the anthropometric indices calculation and comparison with the NCHS reference, were studied. Results 103 of the 174 newborns with available information at the initial point of the study completed 6 months of age. The mean duration of breastfeeding was 96.32 days (13.76 weeks), with median duration of 91.2 days (13 weeks); mean duration of exclusive breastfeeding (AME) was 60.26 days ( 8.6 weeks), with median duration of 30.4 days (4.34 weeks). The weight-for-length deficit $[\mathrm{WHZ}<-2 \mathrm{sd}]$ prevalence at 6 months of age was $1.32 \%$, and weight-forlength $z$-score $>+2 s d[W H Z>+2 s d]$ showed a $9.21 \%$ prevalence. Growth faltering $[\mathrm{HAZ}<-2 \mathrm{sd}]$ prevalence was $2.63 \%$ and no low weight-for-age $[\mathrm{WAZ}<-2 \mathrm{sd}]$ cases were observed at the age of 6 months. The exclusive breastfed infants set "AME" showed a less satisfactory growth performance when compared with the NCHS reference and with the "não AME" set, reinforcing the unsuitability of the present international reference to assess the growth of exclusive breastfed infants. Conclusion Though showing a general satisfactory growth performance, the studied population, even though at intensive follow-up with nutritional counseling, presented feeding practices those are far away from current recommendations.

Key words: infant feeding, nutritional status, cohort, wheezing. 


\section{LISTA DE SIGLAS E ABREVIATURAS}
AA -
Aleitamento artificial.
$\mathrm{ACl}-$
Alimentação complementar insuficiente.
$\mathrm{ACO}-$
Alimentação complementar oportuna.
AME -
Aleitamento materno exclusivo.
AMP -
Aleitamento materno predominante.
$\mathrm{AMPa}-$
Aleitamento materno parcial.
AMT -
Aleitamento materno total.
CET -
Companhia de Engenharia de Tráfego de São Paulo.
CETESB -
Companhia de Tecnologia de Saneamento Ambiental.
COEP - Comitê de Ética em Pesquisa.
CONEP -
Comissão Nacional de Ética em Pesquisa.
FMUSP -
Faculdade de Medicina da Universidade de São Paulo.
Idade insuf. - Idade insuficiente.
INMETRO - Instituto Nacional de Metrologia, Normalização e Qualidade Industrial.
IPA -
Introdução precoce de alimentos.
MGRS -
Multicentre Growth Reference Study.
NCHS -
National Centers for Health Statistics.
ONU -
Organização das Nações Unidas.
OPAS -
Organização Pan-Americana de Saúde.
Sem inf. -
Sem informação.
SM -
Salário mínimo.
UN-SCN -
United Nations - Standing Committee on Nutrition
USP -
Universidade de São Paulo.
VTR -
Vias de trânsito rápido.
WHO -
World Health Organization. 


\section{LISTA DE TABELAS}

Tabela 1: Distribuição do número e porcentagem de crianças participantes do PROJETO CHIADO segundo as variáveis sócioeconômicas estudadas, São Paulo, 2005.

Tabela 2: Número de crianças participantes do PROJETo ChIADO, média e desvio-padrăo, valor mínimo e valor máximo; de peso $(\mathrm{g})$ e comprimento $(\mathrm{cm})$, por sexo, para cada etapa do seguimento, São Paulo, 2005.

Tabela 3: Distribuição do índice peso/idade em escore $Z$ (WAZ) para as crianças participantes do PROJETO CHIADO, segundo sexo e etapa do seguimento, São Paulo, 2005.

Tabela 4: Distribuição do indice estatura [comprimento]/idade em escore Z (HAZ) para as crianças participantes do PROJETO CHIADO, segundo sexo e etapa do seguimento, Săo Paulo, 2005.

Tabela 5: Distribuição do índice peso/estatura [comprimento] em escore $Z$ (WHZ) para as crianças participantes do PROJETO CHIADO, segundo sexo e etapa do seguimento, São Paulo, 2005. 


\section{LISTA DE FIGURAS}

Figura 1: Dinâmica da amostra do Projeto Chiado da fase de recrutamento ao presente estudo, São Paulo, 2005.

Figura 2: Distribuição da quantidade de crianças participantes do PROJETo ChIAdo para cada etapa do seguimento, São Paulo, 2005.

Figura 3: Distribuição das familias das crianças participantes do PROJETO CHIADO com relação à propriedade da casa, São Paulo, 2005.

Figura 4: Distribuição das mães das crianças participantes do PROJETo ChIADo com relação à escolaridade em anos, São Paulo, 2005.

Figura 5: Situação das familias das crianças participantes do PROJETo CHIADO com relação à renda familiar em SM per capita, São Paulo, 2005.

Figura 6: Situação das familias das crianças participantes do PROJETo CHIADo com relação à condição de classe, Săo Paulo, 2005.

Figura 7: Distribuição das crianças participantes do PROJETO CHIADO segundo padrōes de aleitamento nos sete periodos de seguimento, São Paulo, 2005.

Figura 8: Dinâmica do padrăo de aleitamento das crianças participantes do PROJETO CHIADO a partir da situação inicial aos 15 dias de vida, número de crianças e porcentagem para cada padrão, São Paulo, 2005.

Figura 9: Distribuição das crianças participantes do PROJETO CHIADO segundo padrōes de alimentação nos sete períodos de seguimento, São Paulo, 2005.

Figura 10: Dinâmica do padrão de alimentação das crianças participantes do PROJETO CHIADO a partir da situaçăo inicial aos 15 dias de vida, número de crianças e porcentagem para cada padrão, São Paulo, 2005. 
Figura 11: Distribuição das médias de escore $Z$ para 0 índice peso/idade (WAZ) das crianças participantes do PROJETO CHIADO nas sete etapas de seguimento, Săo Paulo, 2005.

Figura 12: Distribuiçăo das médias de escore $Z$ para o índice estatura [comprimento]/idade (HAZ) das crianças participantes do PROJETO CHIADO nas sete etapas de seguimento, São Paulo, 2005.

Figura 13: Distribuiçăo das médias de escore $Z$ para 0 índice peso/estatura [comprimento] (WHZ) das crianças participantes do PROJeto CHIADO nas sete etapas de seguimento, São Paulo, 2005.

Figura 14: Distribuição das médias de escore $Z$ para os indices peso/idade (WAZ), estatura [comprimento]/idade (HAZ) e pesolestatura [comprimento] (WHZ) das crianças participantes do PROJETO CHIAdO nas sete etapas de seguimento, São Paulo, 2005.

Figura 15: Distribuição dos valores de escore $Z$ para 0 indice pesolidade (WAZ) das crianças participantes do PROJETO CHIADO na consulta de 15 dias versus o padrăo de referência do NCHS, São Paulo, 2005.

Figura 16: Distribuiçăo dos valores de escore $Z$ para o índice estatura [comprimento]/idade (HAZ) das crianças participantes do PROJETo CHIADO na consulta de 15 dias versus o padrão de referência do NCHS, São Paulo, 2005.

Figura 17: Distribuição dos valores de escore $Z$ para 0 indice peso/estatura [comprimento] (WHZ) das crianças participantes do PROJETO CHIADO na consulta de 15 dias versus o padrăo de referéncia do NCHS, Săo Paulo, 2005.

Figura 18: Distribuiçăo dos valores de escore $Z$ para 0 indice pesolidade (WAZ) das crianças participantes do PROJETO CHIADO na consulta de 3 meses versus o padrão de referência do NCHS, São Paulo, 2005.

Figura 19: Distribuiçăo dos valores de escore $Z$ para o índice estatura [comprimento]/idade (HAZ) das crianças participantes do PROJETo CHIADO na consulta de 3 meses versus o padrão de referência do NCHS, Såo Paulo, 2005. 
Figura 20: Distribuiçăo dos valores de escore $Z$ para 0 indice peso/estatura [comprimento] ( $\mathrm{WHZ}$ ) das crianças participantes do PROJeto ChiAdo na consulta de 3 meses versus o padrão de referência do NCHS, São Paulo, 2005.

Figura 21: Distribuição dos valores de escore $Z$ para 0 índice peso/idade (WAZ) das crianças participantes do PROJETO CHIADO na consulta de 6 meses versus o padrăo de referência do NCHS, São Paulo, 2005.

Figura 22: Distribuição dos valores de escore $Z$ para o índice estatura [comprimento]/idade (HAZ) das crianças participantes do PROJETO CHIADO na consulta de 6 meses versus o padrăo de referência do NCHS, São Paulo, 2005.

Figura 23: Distribuição dos valores de escore $Z$ para 0 índice peso/estatura [comprimento] $(\mathrm{WHZ})$ das crianças participantes do Projeto Chiado na consulta de 6 meses versus o padrão de referência do NCHS, São Paulo, 2005.

Figura 24: Distribuição das médias de escore $Z$ para 0 índice pesolidade (WAZ) das crianças participantes do PROJETO CHIADO, nas sete etapas de seguimento, segundo estratificação por padrão de aleitamento, São Paulo, 2005.

Figura 25: Distribuição das médias de escore $Z$ para o índice estatura [comprimento]/idade (HAZ) das crianças participantes do PROJETO CHIADO, nas sete etapas de seguimento, segundo estratificação por padrão de aleitamento, São Paulo, 2005.

Figura 26: Distribuição das médias de escore $Z$ para $\circ$ índice peso/estatura [comprimento] (WHZ) das crianças participantes do PROJeto ChIADO, nas sete etapas de seguimento; geral e segundo estratificação por padrão de aleitamento, São Paulo, 2005. 


\section{ÍNDICE}

1 INTRODUÇÃO

1.1 Alimentação no primeiro ano de vida 1

1.2 Alimentação infantil, estado nutricional e fatores sócioeconômicos

1.3 Alimentação infantil, estado nutricional e indicadores antropométricos

\section{OBJETIVOS}

2.1 Objetivo Geral 22

2.2 Objetivos Específicos 22

3 MÉTODO 23

3.1 Desenho do estudo 23

3.2 Critérios de elegibilidade $\quad 23$

3.3 Coleta dos dados 27

3.3.1 O acompanhamento das crianças 27

3.4 Estudo piloto 32

3.5 Entrada e análise dos dados 32

3.5.1 Análise descritiva 38

4 ASPECTOS ÉTICOS

5 RESULTADOS E DISCUSSÃO $\quad 40$

5.1 Dinâmica da amostra 40

5.2 Condições sócio-econômicas $\quad 42$

5.3 Padrão alimentar $\quad 47$

5.4 Antropometria $\quad 58$

5.5 Fonte de erros, vícios e limitações do estudo 81

6 CONCLUSÃO 


\section{ANEXOS}

Anexo 1 - Composição da amostra

Anexo 2 - Termo de Consentimento Livre e Esclarecido (Geral e Grupo Controle)

Anexo 3 - Guia de elegibilidade

Anexo 4 - Acompanhamento Nutricional I

A14

Anexo 5 - Acompanhamento Nutricional II

A19

Anexo 6 - Proposta para classificação da alimentação

A23

Anexo 7 - Parecer do Comitê de Ética em Pesquisa Projeto

ChIADO (COEP)

A24

Anexo 8 - Parecer da Comissão Nacional de Ética em Pesquisa (CONEP)

Anexo 9 - Parecer do Comitê de Ética em Pesquisa (COEP) 


\section{INTRODUÇĀO}

\subsection{Alimentação no primeiro ano de vida}

O primeiro ano de vida é um periodo singular, de grande importância devido às inúmeras e aceleradas alteraçōes e experiências a que a criança está sujeita, periodo em que são construidas as bases para a formação biopsicossocial do indivíduo e a alimentação é tema de grande relevância e interesse.

Os primeiros anos de vida de uma criança, principalmente os dois primeiros, são caracterizados por crescimento acelerado e grandes aquisições no processo de desenvolvimento, incluindo habilidades para receber, mastigar e digerir outros alimentos além do leite materno e no autocontrole do processo de ingestão de alimentos, para atingir o padrão alimentar cultural do adulto (MS/OPAS/OMS 2001).

No início da vida o crescimento se dá de forma acelerada. uma criança normal cresce, em média, $25 \mathrm{~cm}$ no primeiro ano de vida e $12 \mathrm{~cm}$ no segundo ano, passando, a partir dos 3 anos, a crescer de 5 a $7 \mathrm{~cm}$ por ano. $O$ peso do lactente normal dobra aos 4 meses e triplica ao final do primeiro ano de vida. Associada a esse crescimento físico está a aquisição de capacidades psicomotoras e neurológicas que podem ser observadas a cada mês. Tal processo é rápido, de modo que aos 4-5 meses de vida já sustenta a cabeça e, com 6 meses, é capaz de sentar sem apoio (MS/OPAS/OMS 2001, SPOLIDORO 2001).

O crescimento no primeiro trimestre representa 30 a $40 \%$ do consumo energético da criança. As necessidades de energia e nutrientes no primeiro mês de vida são o triplo das de um adulto, por quilo de peso. As necessidades minerais são consideráveis, principalmente em relação ao ferro para a formação da hemoglobina e ao cálcio para a formação dos ossos. Dessa forma, torna-se inquestionável a importância da alimentação da criança nessa fase da vida, uma vez que deficiências nutricionais ou condutas inadequadas quanto à prática alimentar podem, não somente levar a prejuizos imediatos na saúde da criança, elevando a morbimortalidade 
infantil, como também deixar seqüelas como retardo de crescimento, atraso escolar e desenvolvimento de doenças crônicas (MS/OPAS/OMS 2001, SPOLIDORO 2001).

A alimentação da criança no primeiro ano de vida deve atender às necessidades nutricionais, que variam de acordo com a idade, sexo, ritmo de crescimento, atividade física, fatores genéticos, condições ambientais, além da necessidade de multiplicação e diferenciação celular, fenômenos que caracterizam o crescimento e desenvolvimento (PALMA et al. 1998; BRESOLIN et al. 2000; MS/OPAS/OMS 2001; SPOLIDORO 2001; MURAHOVSCHI E MIRANDA 2003).

Segundo BRESOLIN et al. (2000), a imaturidade funcional, principalmente dos apareihos digestório, renal e sistema imunológico, nos primeiros meses de vida, inspira cuidados especiais em relação à alimentação oferecida, que deverá satisfazer as necessidades nutricionais e adequar-se à capacidade funcional e à maturidade neuropsicomotora da criança.

Sabe-se que nas últimas décadas, especialmente após a II Guerra Mundial, ocorreram mudanças fundamentais nos métodos de alimentação infantil e o aleitamento artificial em mamadeira, com fórmulas baseadas no leite de vaca, substituiu o aleitamento natural (BRESOLIN et al. 2000).

Os reflexos de sucção e extrusão, presentes nos primeiros meses de vida, condicionam o recém-nascido à alimentação líquida. A partir dos 6 meses de vida a criança já apresenta maturidade fisiológica e neurológica para receber outros alimentos. Não apresenta mais o reflexo de protrusão da língua, o que facilita a ingestão de alimentos semi-sólidos, produz as enzimas digestivas em quantidade suficiente para essa nova fase e passa a ter um bom desenvolvimento neuromuscular da cabeça e pescoço, o que facilita a manutenção de postura sentada e a oferta de alimento por colher (BRESOLIN et al. 2000; MS/OPAS/OMS 2001, MURAHOVSCHI e MIRANDA 2003).

A introdução de sólidos antes dessa época pode ser considerada como alimentação forçada, o que, além de contrariar os princípios da higiene 
alimentar, pode contribuir para a superalimentação infantil, predispondo a criança à obesidade e suas conseqüências. $O$ desenvolvimento de habilidades para se alimentar e auto-regular a ingestão são passos fundamentais no processo de introdução de alimentos. Dessa forma, as práticas alimentares devem ser condicionadas tanto pelas necessidades nutricionais quanto pelo grau de maturidade funcional do lactente (BRESOLIN et al. 2000; MURAHOVSCHI e MIRANDA 2003).

O leite materno é o alimento essencial da espécie humana, que satisfaz as necessidades globais da criança, tendo sido, por milênios, o único alimento disponível para o recém-nascido e sem o qual a sobrevivência era muito difícil (BRESOLIN et al. 2000). É o alimento ideal para o crescimento e desenvolvimento do lactente, devido às propriedades físico-químicas e imunológicas e sua especificidade em relação às necessidades nutricionais e fisiológicas da criança (BRESOLIN et al. 2000; MS/OPAS/OMS 2001).

O leite materno contém a quantidade de água suficiente para as necessidades do lactente, mesmo em climas muito quentes (MS/OPAS/OMS 2001). Além disso, proporciona o contato, a atenção e o carinho, que são críticos para o desenvolvimento da criança (BRESOLIN et al. 2000).

Muitos estudos científicos embasam a afirmativa de que a alimentação exclusiva ao peito nos primeiros meses de vida do lactente e continuada até a criança completar dois anos de idade é a melhor prática alimentar, tanto para as mães como para os lactentes (BRESOLIN et al. 2000; MSIOPAS/OMS 2001; MURAHOVSCHI e MIRANDA 2003). A proposta da Organização Mundial da Saúde, com apoio do Brasil, é de aleitamento materno exclusivo até os seis meses de idade e a continuidade da amamentação até os dois anos de idade (WHO 2001).

Nos últimos 20 anos, em função dos avanços nos conhecimentos sobre - aleitamento natural, nos aspectos bioquimicos, imunológicos, endocrinológicos e psicofisiológicos, a nutrição infantil vem sofrendo um processo mais amplo de discussão e de reavaliação. Dessa forma, a introdução precoce de alimentos sólidos, recomendada nos esquemas 
alimentares pela influência da propaganda, disponibilidade dos alimentos infantis industrializados e crença em que tais alimentos determinam maior ganho de peso e período de sono mais prolongado nas crianças tem sido objeto de críticas muito sérias. Atualmente, procura-se respeitar a maturação dos aparelhos digestivo e renal e o desenvolvimento do sistema neuropsicomotor da criança ao se indicar a introdução de alimentos sólidos (BRESOLIN et al. 2000).

Há estudos que sugerem que a criança amamentada ao peito tende a manter sua ingestão habitual de energia, assim sendo, a alimentação complementar introduzida precocemente não adiciona conteúdo energético à dieta, pois, em resposta à introduçāo de alimentos, o lactente reduz o consumo de leite materno (BROWN et al. 1995).

Em estudo conduzido em Honduras, BROWN et al. (1995) verificaram que crianças que recebiam alimentos complementares consumiam significativamente menos leite materno. Os autores ponderam também a dificuldade de se estimular uma criança saciada por outras fontes a consumir o leite materno.

Outro estudo do mesmo grupo de pesquisadores, avaliando a idade de introdução de alimentação complementar e o crescimento de lactentes a termo de baixo peso ao nascer amamentados ao peito, em Honduras, verificou que a introdução de alimentos complementares, adequados quanto às condições higiênicas e aspectos culturais da população em estudo, no período de 4 a 6 meses de vida desses lactentes não apresentou efeitos no crescimento dessa população. Além disso, foi observada também a diminuição na duração da amamentação em minutos/dia e da quantidade de leite materno ingerido no grupo em que foi realizada a introdução da alimentação complementar aos 4 meses de vida (16 semanas). Os autores destacam que, embora trate-se de grupo com alta vulnerabilidade nutricional os resultados encontrados foram os mesmos de estudo anterior [BROWN et al. (1995)] que avaliara lactentes normais (DEWEY et al. 1999). 
A oferta de água, chás ou qualquer outro alimento sólido ou líquido aumenta a chance do lactente adoecer, além de substituir o volume de leite materno - muito mais nutritivo - que seria ingerido (MS/OPAS/OMS 2001).

A Sociedade de Pediatria de São Paulo recomenda o aleitamento materno exclusivo até o sexto mês, para as crianças com crescimento e desenvolvimento normais. Se houver desaceleração do ganho de peso após o quarto mês, inicia-se com alimentos não lácteos, complementares ao leite materno (PALMA et al. 1998).

No Brasil, VENÂNCIO e MONTEIRO, em 1998, verificaram uma considerável expansão na prática da amamentação, analisando dados de duas pesquisas nacionais realizadas em 1975 e 1989, passando sua duração mediana de 2,5 para 5,5 meses.

VIANNA (2002) verificou que 96,4\% das 194 mães participantes de seu estudo declararam haverem iniciado a amamentaçāo de suas crianças e somente $83,8 \%$ delas o fizeram de forma exclusiva. A duração mediana do aleitamento materno foi de 30,5 semanas e a do aleitamento materno exclusivo foi de 8,5 semanas.

Quanto ao aspecto anteriormente citado, de que a alimentação com sólidos facilita o ganho de peso e proporciona um sono prolongado, comprovou-se que metabolicamente isso não é vantajoso para a criança, uma vez que o consumo de alimentos em grandes refeiçōes, largamente espaçadas, determina um aumento da concentração sérica de colesterol e um déficit na tolerância à glicose (BRESOLIN et al. 2000).

A partir do sexto mês de vida as necessidades nutricionais da criança já não são mais atendidas apenas com o leite materno, embora este continue sendo uma fonte importante de calorias e nutrientes. Dessa forma, sua complementação a partir dessa idade se faz necessária (PALMA et al. 1998, BRESOLIN et al. 2000, BRASIL. MINISTÉRIO DA SAÚDE 2001, MS/OPAS/OMS 2001, MURAHOVSCHI e MIRANDA 2003).

A alimentação introduzida na dieta das crianças é idealmente denominada alimentação complementar pois, como o próprio termo remete, seu propósito é de complementar o leite materno e não substitui-lo. Os 
alimentos complementares especialmente preparados para a criança são chamados alimentos de transição, cujo papel é fundamental para a criança, por volta dos 8 meses de vida, começar a receber os alimentos preparados para a família, com as devidas adequações de consistência/textura e condimentos (MS/OPAS/OMS 2001).

O periodo da alimentação de transição, definido como o período que a dieta muda do aleitamento materno exclusivo para a alimentação da familia, é uma etapa crítica que, com freqüência, conduz a má-nutrição e à enfermidade quando a criança não recebe uma dieta adequada, tanto em qualidade como em quantidade, preparada higienicamente e aceitável do ponto de vista social, cultural e econômico (BRASIL. MINISTÉRIO DA SAÚDE 2001; MSIOPAS/OMS 2001; SPOLIDORO 2001; MURAHOVSCHI e MIRANDA 2003).

Em paises em desenvolvimento, a idade em que as crianças recebem alimentos complementares pela primeira vez é relevante para a saúde pública, devido ao risco de doença diarréica em decorrência da contaminação dos alimentos e ao risco potencial de déficits de crescimento infantil se os alimentos não forem apropriados (VICTORA et al. 1998a).

Em trabalho proposto para servir de base para o desenvolvimento de manual para profissionais e agentes comunitários de saúde orientarem mães e responsáveis sobre a alimentação de lactentes e crianças pequenas, principalmente durante a transição do aleitamento materno à alimentação da familia, o Ministério da Saúde do Brasil, com apoio da Organização Panamericana da Saúde (OPAS)/Organização Mundial da Saúde (OMS) sistematizou um conjunto de dez condutas que operacionalizam as recomendações dessas entidades para crianças brasileiras menores de dois anos. Tais recomendações foram elaboradas a partir de um diagnóstico baseado em dados secundários compilados com a participação dos profissionais de saúde de todos os estados da Federação que lidam com a nutrição da criança em serviços de saúde, ensino e pesquisa e complementado com o resultado de pesquisa qualitativa especifica por macro-região. Dentre as recomendações propostas destacam-se 0 
aleitamento materno exclusivo até o sexto mês de vida, com alimentação complementar - adequada quanto à variedade, consistência e tipo de alimento oferecido - introduzida de forma lenta e gradual a partir dessa idade e manutenção do leite materno até os 2 anos de idade ou mais (MS/OPAS/OMS 2001).

Os alimentos complementares podem ser constituidos pela maioria dos alimentos básicos que compõem a alimentação do brasileiro, devendo-se complementar a oferta de leite materno com alimentos que sejam mais comuns à região e ao hábito alimentar da familia (MS/OPAS/OMS 2001).

É importante que sejam ministrados à criança alimentos ricos em fibras solúveis $e$ insolúveis, provenientes de cereais integrais e hortaliças, introduzidos a partir do 6 mês, de acordo com seu potencial alergênico. Tais alimentos contribuem, principalmente, devido ao seu conteúdo nutricional (carboidratos, vitaminas, minerais), além do seu papel na colonização intestinal pela flora fermentativa e na formação do bolo fecal. Cuidados devem ser tomados com relação à presença de fatores antinutricionais (fitatos, fitohemaglutininas) e pela interferência na absorção de minerais e elementos traço. É recomendado também que a criança que já esteja recebendo alimentos complementares receba água limpa (filtrada/fervida/tratada) nos intervalos (MS/OPAS/OMS 2001).

A Sociedade de Pediatria de São Paulo recomenda a introdução da papa de frutas e uma refeição de sal por volta dos seis meses. Sugere compor a papa de sal com cereais e tubérculos, leguminosas, carne (bovina, frango ou peixe), hortaliças, óleo, sal e cebola. Introduzem-se também os ovos, levando-se em conta a história familiar de atopia para o consumo da clara do ovo e de outras proteínas potencialmente alergênicas. Entre 7 e 8 meses inicia-se a segunda refeição e sal (PALMA et al. 1998).

MARCHIONI (1999) verificou que o primeiro alimento solido complementar a fazer parte da dieta de sua população de estudo (crianças menores de 1 ano) foram as frutas, seguido de hortaliças, cereais, carnes elou ovo e feijão. Concluiu-se também que a complementação do leite 
materno com alimentos sólidos iniciou-se com alimentos de baixa densidade calórica, contrariando as recomendações para crianças brasileiras.

No estudo de VIANNA (2002) foi observado que, ao final de 4 semanas, $27 \%$ das mães introduziram outro alimento na dieta dos seus filhos e somente $29,7 \%$ das mães mantiveram a prática do aleitamento materno exclusivo para além de 13 semanas. A porcentagem de desmame total até 4 semanas foi de $8,1 \%$ e, após 13 semanas, $73 \%$ das mães ainda forneciam leite materno aos seus filhos. Com relação ao aleitamento materno exclusivo a mediana observada entre as 194 mães foi de 8,54 semanas (IC $95 \% 8,40-8,68$ ). Somente $2,1 \%$ das mães não amamentaram seus filhos e 3,6\% amamentaram por menos de uma semana.

MARQUES et al. (2001), em estudo longitudinal na região nordeste do Brasil, observaram que embora o aleitamento materno seja comum nessa comunidade, raramente é exclusivo e tem relativamente curta duração.

Têm sido descritas relações entre o desmame precoce e determinados processos mórbidos como as "distrofias-minus", por exemplo, a desnutrição energético-protéica, a anemia ferropriva e determinadas carências vitaminicas, como o escorbuto e a xeroftalmia, de alta prevalência nos países em desenvolvimento. As "distrofias-plus", especialmente a obesidade infantil e as cáries dentárias, constituem-se problemas também relacionados às alterações nos padrōes de alimentação infantil, ocorrendo mais freqüentemente nos paises desenvolvidos (BRESOLIN et al. 2000).

Crianças jovens, até dois ou três anos de idade, quando recebem leite de vaca, desenvolvem anticorpos tipo-especificos contra as proteínas desse leite, sendo o nivel máximo desses anticorpos atingido no primeiro semestre de vida. Admite-se que a sensibilização ocorra em lactentes, especialmente no primeiro semestre de vida, por ser a mucosa infantil mais permeável a macromoléculas. (BRESOLIN et al. 2000).

Outros mecanismos citados seriam a deficiência transitória de IgA secretora e uma alteração na resposta imune mediada por lgE, fatores que sustentam a recomendação de se manter o aleitamento exclusivo ao seio até os 6 meses de idade, evitando-se o contato com proteinas estranhas, 
sendo tal conduta tanto mais válida quanto maiores os antecedentes de atopia na criança ou na familia (BRESOLIN et al. 2000).

Embora as implicações relacionadas à prática alimentar no primeiro ano de vida estejam bem estabelecidas, há estudos recentes que desmentem os beneficios relacionados à exposição prolongada ao aleitamento materno ou, até mesmo, sugerem alguns prejuizos relacionados à tal prática alimentar (LEESON et al. 2001, SEARS et al. 2002), gerando, inicialmente, grande polêmica mas, posteriormente, têm suas limitaçōes e vicios evidenciados em editoriais e cartas de revistas científicas de grande credibilidade, que reforçam não haver subsidios de magnitude suficiente para se alterar as recomendações atuais de aleitamento materno como a melhor maneira para a promoção de saúde materna e da criança (BOOTH 2001, GREINER 2002, MAYOR 2002, MYR 2002, O`SULLIVAN 2002, RICHARDS 2002, STERKEN 2002).

A introdução precoce de alimentos sólidos está associada a maior prevalência de infecções gastrointestinais, doença diarreica, alergias alimentares e pior estado nutricional (KUMMER et al. 2000).

Por outro lado, a introdução tardia de alimentos também pode trazer conseqüências indesejadas, tais como maior risco de déficit no crescimento, diminuição da proteção imunológica, desenvolvimento de distúrbios nutricionais e efeitos adversos no desenvolvimento mental em longo prazo (MICHAELSEN 2000).

Segundo MS/OPAS/OMS (2001), cerca de $97 \%$ das crianças brasileiras iniciam o aleitamento materno nas primeiras horas de vida, no entanto, o início do processo de desmame ocorre precocemente - dentro das primeiras semanas ou meses de vida - com a introdução de chás, água, sucos e outros leites, progredindo de modo gradativo. Nos primeiros 6 meses de vida, o número de crianças em aleitamento materno exclusivo é pequeno e o de crianças já totalmente desmamadas é considerável, ficando muito aquém das recomendações do Ministério da Saúde. Pode-se considerar que o processo de introdução de alimentos complementares não é oportuno nem adequado, caracterizando-se pelo uso predominante de 
alimentos lácteos e alimentação monótona e inadequada do ponto de vista calórico e nutricional.

WILSON et al. (1998), em estudo de coorte no Reino Unido, verificaram uma significativa redução na probabilidade de ocorrência de doença respiratória em qualquer periodo da infância se a criança tiver sido amamentada exclusivamente por quinze semanas. Aparentemente há um efeito protetor da amamentação e da introdução tardia de alimentos sólidos.

No estudo de VIANNA (2002), os casos de hospitalização foram menos freqüentes entre as crianças que mamaram exclusivamente, pelo menos, até o primeiro mês de vida.

Segundo ODDY et al. (2003), em estudo de coorte prospectiva com 2602 recém-nascidos na Austrália, aleitamento materno total (exclusivo e predominante) até pelo menos os 6 meses de vida e presença de aleitamento materno até 1 ano de vida são fatores de proteção contra infecção e doença respiratória na infância. Além disso, foi observado que a introdução de outro tipo de leite (normalmente fórmula infantil), bem como a interrupção do aleitamento materno antes dos 6 meses de vida são fatores de risco significantes para procura de serviço médico e hospitalização por infecçōes das vias aéreas superiores e chiado associado a doença do trato respiratório inferior.

Em estudo que objetivava compreender a relação entre consumo de leite de vaca e risco de anemia na infância no município de São Paulo, LEVY-COSTA (2002) pôde concluir que o aumento na participação relativa do leite de vaca na dieta infantil associa-se significativa e independentemente à diminuição da concentração de hemoglobina e ao aumento do risco de anemia. A associaçāo inversa com a concentração de hemoglobina, no caso das crianças mais novas; e a associação direta com o risco de anemia, para o conjunto de crianças estudadas, mostraram-se significativas mesmo após levar-se em conta o efeito negativo do consumo de leite sobre a densidade de ferro da dieta, evidenciando-se, assim, um provável efeito inibidor do leite sobre a absorção do ferro presente nos demais alimentos. 
A prática alimentar adotada, a duração do aleitamento materno e os alimentos de transição constituem elementos fundamentais na morbimortalidade, crescimento e desenvolvimento infantis, com reflexos na vida adulta (VICTORA et al. 1998a, BRESOLIN et al. 2000, VIANNA 2002).

Os órgãos representativos no Brasil já vêm trabalhando, há algum tempo, com a proposta de duração do aleitamento materno exclusivo até o sexto mês de vida e adequação das práticas da alimentação complementar a partir dessa idade (MS/OPAS/OMS 2001).

\subsection{Alimentação infantil, estado nutricional e fatores sócio- económicos}

"A inserção de classe determina, em última instância, o acesso diferencial, entre outros, à infra-estrutura de saúde, à quantidade e qualidade de alimentos, à habitação e ao vestuário" (BRONFMAN e TUIRÁN, 1984).

Segundo BARROS e VICTORA (1998), a avaliação de indicadores sócio-econômicos, ambientais e demográficos tem fundamental importância em pesquisas de saúde infantil, pois permite descrever a situação sócioeconômica e a estrutura de classe da população, possibilitando o estudo da relação entre a situação de saúde e a situação sócio-econômica, a determinação da prevalência de determinados problemas de saúde em diferentes grupos sociais e a identificação dos principais fatores de risco para morbidade infantil.

A renda familiar constitui-se indicador sócio-econômico que apresenta alto poder discriminatório, isto é, crianças pertencentes a familias com diferentes categorias de renda apresentam diferenças importantes nos indicadores de saúde. Apresentam-se também como de especial interesse as variáveis de educação (escolaridade) dos pais, pois, além de serem obtidas com relativa facilidade, verifica-se mundialmente sua forte associação com a morbimortalidade infantil (BARROS e VICTORA 1998).

MONTEIRO e CONDE (2000) verificaram que mudanças positivas em determinantes distais do crescimento infantil — poder aquisitivo das famílias e escolaridade das mães - exerceram influência decisiva sobre a evolução 
favorável da estatura das crianças de São Paulo entre 1984 e 1996.

O progresso nos niveis educativos da população, principalmente da mulher, cria condições favoráveis para a atenção e cuidado integral da criança, mesmo favorecendo o ingresso das mães no mercado de trabalho (CABALLERO et al. 1994).

Segundo CARVALHAES e BENÍCIO (2002), em estudo que objetivava identificar e medir a magnitude do risco de desnutrição associada a fatores determinantes da capacidade materna de cuidado infantil (estrutura familiar, escolaridade, trabalho, saúde física e saúde mental), o trabalho materno iniciado a partir do quarto mês de vida da criança se mostrou um fator de proteção. Além disso, não houve tendência de maior risco de desnutrição quando o retorno ou início do trabalho materno ocorreu antes dessa idade, ao contrário da hipótese levantada de que mães que não trabalham fora, desde o nascimento de suas crianças, estão em condição supostamente mais favorável ao cuidado e ao estado nutricional. Consideram ainda que tais resultados podem indicar um caráter da relação entre trabalho materno e estado nutricional mais associado à sua dimensão econômica do que ao impacto do afastamento materno do cuidado direto da criança.

MARCHIONI, em 1999, num estudo que verificou a prevalência de consumo de alimentos em dois centros de saúde no município de São Paulo, encontrou associação positiva entre aleitamento materno e escolaridade materna, com prevalências de $65 \%$ de aleitamento materno aos 4 meses e $56 \%$ aos 6 meses entre mães de baixa escolaridade (até a $4^{a}$ série do ensino fundamental); e de $83 \%$ de aleitamento materno aos 4 meses e $77 \%$ aos 6 meses entre mães com escolaridade não baixa.

Nesse mesmo estudo não foi encontrada associação estatisticamente significante entre aleitamento materno exclusivo e escolaridade materna, embora mães com baixa escolaridade apresentassem menores taxas (16\% aos 4 meses e $8 \%$ aos 6 meses), ao passo que mães com escolaridade não baixa apresentaram $27 \%$ aos 4 meses e $15 \%$ aos 6 meses. Também não foi observada associação entre o consumo de alimentos complementares e escolaridade dos pais, entre outras variáveis. 
CARVALHAES e BENICIO (2002) encontraram associação entre desnutrição infantil e escolaridade materna, embora sendo parcialmente independente, por exemplo, de renda familiar.

É importante ressaltar também que o local e as condições de moradia, além de serem importantes indicadores sócio-econômicos, relacionam-se causalmente com a morbidade infantil. Sabe-se, por exemplo, que a aglomeração intradomiciliar está associada com maior incidência de infecções respiratórias (BARROS e VICTORA 1998).

Em seu estudo, VIANNA (2002) observou que, no primeiro mês, familias pequenas contribuem para o aleitamento materno exclusivo, assim como a participação dos pais com escolaridade superior a 8 anos. 0 efeito protetor de famílias pequenas diminui com o tempo, perdendo significância estatística após 12 semanas.

Observou também que, acima de 8 semanas, a presença de irmão foi associada com o prolongamento do aleitamento materno exclusivo, porém a duração do aleitamento materno não se mostrara associada com, por exemplo, renda familiar e educação dos pais.

As informações sobre o tipo de trabalho, posição no emprego e renda auxiliam na construção de um sistema de classe social que tem a vantagem de, não apenas descrever as variações na morbidade em diversos grupos dentro da sociedade, como também, de explicar, dentro de um modelo conceitual, por que alguns grupos apresentam maior ou menor risco (BARROS e VICTORA 1998).

A incorporação do conceito de classe social em estudos epidemiológicos apresenta algumas dificuldades, podendo-se destacar primeiramente 0 fato de que tal conceito é passivel de receber diferentes interpretações. A operacionalização desse conceito, a fim de classificar individuos ou famílias por meio de questionários padronizados, representa uma dificuldade adicional. As limitações impostas pela técnica de entrevistas por meio de questionários e as dificuldades metodológicas para o delineamento de indicadores confiáveis sobre a consciência e a prática política das classes tornaram praticamente impossivel a tarefa de 
operacionalizar o conteúdo integral do conceito, obrigando a restringir o mesmo à instância econômica (LOMBARDI et al. 1988).

Segundo BRONFMAN e TUIRÁN (1984), "os questionários não permitem apreender as classes em sua totalidade, ou seja, em suas mutaçōes internas e em suas relaçōes com as outras classes e com sua estrutura social, no entanto, é possível identificar grupos sociais e, assim, definir a "situação/condição de classe" e a forma pela qual esta afeta o comportamento dos indivíduos".

LOMBARDI et al. (1988) propõem uma classificação que visa operacionalizar o conceito de classe social que adapta a classificação desenvolvida por BRONFMAN e TUIRÁN (1984) à realidade brasileira, classificação essa que demonstrou ter alto poder discriminatório em termos de crescimento/desenvolvimento infantil.

\subsection{Alimentação infantil, estado nutricional e indicadores antropométricos}

O monitoramento regular do crescimento é ferramenta importante para a avaliação do estado nutricional de crianças e deve ser parte integral do sistema de saúde (MICHAELSEN et al. 2000).

Durante o primeiro semestre de vida a criança cresce mais rápido do que em qualquer outro periodo após o nascimento, ganhando cerca de $200 \mathrm{~g}$ e $1 \mathrm{~cm}$ por semana. Bebês nascidos a termo triplicam seu peso e aumentam seu comprimento em $50 \%$ durante o primeiro ano de vida. Devido a esse padrão acelerado de crescimento as necessidades nutricionais por quilo de peso são bastante elevadas e as quantidades de proteína e energia necessárias para o crescimento são componentes críticos das necessidades globais (MICHAELSEN et al. 2000).

Crescimento é definido como aumento da massa e dimensōes corporais, o que compreende os componentes peso (medida ponderal) e comprimento/estatura (medida linear). Considera-se comprimento a medida longitudinal de crianças até dois anos de idade, denominada estatura a partir dessa idade (MICHAELSEN et al. 2000). 
A avaliação do estado nutricional constitui-se importante procedimento para a determinação das condições de saúde de indivíduos e populações. Em crianças, deve-se considerar especialmente a influência direta exercida pelo estado nutricional sobre a morbimortalidade e crescimento infantis (MONTEIRO et al. 1995).

Avaliar o estado nutricional implica na utilização de determinados procedimentos diagnósticos a fim de se precisar a magnitude, o comportamento e os determinantes dos agravos nutricionais e, desse modo, identificar grupos de risco, promovendo intervenções não somente visando aos efeitos, como também às causas (GARCIA 2003).

Dentre os métodos mais utilizados na avaliação do estado nutricional destaca-se a antropometria, que quantifica as variações físicas e a composição corporal e é amplamente utilizada para avaliação nutricional de individuos e de grupos populacionais (VICTORA et al. 1998a). O exame antropométrico apresenta-se como parte essencial de diagnóstico de saúde infantil, permitindo avaliar a prevalência das diversas formas de desnutrição protéico-calórica (BARROS e VICTORA 1998).

$A$ avaliação do estado nutricional por meio da antropometria é o método mundialmente mais aceito e empregado por pesquisadores em nutrição e saúde publica, devido a sua simplicidade operacional, baixo custo, sensibilidade e especificidade e possibilidade de comparação com um padrão de referência de manuseio relativamente simples (SARNI 2001; BRASIL. MINISTÉRIO DA SAÚDE 2002).

O emprego do exame antropométrico na avaliação do estado nutricional de crianças fundamenta-se na evidência de que o crescimento e a manutenção das dimensōes corporais exigem condições nutricionais adequadas. Nos primeiros anos de vida, além de avaliar o estado nutricional infantil, pode-se predizer a sobrevida da criança (MONTEIRO 1984, MONTEIRO et al. 1986, citados por GARCIA 2003, p.8).

Para que se obtenham informações confiáveis sobre o crescimento de crianças deve-se atentar para a coleta de informações fundamentais como data de nascimento e uso de gráficos de crescimento provenientes de 
população de referência apropriada (MICHAELSEN et al. 2000).

Toda avaliação do crescimento requer o emprego de um padrão de referência que descreva a variabilidade normal do crescimento, ou seja, a variabilidade do crescimento que é esperada quando são ótimas as condiçōes ambientais. O padrão do National Centers for Health Statistics (NCHS), padrão internacional recomendado pela Organização Mundial da Saúde (OMS), reproduz a distribuição dos valores de peso e estatura/comprimento alcançados em diferentes idades por crianças americanas dos sexos masculino e feminino, tendo sido construido a partir de diversos inquéritos antropométricos realizados nos Estados Unidos (WHO 1995, BARROS e VICTORA 1998, MONTEIRO e CONDE 2000, BRASIL. MINISTÉRIO DA SAÚDE 2002).

Os gráficos de crescimento podem se apresentar de algumas maneiras diferentes. Tais diferenças se relacionam ao número de curvas de referência (percentis) representadas, o que permite a escolha do tipo de gráfico de acordo com a necessidade/padrão da população que se pretende estudar. De maneira geral, apresentam três curvas básicas, a mediana ou percentil 50 , o percentil 3 e o percentil 97 , sendo os dois últimos aproximadamente equivalentes $a-2$ e +2 escore $Z$ da mediana, respectivamente. Os gráficos são também específicos para cada sexo (MICHAELSEN et al. 2000).

Com as medidas de peso e estatura (comprimento) corporais são calculados os indices peso/estatura [comprimento] (W/H), estatura [comprimento]/idade (H/A) e peso/idade (W/A), indices que refletem, de forma diferenciada, alterações crônicas e agudas do estado nutricional, sendo recomendados internacionalmente (WHO 1995, SARNI 2001; BRASIL. MINISTÉRIO DA SAÚDE 2002). $O$ indice de massa corporal (IMC) é também recomendado para crianças mas não tem seu uso muito difundido em crianças menores de 10 anos (WHO 1995, MICHAELSEN et al. 2000).

Esses indices são, posteriormente, comparados ao padrão de referência de escolha, por exemplo, o NCHS, que é baseado em estudos da população norte-americana e amplamente utilizado em inquéritos antropométricos em diversos países, representando satisfatoriamente o 
crescimento e as proporções corporais de crianças bem nutridas (VICTORA et al. 1998a).

Embora, recentemente, tenham sido constatadas imperfeições no padrão NCHS com relação ao ritmo de evolução do peso e da estatura no primeiro ano de vida, são várias as evidências de que populações de menores de cinco anos de diferentes origens étnicas, incluindo descendentes de europeus e de africanos, que constituem a maioria da população brasileira, alcançam sem dificuldade o padrão de crescimento descrito pelo padrão NCHS, desde que estejam asseguradas boas condições de vida e adequadas condições de alimentação e saúde (MONTEIRO e CONDE 2000).

Segundo MICHAELSEN (2000), o uso de referências baseadas em população de crianças de determinado pais para avaliar o crescimento de crianças de outro país mostra-se controverso. Diferenças no potencial genético de crescimento são geralmente o argumento para consubstanciar a necessidade de desenvolvimento de padrões de referência específicos para determinados paises e/ou regiōes. Todavia, enquanto diferenças genéticas existem, são os fatores ambientais que exercem as maiores influências no potencial de crescimento de um indivíduo.

A Organização Mundial da Saúde (OMS) tem admitido que dados de referência sejam utilizados como padrão e recomenda que se tenha a devida precaução na escolha de referências que sejam coerentes com padrōes internacionais. A OMS escolheu a referência do NCHS pois a população na qual essa referência é baseada vivia em ambiente saudável, recebia os cuidados devidos e, provavelmente, desenvolveu o máximo de seu potencial de crescimento. Como um padrão, no entanto, deve-se reconhecer suas limitações. Embora entre a maioria das populações de crianças avaliadas para a referência do NCHS (estudos de 1923 a 1975 e de 1960 a 1975) haja pequenas diferenças no crescimento médio em estatura ou na distribuição em torno da média, o fato de serem incluidas tanto crianças sadias quanto enfermas e crianças em aleitamento materno junto de crianças em aleitamento artificial merece atenção, particularmente ao se comparar 
indivíduos ou grupos específicos com essa referência (WHO 1995, MICHAELSEN 2000).

Um comitê de especialistas da Organização Mundial da Saúde (OMS) recomenda o desenvolvimento de uma nova referência de crescimento para crianças baseada em grupos de crianças de diferentes partes do mundo, amamentados de acordo com suas recomendações (WHO 1995, MICHAELSEN 2000).

Devido ao fato de medidas antropométricas isoladas - como estatura ou peso - terem valor limitado, recomenda-se calcular os índices antropométricos - como peso/idade (WIA), estatura [comprimento]/idade $(H / A)$ e pesolestatura [comprimento] $(W / H)$ - pois levam em conta o sexo e proporcionam comparabilidade aos dados de crescimento. Uma das principais vantagens do uso dos índices antropométricos é sua validade como fator preditor de problemas de saúde subseqüentes especialmente morbidade, mortalidade, desenvolvimento intelectual, capacidade de trabalho, perfomance reprodutiva e risco de doenças crônicas, entretanto, predição não necessariamente indica causabilidade. (MICHAELSEN et al. 2000).

Um indice antropométrico tem o papel de mostrar a "posição" de determinada criança avaliada em relação à distribuição de pesos ou estaturas (comprimentos) de crianças de mesma idade e sexo. Pode ser expresso de três diferentes maneiras: desvio em relação à mediana do padrão de referência, expresso como desvio padrão ou escore $Z$; percentil da população de referência ou porcentagem em relação à mediana do padrão de referência (percentual da mediana) (WHO 1995, BARROS e VICTORA 1998, VICTORA et al. 1998a, MICHAELSEN et al. 2000, BRASIL. MINISTÉRIO DA SAÚDE 2002).

Conforme sugerido pela Organização Mundial da Saúde (OMS), utilizam-se internacionalmente como indicadores de desnutrição as proporções de crianças com índices inferiores a - 2 escores $Z$ da mediana da referência. Para a avaliação do estado nutricional em nivel individual, recomenda-se usualmente que os três índices sejam calculados, uma vez 
que refletem processos diferentes (WHO 1995, BARROS e VICTORA 1998, VICTORA et al. 1998a, MICHAELSEN et al. 2000, BRASIL. MINISTÉRIO DA SAÚDE 2002).

Apesar de guardarem relação entre si, cada índice reflete uma combinação diferente de processos biológicos. Déficits em diferentes indices refletem diferentes processos e sugerem diferentes causas. Pode-se perder ou ganhar peso rapidamente, em resposta a estímulos ambientais, ao passo que estatura, por exemplo, em se tratando de crianças, não pode ser perdida (WHO 1995, MICHAELSEN et al. 2000).

Valores baixos do índice peso/estatura (comprimento) resultam de falhas no ganho de peso ou mesmo perda de peso. Pode evoluir ou regredir rapidamente, sendo um indice de subnutrição aguda que reflete perda de peso severa, a qual geralmente está associada à baixa ingestão alimentar aguda ou doença severa (MICHAELSEN et al. 2000).

$O$ indice estatura (comprimento)/idade retrata a adequação estatural, 0 crescimento linear, e auxilia no diagnóstico de desnutrição pregressa ou crônica, mas não necessariamente o estado nutricional atual. É recomendado para ser utilizado em adição ao indicador peso/idade. A baixa estatura para idade pode refletir uma variação normal ou processo patológico. O termo "retardo de crescimento" indica o processo patológico em que 0 indivíduo não desenvolve plenamente seu potencial de crescimento linear, seja por má nutrição ou saúde inadequada a longo prazo. O índice estatura (comprimento)/idade sofre pouca variação em curtos periodos de tempo, refletindo desnutrição crônica. $O$ déficit de crescimento linear é multifatorial. Os fatores causais mais importantes são alimentação deficiente, infecção (geralmente relacionada a condições sanitárias insatisfatórias) e pobre interação mãe/filho com relação ao cuidado e atenção à criança. A identificação dos problemas relacionados à má nutrição, o tratamento da infecção e a melhoria da interação mãe/filho são indicados para a prevenção de retardos de crescimento em ambientes com baixa qualidade em pesquisas pois essa estratégia combinada melhorará também o desenvolvimento físico e cognitivo (WHO 1995, MICHAELSEN 
2000, BRASIL. MINISTÉRIO DA SAÚDE 2002).

Populações de crianças menores de cinco anos que apresentem médias do índice estatura (comprimento)/idade próximas a 0,0 escore $Z$ e desvios-padrão próximos a 1,0 escore $Z$, estarão crescendo de forma semelhante à população de referência e, por extensão, terão usufruido, até aquele momento, de adequadas condições de alimentação e de saúde e de ótimo estado nutricional. Da mesma forma, populaçōes com médias negativas do indice estatura (comprimento)/idade e desvios-padrão superiores à unidade abrigarão uma certa proporção de crianças com retardo de crescimento, originário, muito provavelmente, de más condições de alimentação e de saúde e de deficiente estado nutricional (MONTEIRO e CONDE 2000).

$O$ indicador peso/idade indica simplesmente a adequação do peso da criança em relação ao esperado para a sua idade e cerca os indices peso/estatura (comprimento) e estatura (comprimento)/idade. $O$ peso abaixo do esperado, por exemplo, pode representar tanto a desnutrição aguda, resultado de um déficit ponderal que gera uma situação de magreza, quanto a desnutrição crônica (ganho de peso inadequado por um longo período de tempo), que vem, geralmente, associada a um déficit estatural (BARROS e VICTORA 1998; MICHAELSEN 2000, BRASIL. MINISTÉRIO DA SAÚDE 2002).

Segundo MICHAELSEN (2000), apresenta limitaçōes como indicador de estado nutricional. Uma criança com, por exemplo, baixo índice pesolidade pode ter um padrão pequeno de dimensões corporais, tendo indice pesolestatura (comprimento) normal. Em lactentes, valores baixos do índice peso/idade refletem a prevalência de baixo indice peso/estatura (comprimento), o que em crianças mais velhas está mais relacionado a baixo indice estatura/idade.

No plano individual, padrões de referência permitem estabelecer a probabilidade de um certo peso ou estatura (ou velocidade de crescimento) ser encontrado em determinada idade e sexo quando são ótimas as condições de nutrição. Estaturas (ou velocidades de crescimento) tão baixas 
que sejam improváveis em populações bem nutridas são tomadas como indicativas de retardo no crescimento. No plano coletivo, padrões de referência permitem identificar quão próximo, ou distante, o padrão de crescimento evidenciado por determinada população, ou estratos da mesma, se encontra em relação àquele esperado na condição de que todos os individuos, dessa população ou estrato, desfrutem de ótimo estado nutricional (MONTEIRO e CONDE 2000).

Há cerca de 2 anos iniciou-se uma coorte de recém-nascidos com o objetivo de estudar a influência da poluição gerada pelo tráfego de veículos e sua interação com a exposição precoce a condições meteorológicas e ambientais intradomiciliares adversas no desenvolvimento das doenças sibilantes, alergia e sensibilização atópica em crianças com história familiar de asma residentes no Municipio de São Paulo.

Dada a importância do padrão de aleitamento e da alimentação para o crescimento infantil, propõe-se um estudo descritivo para avaliar o padrão alimentar e o crescimento de crianças de 0 a 6 meses de vida, participantes do estudo "Poluição ambiental urbana e outros fatores relacionados à ocorrência de chiado na infância: um estudo de coorte na cidade de São Paulo, Brasil - PROJETO ChIADO". 


\section{OBJETIVOS}

\subsection{Objetivo geral}

Descrever e caracterizar o padrão alimentar e o crescimento de crianças de 0 a 6 meses de vida, participantes do estudo "Poluição ambiental urbana e outros fatores relacionados à ocorrência de chiado na infância: um estudo de coorte na cidade de São Paulo, Brasil - Projeto CHIADO".

\subsection{Objetivos específicos}

- Descrever os padrões de aleitamento e da alimentação das crianças no decorrer do seguimento;

- Caracterizar o crescimento das crianças estudadas segundo índices antropométricos;

- Descrever o crescimento infantil segundo o padrão de aleitamento. 


\section{MÉTODO}

Este trabalho faz parte do estudo "Poluição ambiental urbana e outros fatores relacionados à ocorrência de chiado na infância: um estudo de coorte na cidade de São Paulo, Brasil - PROJETo CHIADo", doravante mencionado simplesmente como Projeto CHIADO.

\subsection{Desenho do estudo}

O PROJETo ChiAdo, que tem como objetivo geral estudar a influência da poluição gerada pelo tráfego de veículos e sua interação com a exposição precoce a condições meteorológicas e ambientais intradomiciliares adversas no desenvolvimento das doenças sibilantes, alergia e sensibilização atópica em crianças com história familiar de asma residentes no Município de São Paulo, utiliza-se do desenho de coorte prospectiva, a qual foi iniciada em novembro de 2002 e encontra-se em andamento até o presente momento.

Essa coorte pretende acompanhar 900 recém-nascidos, pelo menos até os 2 anos de idade, estratificados de acordo com a localização de suas residências em relação à densidade do tráfego e história de asma da mãe (áreas com tráfego intenso: $n=450$, sendo 350 crianças com história de mãe asmática e 100 crianças sem essa história; áreas com tráfego local: $n=450$, sendo 350 crianças com história de mãe asmática e 100 crianças sem essa história - ANEXO 1). O recrutamento é realizado em maternidades públicas do Municipio de São Paulo entre recém-nascidos residentes em áreas onde existem estações da CETESB para monitoramento da qualidade do ar.

\subsection{Critérios de elegibilidade}

- Critérios de inclusão:

[A]

- mães com história atual ou pregressa de asma e/ou atopia; 
- crianças aparentemente saudáveis, idade gestacional $\geq 35$ semanas e sem complicações ou infecções no período perinatal;

- famílias residentes em área delimitada pelo estudo e

- Termo de Consentimento Livre e Esclarecido assinado pelas mães (ANEXO 2).

\section{[B]}

- Mães, pais e irmãos sem história atual ou pregressa de asma e/ou atopia;

- crianças aparentemente saudáveis, idade gestacional $\geq 35$ semanas e sem complicações ou infecções no período perinatal;

- famílias residentes em área delimitada pelo estudo e

- Termo de Consentimento Livre e Esclarecido assinado pelas mães (ANEXO 2).

\section{- Critérios de exclusão:}

Os recém-nascidos tiveram sua participação no estudo impedida se:

- apresentassem suspeita de doenças hereditárias ou congênitas sintomáticas;

- apresentassem doenças neurológicas ou neuromusculares;

- apresentassem história de disfunção respiratória grave ao nascer que tenha exigido intubação endotraqueal;

- as mães eram soropositivas para o HIV;

- um ou ambos os pais eram dependentes de drogas ilícitas e

- residissem em favela.

Durante o seguimento, foram considerados fatores de exclusão do estudo:

- manifestação de doenças congênitas ou hereditárias;

- manifestação de doenças neurológicas ou neuromusculares;

- manifestação de doenças imunológicas; 
- presença de tuberculose;

- presença de neoplasias e

- mudança de endereço para local fora da área de abrangência do estudo ou para favela.

A área delimitada pelo estudo abrange toda a grande São Paulo, tendo como fator determinante para a inclusão de uma região a presença de estações da Companhia de Tecnologia de Saneamento Ambiental (CETESB) para monitoramento da qualidade do ar, sendo possível, portanto, a inclusão das 4 zonas (norte, sul, leste e oeste) e da região central da cidade.

A história materna e familiar de asma e/ou atopia é caracterizada no momento da aplicação do questionário Guia de Elegibilidade, na maternidade. Na seção "Informaçōes da familia" desse questionário, por meio de questões pré-codificadas especificas - formuladas ou adaptadas pelos pneumologistas da equipe do PROJETO CHIADO com base em padrões internacionais consagrados - sobre sintomas ou manifestações típicas que proporcionam uma caracterização da asma e também de condição atópica, bem como sobre 0 uso de medicamentos especificos, o entrevistador identifica em qual grupo ([A] mãe com história de asma e/ou atopia ou [B] mãe, pai e irmão (s) sem história de asma e/ou atopia) a criança se enquadra utilizando um gabarito que determina a condição materna e familiar de acordo com o padrão de respostas apresentado (ANEXO 3).

Quanto à estratificação das residências segundo a localização em relação à densidade do tráfego, classifica-se como área de tráfego local aquela que apresenta prioritariamente vias de classe local, subclasse local, as quais caracterizam-se por pista única ou dupla ( 1 ou mais faixas de tráfego por sentido) com função de atender aos deslocamentos de tráfego estritamente locais sendo a acessibilidade prioritária à circulação. Por outro lado, área de tráfego intenso é aquela servida por vias de classe coletora, subclasses coletora I ou coletora II, as quais caracterizam-se respectivamente por pista única ou dupla (1 ou mais faixas de tráfego por 
sentido) e pista única (1 faixa de tráfego por sentido), que coletam e distribuem os fluxos veiculares entre as vias da rede principal e local, com tráfego de passagem e local geralmente na mesma proporção; e/ou vias de classe trânsito rápido e arteriais, subclasses VTR (vias de trânsito rápido) ou arterial I ou arterial II ou arterial III, caracterizadas por, respectivamente, pista única ou dupla ( 1 ou mais faixas de tráfego por sentido), pista dupla (2 ou mais faixas de tráfego por sentido), pista única ( 1 faixa de tráfego por sentido) e pista única ( 1 faixa de tráfego por sentido), que formam a principal estrutura viária da cidade, recebendo os fluxos veiculares da rede secundária e local, permitindo articulaçōes extremas da cidade, com predominância do tráfego de passagem ao local, sendo a circulação prioritária à acessibilidade (CET 1999, citado por MOURA 2002, p.16).

Como beneficios oferecidos às mães participantes do ProJETO CHIADO destacam-se: filho matriculado no Instituto da Criança Prof. Pedro de Alcântara do Hospital das Clínicas - FMUSP, com acompanhamento de puericultura realizado por equipe qualificada, acesso às diversas especialidades pediátricas quando necessário, exames e medicamentos; fornecimento de bilhete único para que possa comparecer às consultas sem gastos com condução; possibilidade de contato telefônico com a equipe do projeto a qualquer momento para suporte elou esclarecimento de dúvidas referentes à saúde da criança, a procedimentos ou agendamento.

As mães das crianças participantes em seguimento intensivo recebem também um caderno de acompanhamento da saúde da criança. Esse caderno funciona como um incentivo para a adesão às consultas e exames e é a carteira de saúde da criança, com um resumo de informações sobre o PROJETO ChIADO e os telefones para contato com a equipe, informaçōes básicas sobre saúde, alimentação e higiene da mulher e do recém-nascido, registro de intercorrências de saúde que a criança possa apresentar e, por algum motivo, seja atendida em outro serviço médico, tabela de vacinação infantil, gráficos de crescimento e folha de agendamento de consultas e procedimentos. As mães são orientadas a arquivar tudo o que é relacionado à saúde da criança. 


\subsection{Coleta dos dados}

\subsubsection{O acompanhamento das crianças}

Os recém-nascidos são recrutados na maternidade por entrevistadores treinados que, após aplicarem o questionário Guia de Elegibilidade (ANEXO 3), confirmarem a área de residência e explicarem os propósitos do estudo, solicitam o consentimento informado das mães para inclusão de suas crianças na pesquisa (ANEXO 2). Os dados relativos ao periodo perinatal são obtidos nos registros hospitalares e/ou na "Carteira de acompanhamento da gestante". Até o presente momento os hospitais/maternidades onde há atuação das equipes de recrutamento de mães/crianças para o projeto são: Hospital Universitário - USP (zona oeste), Hospital e Maternidade Vila Nova Cachoeirinha (zona norte) e Santa Casa de Misericórdia de São Paulo (região central).

Dentre as crianças participantes desse estudo, pretende-se que 700 (350 que residem em áreas com tráfego intenso e 350 em áreas com tráfego local, sendo que em cada um desses grupos haverá 100 crianças sem história familiar de asma) sejam acompanhadas regularmente por pediatras, nutricionistas e entrevistadores para o monitoramento da saúde e condições de vida. Pretende-se também que uma sub-amostra de 200 crianças com história materna de asma e/ou atopia, sendo 100 que vivem em área de tráfego intenso e 100 residentes em área de tráfego local, não sejam acompanhadas de forma intensiva pela equipe da pesquisa (sem consultas com pediatras e nutricionistas do projeto, sem instalação de equipamentos em seus domicílios, sem coletas periódicas de material biológico), recebendo apenas algumas visitas domiciliares para a aplicação de questionários para coleta de informações acerca da saúde dessas crianças e seua familiares, de fatores sócio-econômicos, hábitos domiciliares e condiçōes de vida da família (ANEXO 1). Esse grupo com 200 crianças atuaria como controle de viés de intervenção, pois acredita-se que o seguimento intensivo, com visitas domiciliares, coletas de amostras de poeira e instalação de equipamentos, pode alterar o comportamento das 
pessoas com relação ao ambiente doméstico e ao cuidado prestado à criança, o que acarretaria distorções nos resultados.

As crianças em seguimento intensivo são acompanhadas por pediatras e nutricionistas da equipe envolvida na pesquisa, com consultas regulares agendadas da seguinte forma:

- consultas mensais até os 6 meses de vida;

- consultas bimestrais dos 6 aos 12 meses de vida;

- consultas trimestrais dos 12 aos 24 meses de vida.

O atendimento das crianças é realizado no Ambulatório Unidade ASPN 004 - Grupo de Chiado, do Instituto da Criança Prof. Pedro de Alcântara do Hospital das Clínicas - FMUSP, ambulatório especialmente criado para atender à demanda do projeto.

Além das consultas regulares, todas as crianças que, durante o seguimento, apresentam episódios de doenças respiratórias do trato inferior com chiado, são examinadas por pediatra da equipe da pesquisa. Alguns pacientes nessa situação são submetidos à coleta de aspirado de nasofaringe para pesquisa de vírus respiratórios.

Há uma pessoa responsável pelo controle do agendamento dos pacientes, que entra em contato com as mães e/ou responsáveis pelas crianças alguns dias antes da consulta para confirmar a presença $e$, se necessário, realizar algum remanejamento. Da mesma forma, quando ocorrem faltas, entra em contato para identificar o motivo e agendar uma nova consulta para o mesmo mês. Essa pessoa também é responsável pela entrada de pacientes "fora de dia" na agenda, quando alguma intercorrência é passivel de avaliação médica imediata.

\section{- Acompanhamento nutricional}

Insere-se na área clínica do PROJETO CHIADO, com consultas ambulatoriais seguindo os critérios de freqüência estabelecidos para as consultas médicas, como já mencionado (consultas mensais até os 6 meses de vida, consultas bimestrais dos 6 aos 12 meses de vida e consultas trimestrais dos 12 aos 24 meses de vida). 
Os dados de consumo alimentar são coletados em dois questionários especificos: Acompanhamento Nutricional I - alimentos liquidos, água e chá (ANEXO 4) e Acompanhamento Nutricional II - Introdução de alimentos (alimentação de transição) (ANEXO 5).

Para este estudo os dados antropométricos foram obtidos dos Prontuários Médicos de Primeira Consulta e Consultas de Seguimento.

No exame físico as crianças são pesadas por enfermeira treinada, sem roupa, em decúbito dorsal ou sentadas, em balança digital marca Filizola, modelo "BP BABY" com capacidade 15,0kg e precisão de 5,0g, devidamente vistoriada por órgão competente (Instituto Nacional de Metrologia, Normalização e Qualidade Industrial - INMETRO).

As medidas de comprimento são realizadas também por enfermeira treinada, com a criança em decúbito dorsal sobre a maca, sem roupa, utilizando-se régua portátil com precisão de $1 \mathrm{~mm}$.

O acompanhamento nutricional das crianças tem como referência o padrão de conduta utilizado pelo Serviço de Nutrição e Dietética do Instituto da Criança Prof. Pedro de Alcântara do Hospital das Clínicas - FMUSP que, por sua vez, está de acordo com o que é atualmente preconizado por entidades como a Organização Mundial da Saúde (OMS) e o Ministério da Saúde (MICHAELSEN et al. 2000, MS/OPAS/OMS 2002) e segundo MARCONDES (2002/2003):

- Incentivo ao aleitamento materno exclusivo até o sexto mês de vida, com manutenção do leite materno até os dois anos de vida;

- Indicação de fórmula infantil e/ou tipo e diluição de leite adequados para a idade e condição de saúde, em casos de aleitamento misto ou artificial;

- Crianças em aleitamento misto ou artificial: introdução de suco de fruta aos 2 meses, papa de fruta aos 3 meses, gema de ovo e primeira papa salgada aos $41 / 2$ meses e segunda papa salgada aos 6 meses de vida;

- Crianças em aleitamento materno exclusivo: introdução de suco e papa de fruta aos 6 meses, gema de ovo e primeira papa salgada aos $61 / 2$ meses e segunda papa salgada aos 7 meses de vida. 
Evidentemente, de acordo com a especificidade de cada caso, eventuais alterações na conduta podem ocorrer.

\section{- Avaliação clínica das crianças e exames laboratoriais}

Os dados clínicos são coletados em hospitais/maternidades públicos (Hospital Universitário-USP, Hospital e Maternidade Vila Nova Cachoeirinha e Santa Casa de Misericórdia de São Paulo), no Instituto da Criança Prof. Pedro de Alcântara do Hospital das Clínicas - FMUSP e nos domicílios. Durante o seguimento são registradas informações detalhadas sobre os eventos clínicos relativos às crianças em estudo, às suas mães e outros familiares.

Nas diferentes localidades são obtidas as seguintes informações:

Hospitais/maternidades públicos: história do nascimento e do periodo perinatal, história de episódios graves de doenças respiratórias ou de outros distúrbios que tenham exigido cuidados hospitalares;

Instituto da Crianca Prof. Pedro de Alcântara do Hospital das Clínicas FMUSP: dados sobre a saúde e o desenvolvimento da criança (acompanhamento médico e nutricional) e coleta de material biológico para exames laboratoriais;

Domicilio: por meio de questionários especificos obtêm-se informações sobre história familiar de doenças respiratórias, dados sobre os episódios familiares de doenças respiratórias ocorridos durante o seguimento e informações a respeito do uso de medicamentos.

Os exames laboratoriais realizados são:

Hemograma: aos 12 e 24 meses de idade.

Avaliação imunológica: aos 3, 6, 12 e 24 meses de idade.

Parasitológico de fezes: (a) para a criança: entre os periodos de 4 a 6 , de 7 a 9 , de 10 a 12, 16 a 18 e 22 a 24 meses de idade e (b) para a mãe: na $1^{2}$ semana após o parto.

Aspirado de nasofaringe para pesquisa de infeccões virais: sempre que houver episódios de secreção nasal presente. 
Coleta de leite materno para avaliação da concentração de dioxinas e furanos: entre a $3^{\circ}$ e a $4^{\prime \prime}$ semana após o parto.

\section{- Avaliação das exposiçōes ambientais}

Os dados meteorológicos e ambientais utilizados no PROJETo CHIADO são aqueles rotineiramente coletados pelas estações de monitoramento da qualidade do ar da Companhia de Tecnologia de Saneamento Ambiental (CETESB), pelas estações meteorológicas localizadas no municipio de São Paulo e pela Companhia de Engenharia de Tráfego de São Paulo (CET) e, em âmbito intradomiciliar são coletados com a instalação de equipamentos especificos.

As características da construção da residência da criança são registradas em um formulário especifico.

\section{- Avaliação de outros potenciais fatores de risco}

Entrevistadores são responsáveis pela aplicação de questionários, em domicilio, às mães e chefes de família de todas as crianças participantes para coletar informaçōes detalhadas sobre condiçōes sócio-econômicas, abastecimento de água e saneamento básico, aglomeração intradomiciliar, freqüência à creche, ocupação da mãe, presença de fumantes e alérgenos no domicilio, utilização e presença de produtos irritantes, entre outros. Eventualmente, quando não é possível contatar o chefe da família ou mesmo a mãe da criança na visita domiciliar para responder aos questionários, a aplicação de algum questionário é feita por telefone ou no Instituto da Criança Prof. Pedro de Alcântara do Hospital das Clínicas FMUSP, aproveitando a presença da mãe enquanto aguarda a consulta.

Especificamente com relação às informações sobre condições sócioeconômicas, de interesse para o presente estudo, cabe ressaltar que são obtidas informações sobre escolaridade dos pais, renda familiar, ocupação dos pais, caracterização do chefe da família, propriedade da residência e número de moradores no domicilio. 
Essas informações sobre características socioeconômicas e condiçōes de vida das familias vêm para este estudo dos questionários Familiar e Socioeconômico, instrumentos utilizados na coleta de dados no ProJeto CHIADO.

\subsection{Estudo Piloto}

Anteriormente ao início da coorte, em novembro de 2002, foi realizado um estudo piloto com 30 mães/crianças recrutadas no Hospital Universitário - USP. Nesse estudo foram testados todos os procedimentos envolvidos para o recrutamento dos recém-nascidos e para a coleta dos dados e, também, foram testados todos os formulários e questionários. Nessa etapa houve ainda a avaliação da utilização dos equipamentos.

Um programa de treinamento com toda a equipe envolvida na pesquisa foi desenvolvido antes do estudo piloto, com informações detalhadas sobre todas as fases do trabalho e preparação de manuais de aplicação e codificação dos questionários.

\subsection{Entrada e análise dos dados}

Todos os formulários e questionários foram elaborados, na medida do possivel, com respostas pré-codificadas ajustadas para entrada direta no computador. No entanto, o preenchimento e a acurácia desses instrumentos são verificados antes da entrada dos dados, o que possibilita uma análise da consistência.

Este estudo utiliza algumas das informações do Projeto Chiado, coletadas até 25 de outubro de 2004 .

Para a análise dos dados foram utilizados os softwares Intercooled Stata 7.0 for Windows 98/95 NT (STATA CORPORATION 2002), Microsoft Excel 2000 (MICROSOFT CORPORATION 1999) e ANTHRO 1.02 (CDCMHO 1999).

Particularmente neste estudo, foram avaliadas variáveis sócioeconômicas, alimentares e antropométricas, a saber: 


\section{- Sócio-econômicas:}

- Propriedade da casa;

- Escolaridade materna;

- Renda per capita em salários mínimos;

- Condição de classe.

As informações sobre as variáveis sócio-econômicas foram obtidas dos questionários aplicados ao chefe da familia e às mães das crianças pelas equipes da coorte.

A variável propriedade da casa foi dividida nas seguintes categorias: a categoria "própria", constituída por famílias com residência quitada e familias ainda pagando sua moradia; a categoria "alugada", composta por famílias que vivem em imóvel alugado e a categoria "outros", que se refere a habitações cedidas e outras situações não contempladas pelas demais categorias existentes.

A variável escolaridade materna foi categorizada da seguinte maneira: "menos de 4 anos de escolaridade"; "de 4 a 7 anos de escolaridade" (ensino fundamental incompleto); "de 8 a 10 anos de escolaridade" (ensino fundamental completo ou ensino médio incompleto) e "11 ou mais anos de escolaridade" (têm, pelo menos, o ensino médio completo).

A variável renda per capita em salários mínimos foi calculada pela soma da renda em reais de cada membro da familia que contribuia no orçamento do domicilio dividida pelo número de pessoas da família que eram sustentadas por essa renda. $O$ resultado da renda per capita em reais obtido era então dividido pelo valor em reais do salário mínimo vigente $(R \$ 260,00)$. Essa variável apresentou a seguinte categorização: "renda per capita menor que meio salário mínimo"; "renda entre 0,5 e 1 salário minimo per capita"; "renda de 1 a 3 salários mínimos per capita" e "renda per capita de 3 ou mais salários mínimos".

A variável condição de classe foi utilizada segundo o modelo de operacionalização do conceito de classe social proposto por LOMBARDI et al (1988). 
As familias das crianças do presente estudo se distribuíram nas seguintes classes sociais: "sub proletariado"; "proletariado não típico"; "proletariado típico"; "pequena burguesia" e "outros", sendo que esta envolve donas de casa (atividades domésticas não remuneradas), pensionistas, estudantes, pessoas sem ocupação e as que vivem de renda, inválidos e detidos em cumprimento de pena.

\section{- Padrão alimentar:}

- Aleitamento;

- Classificação da alimentação.

O padrão alimentar das crianças foi caracterizado sob dois aspectos, duas fases, $O$ aleitamento, que se refere única e exclusivamente ao tipo de leite que a criança recebe/recebeu no período avaliado e, de forma mais abrangente, a classificação da alimentação, que resulta da associação de um conjunto de informações como idade da criança, condições gerais de saúde e desenvolvimento, tipo de aleitamento e consumo de alimentos (tipo, quantidade e freqüência) no período avaliado, levando em consideração um padrão de referência que corresponde, representa, a situação ideal ou esperada, baseada em recomendações da Organização Mundial da Saúde (OMS), do Ministério da Saúde (MICHAELSEN et al. 2000, MS/OPAS/OMS 2002) e segundo MARCONDES (2002/2003), citadas anteriormente no padrão de conduta do acompanhamento nutricional.

As categorias propostas para as duas variáveis de padrão alimentar estudadas resultam de adaptaçōes de classificações propostas pelo Ministério da Saúde (BRASIL. MINISTÉRIO DA SAÚDE 2001).

Com relação à variável aleitamento, temos 3 categorias definidas:

- Aleitamento materno:

Quando a alimentação láctea da criança é composta apenas por leite materno. 
- Aleitamento misto:

Quando a alimentação láctea da criança é composta por leite materno e outro(s) tipo(s) de leite(s) *.

- Aleitamento artificial:

Quando a alimentação láctea da criança é composta apenas por outro(s) tipo(s) de leite(s) e não recebe nenhum leite materno.

Com relação à variável classificação da alimentação, propõe-se uma classificação que sintetize alguns aspectos relevantes em relação à prática alimentar, tornando prática a visualização da situação alimentar da criança, considerando-se que tal classificação resulta da associação de informaçōes como idade da criança, padrão de aleitamento e bebidas/alimentos introduzidos, no periodo avaliado. Uma classificação é dada comparando-se os aspectos anteriormente citados da criança em questão com o que seria uma situação ideal para aquela faixa etária e condição de saúde e desenvolvimento, segundo o preconizado por BRESOLIN et al. (2000), BRASIL. MINISTĖRIO DA SAÚDE (2001), WHO (2001), MSIOPASIOMS (2002) e MARCONDES (2002/2003).

Para a variável classificação da alimentação foi criado o seguinte grupo de categorias:

- Aleitamento materno exclusivo (AME):

"Quando a criança só recebe leite materno, diretamente do seio de sua mãe ou ordenhado, ou, ainda, leite humano ordenhado e não recebe nenhum outro líquido ou alimento sólido (com exceção de gotas ou xaropes de vitaminas, remédios ou sais minerais)" (BRASIL. MINISTÉRIO DA SAÚDE 2001), com idade de 0 a 6 meses.

\footnotetext{
"Neste estudo, a terminologia "outro tipo de leite" envolve todo tipo de leite que não o leite materno (fórmulas infantis, leite de bar, leite longa vida, leite em pó; de vaca, cabra, ou soja).
} 
- Aleitamento materno predominante (AMP):

"Quando a principal fonte de alimento da criança é o leite materno, sendo permitido apenas receber água ou outros alimentos a base de água (água açucarada, chás e infusões, etc.), sucos de frutas, soro de reidratação oral, gotas ou xaropes de vitaminas, sais minerais ou remédios. Nenhum outro alimento aquoso é permitido nesses casos" (BRASIL. MINISTÉRIO DA SAÚDE 2001), com idade de 0 a 6 meses.

- Aleitamento materno parcial (AMPa):

Quando a criança em aleitamento materno recebe, antes da época adequada, alimentos complementares (cereais, frutas ou outros) em algumas refeiçōes ou, quando a criança encontra-se em aleitamento misto, fora da época adequada para as introduções (menor de 2 meses), independente de estar ou não recebendo algum outro alimento. $O$ simples fato da criança estar em aleitamento misto, em idade menor de 2 meses, leva sua classificação da alimentação a AMPa.

- Aleitamento artificial (AA):

Criança menor de 2 meses em aleitamento artificial e sem receber nenhum outro alimento.

- Alimentação complementar oportuna (ACO):

Criança recebendo alimentação complementar adequada, quanto ao momento de introdução e ao tipo de alimento, de acordo com a situação da criança (tipo de aleitamento, idade e condição de saúde).

- Alimentação complementar insuficiente (ACl):

Criança recebendo alimentação complementar, porém inadequada (insuficiente) em relação à época (idade) e/ou tipo aleitamento e/ou condição de saúde. 
- Introdução precoce de alimentos (IPA):

Criança em aleitamento artificial, menor de 3 meses, recebendo alimentos complementares de quaisquer natureza.

O Anexo 6 ilustra a dinâmica das classificaçōes propostas.

\section{- Antropométricas:}

- Peso ao nascer;

- Peso;

- Comprimento.

A informação do peso ao nascer foi utilizada para identificar os recémnascidos de baixo peso (peso inferior a $2500 \mathrm{~g}$ ), os quais foram excluídos da análise no momento do cálculo dos índices antropométricos observados a seguir. Tal exclusão deveu-se ao padrão diferenciado de crescimento apresentado por crianças nessa condição.

As variáveis peso e comprimento foram utilizadas para o cálculo dos indices antropométricos de interesse na caracterização do crescimento dos lactentes, as quais foram obtidas dos questionários médicos.

As medidas utilizadas para a caracterização do crescimento dos lactentes foram os indices estatura (comprimento)/idade (H/A), peso/idade (W/A) e peso/estatura (W/H), expressos em escores $Z$ do padrão $N C H S$, como recomendado por BRASIL. MINISTÉRIO DA SAÚDE (2002).

O software utilizado para os cálculos dos índices antropométricos e comparações com o padrão de referência [ANTHRO 1.02 (CDCMHO 1999)] apresenta critério de exclusão para valores de escore $Z$ extremos $(-6$ e +6 para os índices estatura [comprimento]/idade e peso/idade; -4 e +6 para 0 indice peso/estatura [comprimento]) 


\subsubsection{Análise descritiva}

Descreveu-se, inicialmente, a dinâmica da amostra da fase de recrutamento para o PROJETO CHIADO ao presente estudo e, em seguida, as principais características das crianças participantes.

Posteriormente, caracterizou-se a amostra com relação à condiçōes sócio-econômicas, padrão de aleitamento, alimentar e de crescimento.

A seguir, procedeu-se a análise do crescimento infantil segundo padrão de aleitamento. Foi avaliada a evolução dos índices antropométricos de crianças que mantiveram aleitamento materno exclusivo (AME) durante todo - período versus crianças com alimentação classificada nas demais categorias durante todo o periodo de seguimento 


\section{ASPECTOS ÉTICOS}

O presente estudo, por estar inserido no PRojeto ChIADo, tem seus quesitos éticos contemplados por este, que foi planejado de maneira que as normas regulamentadoras de pesquisas envolvendo seres humanos contidas na Resolução $N^{\circ} 196$ sejam rigorosamente obedecidas.

Todo e qualquer procedimento da pesquisa é precedido de informação completa para os pais ou responsáveis sobre os possiveis riscos e benefícios para a criança. Além disso, os procedimentos foram executados somente após a assinatura do Termo de Consentimento Livre e Esclarecido (ANEXO 2) para a participação no estudo. Fica assegurada aos participantes a possibilidade de desistência da pesquisa a qualquer momento ou a recusa em coletar materiais biológicos e/ou realizar algum exame, sem que isso cause qualquer constrangimento ou prejuizo para a familia.

Os pesquisadores se comprometem a garantir a privacidade dos participantes do estudo e a confidencialidade dos dados levantados.

O PRojeto Chiado foi aprovado pelo Comitê de Ética em Pesquisa [COEP] da Faculdade de Saúde Pública - USP (ANEXO 7) e pela Comissão Nacional de Ética em Pesquisa [CONEP] (ANEXO 8).

O presente estudo, da mesma forma, foi analisado e aprovado pelo Comitê de Ética em Pesquisa [COEP] da Faculdade de Saúde Pública USP (ANEXO 9). 


\section{RESULTADOS E DISCUSSÃO}

\subsection{Dinâmica da amostra}

Das 2230 puérperas contactadas até 25 de outubro de 2004 (data limite para a entrada de informaçōes) pelas equipes de recrutamento do Projeto ChIADo em três maternidades públicas da cidade de São Paulo, 249 mães/251 crianças ( 1 caso de parto gemelar e 1 criança nascida de mãe que já possuia um filho em seguimento) foram elegíveis para o ingresso no estudo. Dessas, 193 crianças iniciaram a coorte e, até o presente momento, 156 encontram-se em seguimento. Foram consideradas como crianças que iniciaram a participação no estudo aquelas que, pelo menos, receberam a primeira visita domiciliar da equipe para a instalação de equipamentos, coleta de amostra de poeira doméstica e aplicação de questionários. Dentre as 37 crianças desligadas da coorte após seu início encontram-se desistências espontâneas, mudanças de endereço para localidades fora da área de abrangência do PROJETO CHIADO e mudanças para favela. Tal cifra corresponde a uma proporção de $19,17 \%$ de perdas, situação absolutamente factivel com a estimativa de $20 \%$ de perdas no seguimento estabelecida quando do cálculo do tamanho da amostra para o PROJeto CHIADO.

BUENO et al. (2003), em estudo de coorte potencial de 506 recémnascidos de um hospital universitário no município de São Paulo, observou, em 1 ano de seguimento, 123 perdas, o que equivale a $24,3 \%$ do total de crianças que iniciaram $\circ$ estudo, sendo o principal motivo a mudança de endereço.

Em estudo de coorte de $99,0 \%$ dos nascimentos em Pelotas RS no ano de 1982, VICTORA et al. (2003) observaram, em 19 anos de seguimento, uma taxa média de perdas de $22,9 \%$.

O presente estudo conta com informações de 174 crianças, $90,1 \%$ das que iniciaram o Projeto ChIADO, com 19 crianças não captadas especificamente para o acompanhamento nutricional $(9,8 \%)$. 
A figura 1 mostra o fluxo de crianças da fase de recrutamento para o PROJETO ChIADO ao presente estudo.

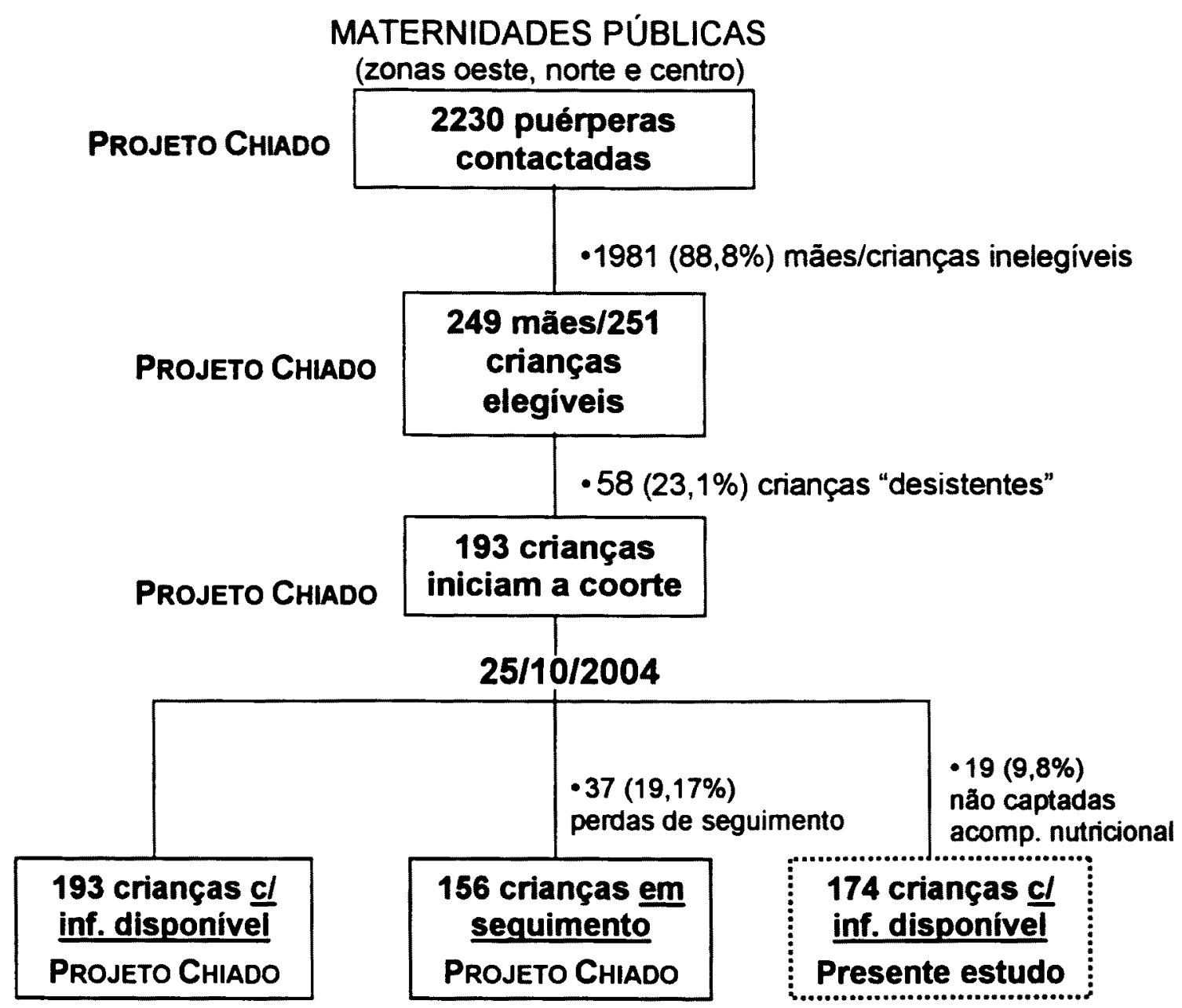

Figura 1: Dinâmica da amostra do PROJETO CHIADO da fase de recrutamento ao presente estudo, São Paulo, 2005.

Para a consulta de 15 dias de vida (ponto inicial do estudo) havia dados de 174 crianças, sendo 91 do sexo feminino $(52,30 \%)$ e 83 do sexo masculino (47,70\%). Dessas, 103 atingiram a idade de 6 meses até 0 término do estudo, sendo 57 crianças do sexo feminino $(55,34 \%)$ e 46 do sexo masculino $(44,66 \%)$.

Essa diferença no número de crianças analisadas em cada momento do seguimento é uma peculiaridade do presente estudo, pois utiliza-se de dados de uma coorte ainda em andamento, com recrutamento de crianças ativo. 
Até o momento da interrupção da inclusão de informaçōes no presente estudo (25/10/2004) havia crianças com, por exemplo, 21 meses de vida que, portanto, considera-se que tenham passado por todas as consultas em questāo (15 dias a 6 meses) e, indivíduos com 1 mês de vida, idade suficiente para ter comparecido apenas até o acompanhamento de 1 mês. A figura 2 resume a distribuição do número de crianças com idade suficiente para cada fase do seguimento.

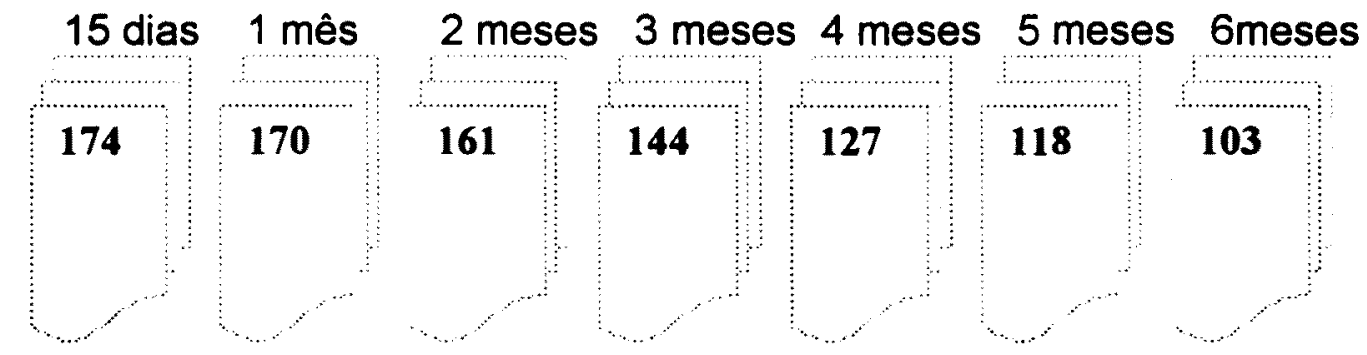

Figura 2: Distribuição da quantidade de crianças participantes do PROJETo CHIADO para cada etapa do seguimento, São Paulo, 2005.

\subsection{Condiçōes sócio-econômicas}

As variáveis sócio-econômicas estudadas foram propriedade da casa, escolaridade materna (em anos), renda familiar em SM per capita e condição de classe.

A descrição das caracteristicas sócio-econômicas das crianças encontra-se na tabela 1, com ausência de informação sobre propriedade da casa para 40 crianças, sobre escolaridade materna para 9 crianças, sobre renda familiar para 47 e sobre condição de classe para 40 , das 174 crianças participantes do estudo. 
Tabela 1: Distribuição do número e porcentagem de crianças participantes do PROJETO CHIADO segundo as variáveis sócioeconômicas estudadas, São Paulo, 2005.

n $\%$

Propriedade da casa $(n=134)$

Própria

55

41,0

Alugada

55

41,0

Outro

24

17,9

Escolaridade materna $(n=165)$ [anos]

$01-4$

10

6,1

$4 \vdash 8$

41

24,8

$81-11$

53

32,1

$111-$

61

37,0

Renda familiar $(n=127)$

[SM per capita]

010,5

30

23,6

$0,5 \mid-1$

$11-3$

$31-$

Condição de classe $(n=134)$

Sub proletariado

$20 \quad 15,0$

Proletariado não típico

62

Proletariado tipico

11

Pequena burguesia

30

Outros
46,3

8,2

22,4

34,6

34,6

7,1

11

8,2

Como observado na tabela 1 e na figura 3 , com relação à variável propriedade da casa, nota-se uma distribuição homogênea entre familias vivendo em casas próprias e alugadas, $41,0 \%$ para cada tipo, lembrando que a categoria "própria" é constituida por familias com residência quitada e famílias ainda pagando sua moradia.

A categoria "outros", que se refere a habitações cedidas e outras situações não contempladas pelas categorias existentes, responde por $17,9 \%$ das familias. 


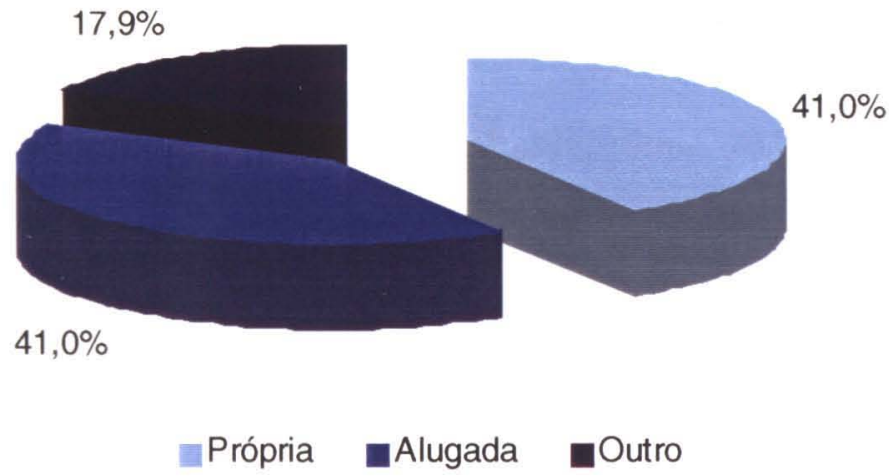

Figura 3: Distribuição das famílias das crianças participantes do PROJETO CHIADO com relação à propriedade da casa, São Paulo, 2005.

Com relação à variável escolaridade materna, de acordo com a tabela 1 e a figura 4 , temos $37 \%$ das mães com 11 ou mais anos de escolaridade, ou seja, têm, pelo menos, o ensino médio completo.

Uma proporção de $32,1 \%$ das mães encontra-se na categoria de 8 a 10 anos de escolaridade (ensino fundamental completo ou ensino médio incompleto) e $24,8 \%$ das mães têm de 4 a 7 anos de escolaridade (ensino fundamental incompleto).

Em menor proporção $(6,1 \%)$ estão mães com menos de 4 anos de escolaridade, sendo 2 casos de mães que nunca freqüentaram a escola. 


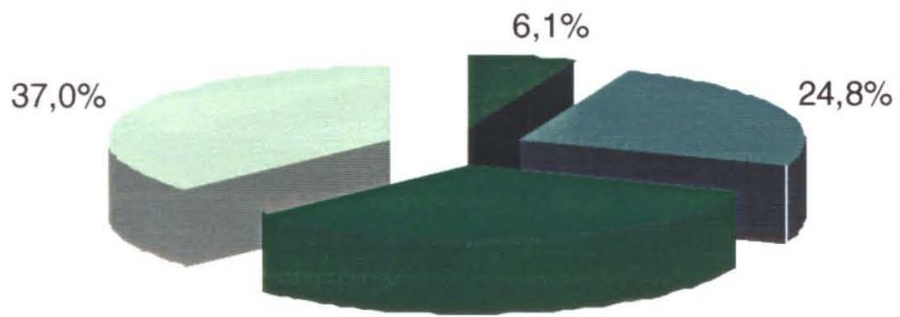

$32,1 \%$

Menos de 4 anos $\square$ a 7 anos $\square$ a 10 anos 11 ou mais anos

Figura 4: Distribuição das mães das crianças participantes do PROJETO CHIADO com relação à escolaridade em anos, São Paulo, 2005.

Para renda familiar em SM per capita, de acordo com a tabela 1 e a figura 5 , temos novamente uma distribuição homogênea $(34,6 \%)$ para duas categorias, famílias com renda entre 0,5 e 1 salário mínimo per capita e com renda de 1 a 3 salários mínimos per capita, sendo essas as duas categorias em que se encontram a maioria das famílias (44 famílias em cada).

Trinta famílias $(23,6 \%)$ têm renda per capita menor que meio salário mínimo e 9 famílias $(7,1 \%)$ possuem renda per capita de 3 ou mais saláriosmínimos.

Cabe ressaltar ainda que, para as 127 observações com relação à renda familiar em SM per capita foi observada média de 0,92 ( $d p=0,87)$ salário mínimo per capita com valores mínimo e máximo de 0 (zero) e 6,41, respectivamente. 


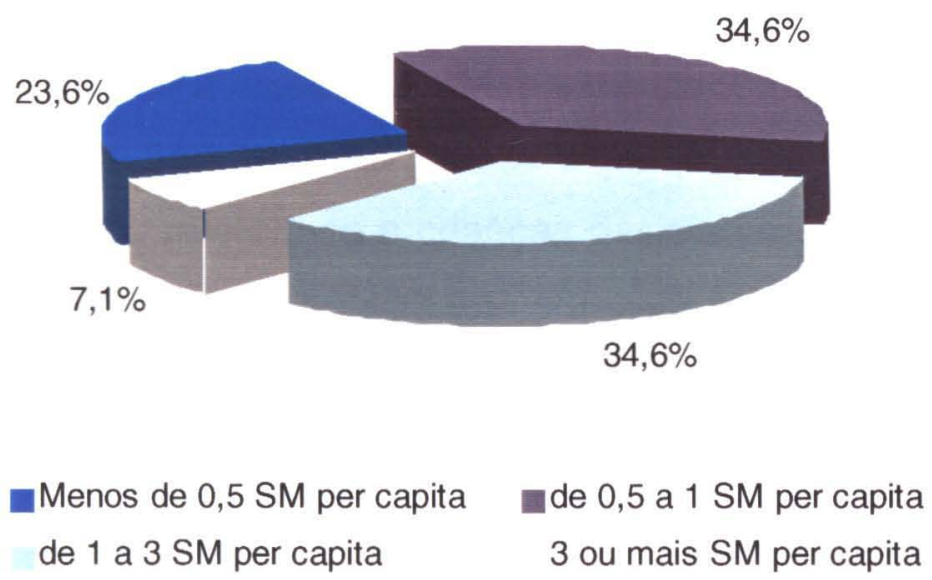

Figura 5: Situação das famílias das crianças participantes do PROJETO CHIADO com relação à renda familiar em SM per capita, São Paulo, 2005.

Finalmente, segundo a condição de classe, segundo a tabela 1 e a figura 6 , observa-se que a maior parte das famílias $(46,3 \%)$ pertence ao proletariado não típico, seguido da pequena burguesia com 22,4\% e do sub proletariado com $15,0 \%$ das famílias. Proletariado típico e Outros são classes que respondem por $8,2 \%$ das famílias.
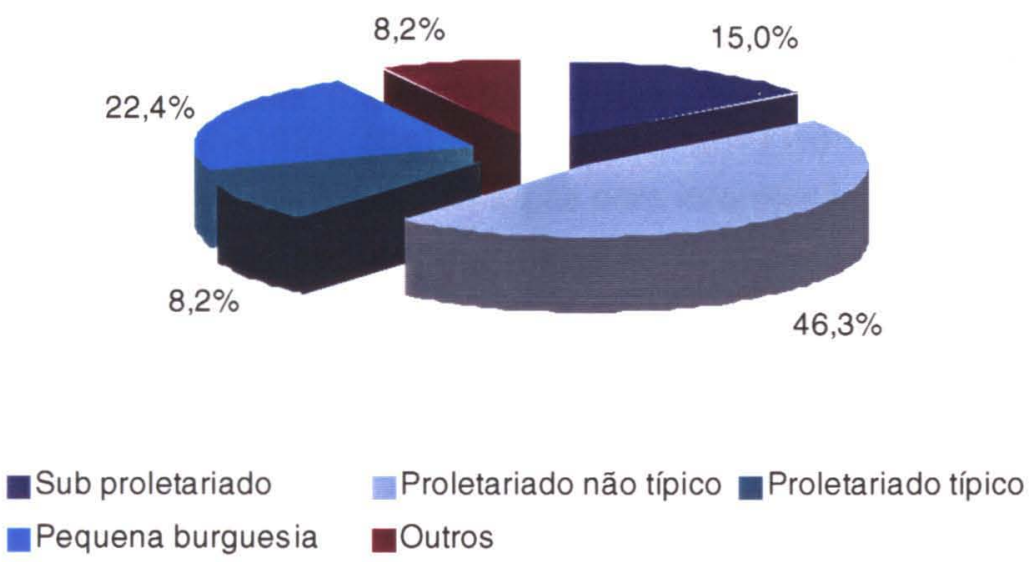

Figura 6: Situação das famílias das crianças participantes do PROJETO CHIADO com relação à condição de classe, São Paulo, 2005. 


\subsection{Padrão alimentar}

Para as informações alimentares houve 8 perdas $(4,7 \%)$ na consulta de 1 mês, $14(8,7 \%)$ na de 2 meses, $16(11,1 \%)$ na de 3 meses, $17(13,4 \%)$ na de 4 meses, $23(19,5 \%)$ na de 5 meses e $18(17,5 \%)$ na consulta de 6 meses. Essas perdas referem-se a crianças desistentes que teriam a idade adequada para a consulta de seguimento em questão, pacientes faltosos ou que, embora com idade suficiente, ainda não tenham passado em consulta por peculiaridades do agendamento (falta de vaga nos dias mais próximos à data de nascimento da criança ou recesso de fim de ano).

A figura 7 mostra a distribuição das crianças segundo o padrão de aleitamento para cada etapa de seguimento.

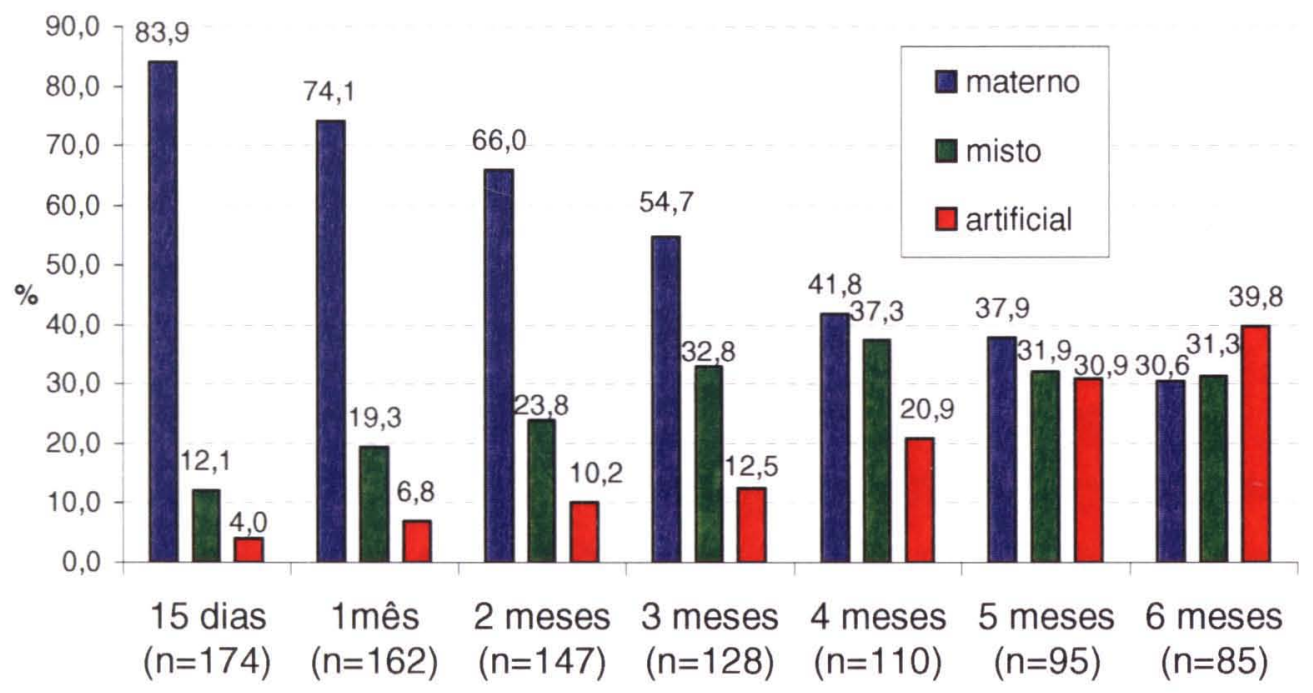

Consultas ( $\mathrm{n}$ para crianças com informação disponível)

Figura 7: Distribuição das crianças participantes do PROJETO CHIADO segundo padrões de aleitamento nos sete períodos de seguimento, São Paulo, 2005.

Com relação ao aleitamento, nota-se decréscimo na proporção de aleitamento materno no decorrer do seguimento, passando de $83,9 \%$ na consulta de 15 dias de vida a 30,6\% na consulta de 6 meses.

O aleitamento artificial, em contraponto ao aleitamento materno, apresenta tendência crescente no decorrer do seguimento, iniciando em 
$4,0 \%$ na consulta de 15 dias e alcançando taxa praticamente dez vezes maior na consulta de 6 meses $(39,8 \%)$.

Até o seguimento de 4 meses a proporção de crianças em aleitamento misto também apresenta evolução, iniciando em 12,1\% na consulta de 15 dias de vida e atingindo valor máximo na consulta de 4 meses $(37,3 \%)$, diminuindo na consulta de 5 meses e alcançando a taxa de $31,3 \%$ na consulta de 6 meses.

A figura 7 retrata claramente a dinâmica de diminuição na prevalência de aleitamento materno e concomitante evolução nas taxas de aleitamento misto e artificial no decorrer do seguimento.

A duração média do aleitamento materno foi de 96,32 dias (13,76 semanas) sendo a duração mediana de 91,2 dias (13,0 semanas).

Devido ao fato de diferentes estudos apresentarem dados em relação ao aleitamento materno de acordo com definiçōes sutilmente distintas para as categorias, foram calculadas as durações média e mediana do que se pode chamar de "presença de leite materno na alimentação", que se refere a aleitamento materno e misto, lembrando que essa classificação refere-se exclusivamente à alimentação láctea da criança.

Tal procedimento viabilizou a comparação do presente achado (duração mediana da "presença de leite materno na alimentação" de 182,4 dias) com o encontrado por BUENO et al. (2003), de 205 dias, ressaltandose que seu estudo acompanhara recém-nascidos até 1 ano de idade.

Uma outra abordagem da análise é a apresentação da evolução do aleitamento no decorrer do seguimento considerando o padrão inicial apresentado na consulta de 15 dias, como mostra a figura 8. 

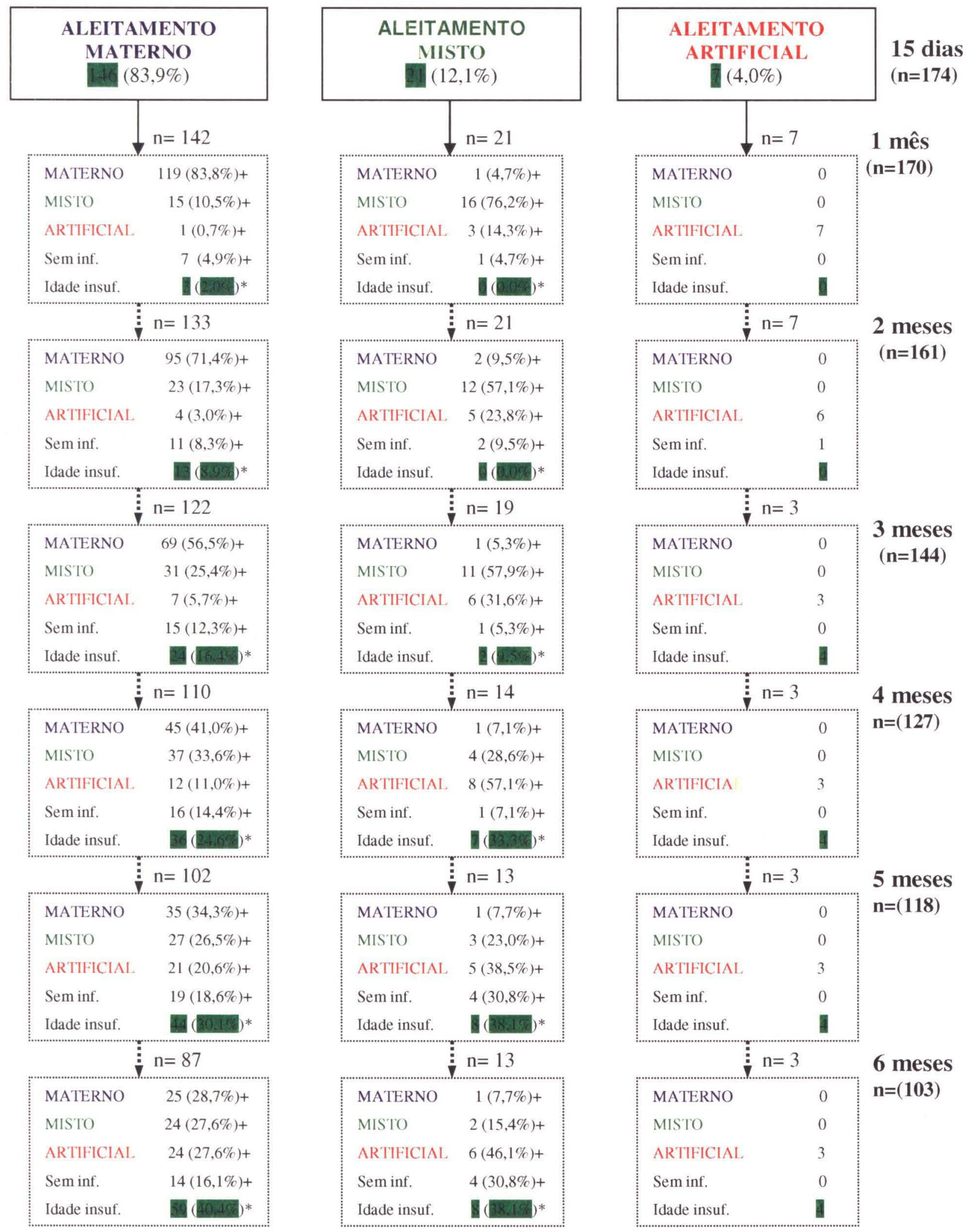

${ }^{+} \%$ em relação ao $n^{\circ}$ de crianças com idade suficiente para o seguimento, a partir do $n^{\circ}$ de crianças na categoria de aleitamento inicial.

* \% em relação ao $\mathrm{n}^{\circ}$ inicial de crianças (consulta 15 dias) em cada categoria.

Figura 8: Dinâmica do padrão de aleitamento das crianças participantes do PROJETO CHIADO a partir da situação inicial aos 15 dias de vida, número de crianças e porcentagem para cada padrão, São Paulo, 2005. 
Na situação inicial do estudo (consulta de 15 dias), observa-se na figura 8, assim como apresentado na figura 7 para a mesma etapa do seguimento, uma distribuição do aleitamento com $83,9 \%$ das crianças em aleitamento materno, $12,1 \%$ em aleitamento misto e $4,0 \%$ em aleitamento artificial.

Entretanto, diferentemente do propósito da figura 7 (distribuição dos padrōes de aleitamento nos sete periodos de seguimento), a figura 8 aborda a dinâmica do aleitamento a partir de uma situação inicial verificada na consulta de 15 dias. É possível, então, observar o comportamento daquelas 146 crianças em aleitamento materno, das $21 \mathrm{em}$ aleitamento misto e das 7 em aleitamento artificial no decorrer do seguimento, para aquelas com idade suficiente para as consultas seguintes e informação disponivel.

Assim como observado na figura 7, é também notável a tendência de diminuição na taxa de aleitamento materno.

Das 146 crianças em aleitamento materno, que correspondem a $83,9 \%$ das 174 crianças avaliadas na consulta de 15 dias, observa-se que 87 delas $(59,6 \%)$ tinham idade suficiente para a consulta de 6 meses a taxa de aleitamento materno observada para as crianças com informação disponivel nessa etapa do seguimento foi de $28,7 \%$. A figura 8 proporciona a observação do "caminho" percorrido por essas crianças, a migração no decorrer do seguimento de crianças em aleitamento materno para as categorias misto e artificial, culminando, na consulta de 6 meses, numa distribuição extremamente homogênea entre as categorias: $28,7 \%$ das crianças em aleitamento materno, $27,6 \%$ das crianças em aleitamento misto e $27,6 \%$ das crianças em aleitamento artificial, o que se encontra muito aquém das recomendaçōes atuais com relação à alimentação do lactente.

Quanto às 21 crianças em aleitamento misto, 12,1\% das 174 crianças avaliadas na consulta de 15 dias, $13(61,9 \%)$ atingiram idade suficiente para a consulta de 6 meses, sendo que a taxa de aleitamento misto observada nessa etapa do seguimento para essas crianças foi de $15,4 \%$. Nota-se, no decorrer do seguimento, a evolução na taxa de aleitamento artificial, 
chegando a $57,1 \%$ na consulta de 4 meses, concomitantemente à diminuição na taxa de aleitamento misto.

Uma observação surpreendente é a do surgimento de 1 criança respondendo pela categoria aleitamento materno já na consulta de 1 mês (representando $4,7 \%$ das crianças com idade suficiente para essa etapa do seguimento), chegando a 2 crianças na consulta de 2 meses (9,5\% das crianças com idade suficiente para essa etapa do seguimento) e permanecendo 1 criança nessa categoria até a consulta de 6 meses $(7,7 \%)$, considerando-se que o ponto de partida foi apenas crianças em aleitamento misto. Tal fato pode, possivelmente, refletir a receptividade dessas mães à orientação nutricional recebida.

Já as 7 crianças em aleitamento artificial já na consulta de 15 dias, $4,0 \%$ das 174 crianças avaliadas nessa etapa, apenas 3 completaram 6 meses até a data de encerramento de inclusão de informações para o presente estudo. Esse grupo apresentou a dinâmica mais estável, com todas as crianças com informação disponível para cada etapa do seguimento mantendo a categoria aleitamento artificial, o que pode ser explicado pelo número reduzido de crianças que o compunham, quando comparado, principalmente, ao grupo em aleitamento materno na etapa inicial, sendo, possivelmente, um grupo mais homogêneo.

Em ambas as abordagens de observação da variável aleitamento propostas, nota-se uma realidade coerente com o observado em diversos estudos sobre alimentação infantil (AUDI et al. 2003, BUENO et al. 2003, HEATH et al. 2002, KUMMER et al. 2000, LAUER et al. 2004, MARQUES et al. 2001), especificamente com relação ao aleitamento materno: um grande distanciamento em relação às recomendações das entidades de saúde mundiais.

Adiante serão expostos os dados de segunda variável alimentar estudada, que proporciona uma visualização mais abrangente da condição alimentar das crianças. 
A figura 9 mostra a distribuição das crianças com informação alimentar disponível segundo a variável classificação da alimentação para cada etapa de seguimento.

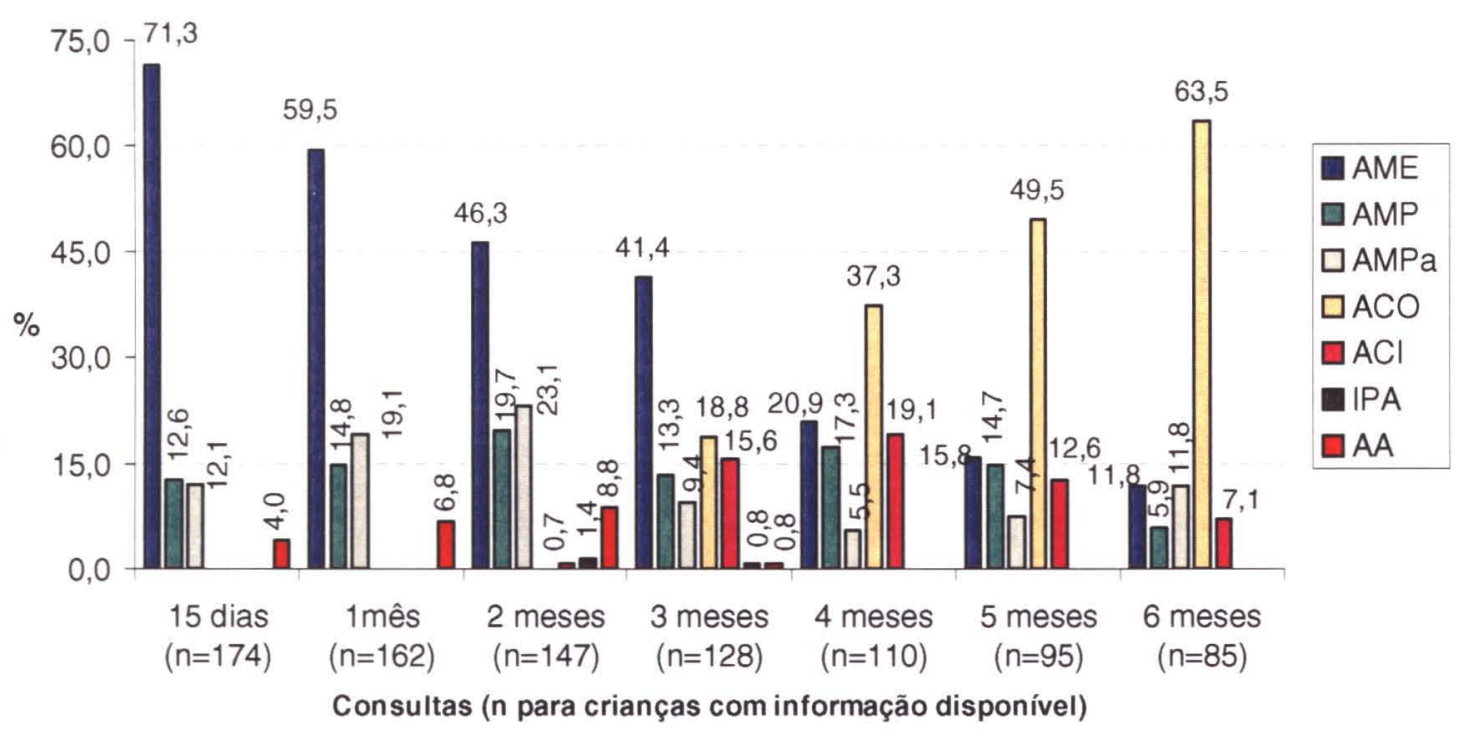

Figura 9: Distribuição das crianças participantes do PROJETO CHIADO segundo padrões de alimentação nos sete períodos de seguimento, São Paulo, 2005.

Com relação à classificação da alimentação, variável com a proposta de uma classificação que sintetize alguns aspectos relevantes em relação à prática alimentar, tornando prática a visualização da condição alimentar da criança; o que pode ser observado na figura 9 é o reflexo daquilo que fora observado nas figuras 7 e 8 , que se referiam ao aleitamento. A prevalência de aleitamento materno exclusivo (AME) sofre decréscimo no decorrer do seguimento, passando de $71,3 \%$ na consulta de 15 dias a $11,8 \%$ na consulta de 6 meses. Destaca-se que já na consulta de 4 meses a prevalência observada para o AME (20,9\%) é menor que a metade do observado no início do seguimento (71,3\% - consulta de 15 dias), culminando numa prevalência de $11,8 \%$ na consulta de 6 meses.

Avaliando-se, das 103 crianças que completaram 6 meses, as 83 cuja informação alimentar para todas as etapas do seguimento era disponível, verificou-se duração média do aleitamento materno exclusivo (AME) de 
60,26 dias (8,60 semanas) e a duração mediana de 30,40 dias $(4,34$ semanas).

Por se tratar de indicador de aleitamento materno relevante, calcularam-se os valores médio e mediano da duração do aleitamento materno total (AMT) - aleitamento materno exclusivo e predominante (BRASIL. MINISTÉRIO DA SAÚDE 2001) - sendo eles, respectivamente, 89,05 e 91,20 dias (12,72 e 13,02 semanas).

No quinto relatório sobre a situação nutricional mundial do Comitê Permanente em Nutrição da Organização das Nações Unidas (UN-SCN) publicado em março de 2004, o Brasil apresentou as seguintes taxas para o período de 1995 a 2002: menores de 6 meses em AME: 42\%, crianças de 6 a 9 meses de vida em aleitamento materno com alimentação complementar $30 \%$ e crianças de 20 a 23 meses ainda em aleitamento materno $17 \%$ (UNSCN 2004).

Quanto à alimentação complementar oportuna (ACO), que deveria se apresentar, salvo exceções, apenas a partir do sexto mês completo de vida (MICHAELSEN 2000), observa-se, já na consulta de 3 meses, $18,8 \%$ das crianças com informação disponivel nessa etapa enquadradas na referida categoria. A prevalência de alimentação complementar oportuna (ACO) apresenta valores crescentes da consulta de 3 meses à de 6 meses, atingindo nesta a taxa de $63.5 \%$.

O comportamento observado para a categoria ACO está diretamente relacionado às categorias $A M P a$ e $A A$, que se referem a crianças com padrão alimentar que requer complementação precoce, fazendo com que crianças pertencentes às duas categorias citadas até a consulta de 2 meses passem a pertencer à categoria ACO a partir da consulta de 3 meses, se for oferecida a alimentação complementar adequada.

Destacam-se, já na consulta de 2 meses, as presenças de crianças classificadas em "introdução precoce de alimentos - IPA" (1,4\%) e crianças em "alimentação complementar insuficiente - $\mathrm{ACl}$ " $(0,7 \%)$, sendo estas, crianças em aleitamento artificial ou misto que ainda não recebem suco de fruta como alimentação complementar para a faixa etária em questão. 
Com relação à categoria "alimentação complementar insuficiente ACl", pode-se notar pelo exposto na figura 9 um comportamento crescente de sua taxa da consulta de 2 meses $(0,7 \%)$ até a consulta de 4 meses, etapa em que atinge taxa máxima de 19,1\%, decrescendo dai em diante. $\mathrm{Na}$ consulta de 6 meses há taxa de $7,1 \%$ de crianças em $\mathrm{ACl}$. Os fatores que podem estar relacionados às altas taxas de $\mathrm{ACl}$ verificadas, segundo o observado no dia-a-dia do atendimento ambulatorial, são falta de atenção da mãe para com a criança devido à imaturidade materna, necessidade de trabalhar ou excesso de filhos e condições financeiras inadequadas.

Considerando que as crianças se encontram em seguimento intensivo, com consultas mensais e disponibilidade de contato telefônico diário com a equipe do PROJETO CHIADO, era esperado que as condiçōes consideradas indesejáveis (AMP, AMPa, ACI, IPA e AA), caso se manifestassem, o fizessem em taxas extremamente baixas, o que não foi observado no presente estudo.

A figura 10, assim como o apresentado na figura 8, ilustra uma outra abordagem de análise com a apresentação da evolução da classificaçăo da alimentação no decorrer do seguimento, considerando o padrão inicial apresentado na consulta de 15 dias para a variável em questão. 


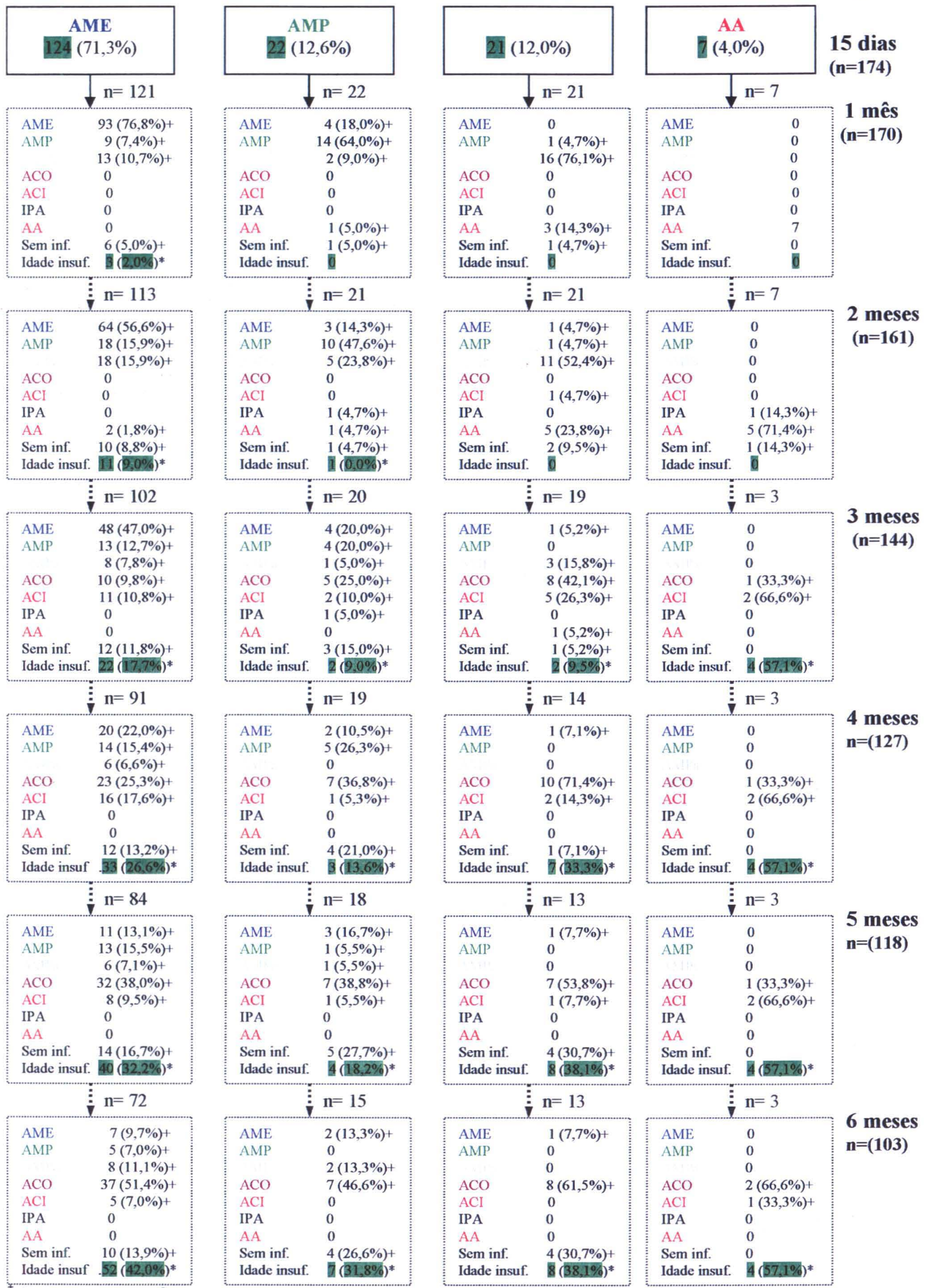

$\%$ em relação ao $\mathrm{n}^{\circ}$ de crianças com idade suficiente para o seguimento, a partir do $\mathrm{n}^{\circ}$ de crianças na categoria de padrão alimentar inicial.

* \% em relação ao $\mathrm{n}^{\circ}$ inicial de crianças em cada categoria (consulta 15 dias).

Figura 10: Dinâmica do padrão de alimentação das crianças a partir da situação inicial aos 15 dias de vida, número de crianças e porcentagem para cada padrão, São Paulo, 2005. 
$\mathrm{Na}$ situação inicial do estudo (consulta de 15 dias), observa-se na figura 10, assim como apresentado na figura 9 para a mesma etapa do seguimento, uma distribuição de padrōes alimentares com $71,3 \%$ das crianças em aleitamento materno exclusivo (AME), 12,6\% em aleitamento materno predominante (AMP), $12,0 \%$ em aleitamento materno parcial (AMPa) e 4,0\% em aleitamento artificial (AA).

Observa-se, então, na figura 10, o comportamento daquelas 124 crianças em aleitamento materno exclusivo (AME), das 22 crianças em aleitamento materno predominante (AMP), das $21 \mathrm{em}$ aleitamento materno parcial (AMPa) e das 7 crianças em aleitamento artificial (AA), no decorrer do seguimento, para aquelas com idade suficiente para as consultas e informação disponivel.

Assim como observado na figura 9, é também notável a tendência de diminuição na taxa de aleitamento materno exclusivo (AME) apresentada na figura 10.

Das 124 crianças em aleitamento materno exclusivo (AME), que correspondem a $71,3 \%$ das crianças avaliadas na consulta de 15 dias, observa-se que 72 delas $(58,0 \%)$ tinham idade suficiente para a consulta de 6 meses e a taxa de aleitamento materno exclusivo observada para as crianças com informação disponível nessa etapa do seguimento foi de $9,7 \%$.

Em relação às 22 crianças em aleitamento materno predominante (AMP), que correspondem a $12,6 \%$ das 174 crianças avaliadas na consulta de 15 dias, observa-se que, curiosamente, já na consulta de 1 mês 4 delas passam a apresentar padrão alimentar de aleitamento materno exclusivo (AME), o que reflete possivelmente o efeito positivo da orientação nutricional recebida na primeira consulta. Ao final do seguimento (consulta de 6 meses) há ainda 2 crianças em AME.

As 21 crianças em aleitamento materno parcial (AMPa), correspondentes a $12,0 \%$ das 174 crianças avaliadas na consulta de 15 dias apresentaram apenas 1 caso de reversão da situação alimentar de AMPa para AME, o qual persistiu até a consulta de 6 meses, representando mais um êxito da orientação nutricional. 
Finalmente, as 7 crianças em aleitamento artificial (AA), 4,0\% das 174 crianças avaliadas na consulta de 15 dias, foram as que apresentaram comportamento mais homogêneo, possivelmente devido ao reduzido número de crianças com essa classificação da alimentação, mantendo-se em categorias consideradas "não desejáveis" como AA, IPA e ACI.

A figura 10 proporciona a observação da dinâmica apresentada por essas crianças, a migração no decorrer do seguimento de crianças em aleitamento materno exclusivo (AME) para as demais categorias, resultando em diminuição contínua de sua prevalência, havendo, já na consulta de 3 meses, menos da metade das crianças com idade suficiente e informação disponível que iniciaram nessa categoria ainda em AME.

Destacam-se 4 crianças que passaram de aleitamento materno predominante (AMP) a aleitamento materno exclusivo (AME) na consulta de 1 mês e 1 criança que fora de aleitamento materno parcial (AMPa) a aleitamento materno exclusivo (AME) na consulta de 2 meses, indicando de forma discreta uma orientação nutricional bem sucedida.

$\mathrm{Na}$ consulta de 6 meses observa-se uma prevalência de AME de 9,7\% dentre as crianças que iniciaram o seguimento nessa categoria, sendo a alimentação complementar oportuna (ACO) a categoria de maior prevalência nessa etapa do seguimento para todas os grupos segundo padrão alimentar inicial, situação distante do desejável segundo as recomendações atuais com relação à alimentação do lactente.

MARTINS (2002), em estudo transversal com 229 crianças de 6 a 24 meses de idade, na cidade de Curitiba PR observou que a orientação alimentar, ainda que efetivamente aplicada à rotina alimentar diária das crianças, não foi uma atividade suficiente para prevenir a ocorrência de anemia e de sua precursora, a deficiência de ferro.

No presente estudo observou-se que, embora com orientação nutricional intensiva, os padrões alimentares observados estão aquém do esperado e apresentam, como encontrado por outros estudos (AUDI et al. 2003, BUENO et al. 2003, HEATH et al. 2002, KUMMER et al. 2000, LAUER 
et al. 2004, MARQUES et al. 2001), grande distanciamento do que é proposto pelas entidades de saúde mundiais.

\subsection{Antropometria}

A tabela 2 apresenta a distribuição do número de crianças por sexo ( $\boldsymbol{M}$ masculino, F-feminino), média e desvio padrāo, valores máximos e mínimos de peso e comprimento, para cada etapa do seguimento.

Tabela 2: Número de crianças participantes do PROJETO CHIADO, média e desvio-padrão, valor mínimo e valor máximo; de peso (g) e comprimento (cm), por sexo, para cada etapa do seguimento, São Paulo, 2005.

\begin{tabular}{lcccccccc}
\hline & \multicolumn{2}{c}{$n$} & \multicolumn{2}{c}{ média (dp) } & \multicolumn{2}{c}{ Minimo } & \multicolumn{2}{c}{ Máximo } \\
& $M$ & $F$ & $M$ & $F$ & $M$ & $F$ & $M$ & $F$ \\
\hline Peso ao nascimento & $79^{\dagger}$ & $85-$ & $3354(442)$ & $3235(405)$ & 2535 & 2500 & 4715 & 4485 \\
Peso 15 dias & 68 & 76 & $3716(490)$ & $3534(456)$ & 2660 & 2250 & 5170 & 4620 \\
Peso 1 més & 69 & 73 & $4520(535)$ & $4250(513)$ & 3200 & 3240 & 5555 & 5550 \\
Peso 2 meses & 65 & 72 & $5563(635)$ & $5079(515)$ & 3625 & 4115 & 6990 & 6780 \\
Peso 3 meses & 53 & 60 & $6297(751)$ & $5885(720)$ & 4200 & 4680 & 8170 & 8465 \\
Peso 4 meses & 43 & 53 & $6926(810)$ & $6498(848)$ & 5645 & 5200 & 9190 & 9180 \\
Peso 5 meses & 39 & 52 & $7552(904)$ & $7034(948)$ & 5930 & 5190 & 9885 & 10010 \\
Peso 6 meses & 33 & 42 & $7942(865)$ & $7592(1121)$ & 6670 & 5750 & 10810 & 10655 \\
Comprimento 15 dias & 68 & 76 & $51,2(3,1)$ & $50,7(2,0)$ & 35,5 & 47,2 & 60,0 & 58,0 \\
Comprimento 1 mês & 69 & 73 & $54,5(2,3)$ & $53,4(2,0)$ & 49,6 & 48,7 & 60,0 & 59,0 \\
Comprimento 2 meses & 65 & 72 & $58,2(2,3)$ & $56,7(2,2)$ & 52,5 & 51,5 & 64,0 & 62,0 \\
Comprimento 3 meses & 53 & 60 & $61,6(2,5)$ & $59,8(2,3)$ & 56,3 & 55,5 & 69,0 & 65,0 \\
Comprimento 4 meses & 43 & $52^{*}$ & $63,6(2,3)$ & $62,5(2,4)$ & 59,4 & 57,7 & 70,4 & 68,0 \\
Comprimento 5 meses & $38^{*}$ & 52 & $66,1(2,6)$ & $64,2(2,2)$ & 61,0 & 60,0 & 73,0 & 69,0 \\
Comprimento 6 meses & 33 & 42 & $67,5(2,1)$ & $66,3(2,3)$ & 62,0 & 61,0 & 71,0 & 70,5 \\
\hline dp: desviopadra, & & & & & & & &
\end{tabular}

\footnotetext{
dp: desvio padrão.

* 1 criança sem informação para a medida em questão.

†4 crianças do sexo masculino excluídas por apresentarem peso de nascimento $<2500 \mathrm{~g}$.

- 6 crianças do sexo feminino excluídas por apresentarem peso de nascimento $<2500 \mathrm{~g}$.
} 
De acordo com a tabela 2 , com relação ao peso, observa-se que as crianças do sexo masculino apresentaram, ao nascimento e em todas as etapas do seguimento, médias superiores às médias femininas.

Em estudo que avaliou o crescimento de crianças em aleitamento materno exclusivo durante os 6 primeiros meses de vida em Belém do Pará, MARQUES et al. (2004), diferentemente do observado no presente estudo, observaram que os lactentes do sexo masculino apresentaram média de peso de nascimento mais baixa que os do sexo feminino $(3,254 \mathrm{~g}$ e $3,291 \mathrm{~g}$, respectivamente), igualando sua média ao sexo feminino com 1 mês de vida e, a partir do quarto mês, apresentando médias de peso superiores às femininas. Foi observado também que aos 4 meses de vida todas as crianças apresentaram peso maior ou igual ao dobro do peso de nascimento, o mesmo observado no presente estudo.

Quanto ao comprimento, pode-se observar o mesmo comportamento de médias masculinas superiores às femininas em todas as etapas do seguimento no presente estudo. Por outro lado, MARQUES et al. (2004) observaram que os recém-nascidos do sexo feminino tinham comprimento médio ao nascimento maior que os do sexo masculino, $49,2 \mathrm{~cm}$ versus $48,7 \mathrm{~cm}$, respectivamente. A partir do quarto mês de vida tal situação fora revertida, com a média de comprimento masculina superando a feminina.

Para a caracterização do estado nutricional utilizaram-se os índices peso/idade, estatura (comprimento)/idade e peso/estatura (comprimento), obtidos a partir das variáveis antropométricas peso e comprimento, para cada etapa do seguimento.

A tabela 3 apresenta a distribuiçāo do indice peso/idade em escore $Z$ (WAZ), por etapa do seguimento e sexo. 
Tabela 3: Distribuição do indice pesolidade em escore Z (WAZ) para as crianças participantes do PROJETO CHIADO, segundo sexo e etapa do seguimento, São Paulo, 2005.

\begin{tabular}{|c|c|c|c|c|c|c|c|c|c|c|}
\hline \multirow{3}{*}{ Seg. } & \multicolumn{10}{|c|}{ Indice peso/idade em escore Z (WAZ) } \\
\hline & \multicolumn{2}{|c|}{$\mathbf{n}$} & \multicolumn{2}{|c|}{ Média $\left(d p^{+}\right)$} & \multicolumn{2}{|c|}{$<-2 d p$} & \multicolumn{2}{|c|}{$-2 d p a+2 d p$} & \multicolumn{2}{|c|}{$>+2 d p$} \\
\hline & $\mathbf{M}^{*}$ & $F^{*}$ & $\mathbf{M}^{*}$ & $F^{*}$ & $\mathbf{n}$ & $\%$ & $\mathbf{n}$ & $\%$ & $\mathbf{n}$ & $\%$ \\
\hline 15 dias & 68 & 76 & $-0,25(0,78)$ & $-0,18(0,86)$ & 2 & 1,39 & 142 & 98,61 & 0 & 0,00 \\
\hline 1 mès & 69 & 73 & $0,12(0,75)$ & $0,29(0,84)$ & 0 & 0,00 & 140 & 98,60 & 2 & 1,40 \\
\hline 2 meses & 65 & 72 & $0,33(0,75)$ & $0,47(0,75)$ & 0 & 0,00 & 132 & 96,35 & 5 & 3,65 \\
\hline 3 meses & 53 & 60 & $0,25(0,83)$ & $0,53(0,90)$ & 0 & 0,00 & 107 & 94,70 & 6 & 5,30 \\
\hline 4 meses & 43 & 53 & $0,21(0,89)$ & $0,46(0,99)$ & 0 & 0,00 & 89 & 92,71 & 7 & 7,29 \\
\hline 5 meses & 39 & 52 & $0,20(0,93)$ & $0,35(1,07)$ & 0 & 0,00 & 86 & 94,50 & 5 & 5,50 \\
\hline 6 meses & 33 & 41 & $-0,03(0,83)$ & $0,25(1,20)$ & 0 & 0,00 & 73 & 96,05 & 3 & 3,95 \\
\hline
\end{tabular}

Observa-se na tabela 3 que, em todas as etapas do seguimento, os valores médios de escore $Z$ observados, para ambos os sexos, estão próximos à média do padrão de referência do NCHS e os desvios-padrão têm valores próximos a 1,0 . Na consulta de 15 dias, ambos os sexos apresentaram valores médios de escore $Z$ menores que zero, sendo 2 individuos com baixo peso para a idade (WAZ < -2dp), o que corresponde a $1,39 \%$ das crianças com informação para o índice em questão na consulta de 15 dias.

A partir da consulta de 1 mês, não se verificam crianças com valores de WAZ menores que -2dp, entretanto, é a partir dessa etapa do seguimento que se observam crianças apresentando valores de WAZ superiores $a+2 d p$ (sobrepeso para a idade), sendo a proporção máxima de crianças nessa situação de $7,29 \%$ na consulta de 4 meses.

A freqüência de peso/idade acima de $+2 \mathrm{dp}$ atinge, aproximadamente, o dobro do esperado na população de referência do padrão do $\operatorname{NCHS}(2,3 \%)$ a partir dos 3 meses de idade. 
A figura 11 apresenta a distribuição em relação ao padrão NCHS das médias de escore $Z$ para o índice peso/idade (WAZ) nas sete etapas de seguimento para crianças com informação disponível em cada etapa.

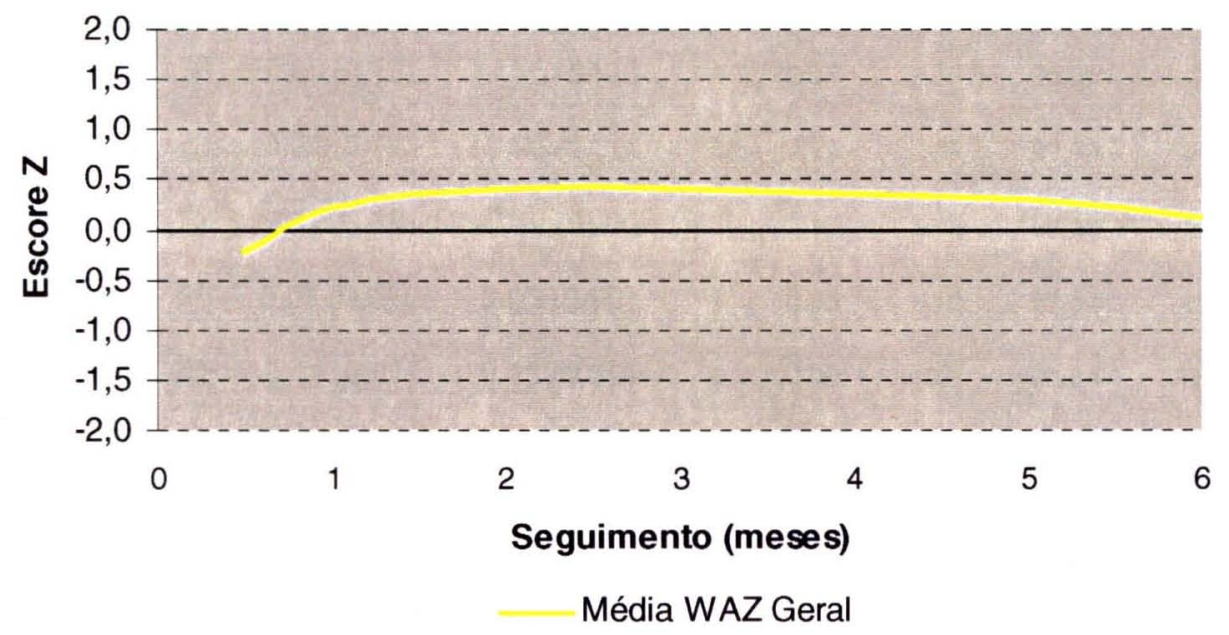

Figura 11: Distribuição das médias de escore $Z$ para o índice peso/idade (WAZ) das crianças participantes do PROJETO CHIADO nas sete etapas de seguimento, São Paulo, 2005.

De acordo com a figura 11, observa-se em média boa evolução do índice peso/idade no decorrer do seguimento em relação ao padrão de referência, mantendo, com exceção da consulta de 15 dias, padrão acima da média da referência do NCHS na faixa de 0,0 a +0,4 escore $Z$.

A curva dos valores das médias de escore $Z$ para o índice peso/idade no decorrer do seguimento representada na figura 11 apresenta padrão crescente até a consulta de 2 meses, mantendo-se relativamente estável e em valor máximo $(+0,4 \mathrm{dp})$ até a consulta de 3 meses, com decréscimo constante e sutil desta etapa do seguimento em diante, não apresentando, porém, valores negativos de escore $Z$, ou seja, médias menores que a média do padrão de referência do NCHS, salvo o apresentado na consulta de 15 dias $(-0,21 d p)$.

A tabela 4 apresenta a distribuição do índice estatura [comprimento]/idade em escore Z (HAZ), por etapa do seguimento e sexo. 
Tabela 4: Distribuição do índice estatura [comprimento]/idade em escore $Z$ (HAZ) para as crianças participantes do PROJETO CHIADO, segundo sexo e etapa do seguimento, São Paulo, 2005.

\begin{tabular}{|c|c|c|c|c|c|c|c|c|c|c|}
\hline \multirow{3}{*}{ Seg. } & \multicolumn{10}{|c|}{ Índice estatura [comprimento]/idade em escore Z (HAZ) } \\
\hline & \multicolumn{2}{|c|}{$\mathbf{n}$} & \multicolumn{2}{|c|}{ Média (dp $\left.{ }^{+}\right)$} & \multicolumn{2}{|c|}{$<-2 d p$} & \multicolumn{2}{|c|}{$-2 d p a+2 d p$} & \multicolumn{2}{|c|}{$>+2 d p$} \\
\hline & $M^{*}$ & $\mathbf{F}^{*}$ & $M^{*}$ & $F^{*}$ & $\mathbf{n}$ & $\%$ & $\mathbf{n}$ & $\%$ & $\mathbf{n}$ & $\%$ \\
\hline 15 dias & 66 & 76 & $-0,50(0,10)$ & $-0,56(0,93)$ & 4 & 2,81 & 135 & 95,06 & 3 & 2,11 \\
\hline 1 mès & 69 & 73 & $-0,24(0,92)$ & $-0,26(0,85)$ & 3 & 2.11 & 138 & 97,19 & 1 & 0,70 \\
\hline 2 meses & 65 & 72 & $-0,12(0,89)$ & $-0,12(0,88)$ & 3 & 2,19 & 132 & 96,36 & 2 & 1,46 \\
\hline 3 meses & 53 & 60 & $0,05(0,93)$ & $0,00(0,90)$ & 1 & 0,88 & 110 & 97,34 & 2 & 1,76 \\
\hline 4 meses & 43 & 52 & $-0,11(0,91)$ & $0,16(0,89)$ & 0 & 0,00 & 92 & 96,84 & 3 & 3,16 \\
\hline 5 meses & 38 & 52 & $-0,01(1,01)$ & $-0,01(0,85)$ & 0 & 0,00 & 89 & 98,89 & 1 & 1,11 \\
\hline 6 meses & 33 & 41 & $-0,38(0,77)$ & $0,06(0,89)$ & 2 & 2,63 & 74 & 97,37 & 0 & 0,00 \\
\hline
\end{tabular}

Observa-se na tabela 4 que, novamente, em todas as etapas do seguimento, os valores médios de escore $Z$ observados, para ambos os sexos, estão próximos à média do padrão de referência do $N C H S$ e os desvios-padrão têm, de maneira geral, valores próximos a 1,0, sendo que há maior quantidade de valores médios menores que zero em relação ao apresentado na tabela 3, para ambos os sexos.

Com relação ao índice estatura (comprimento)/idade, na consulta de 15 dias há 4 crianças com déficit estatural (HAZ< $-2 d p)$, o que corresponde a $2,81 \%$ das crianças com informação disponivel na etapa em questão. Dessa etapa à consulta de 3 meses nota-se a presença de crianças com retardo de crescimento, sendo as taxas de $2,11 \%$ na consulta de 1 mês, $2,19 \%$ na consulta de 2 meses e $0,88 \%$ na consulta de 3 meses, com nova manifestação de crianças nessa condição na consulta de 6 meses a uma taxa de $2,63 \%$.

A figura 12 apresenta a distribuição em relação ao padrão NCHS das médias de escore $Z$ para $o$ indice estatura [comprimento]/idade (HAZ) nas sete etapas de seguimento para crianças com informação disponivel em cada etapa. 


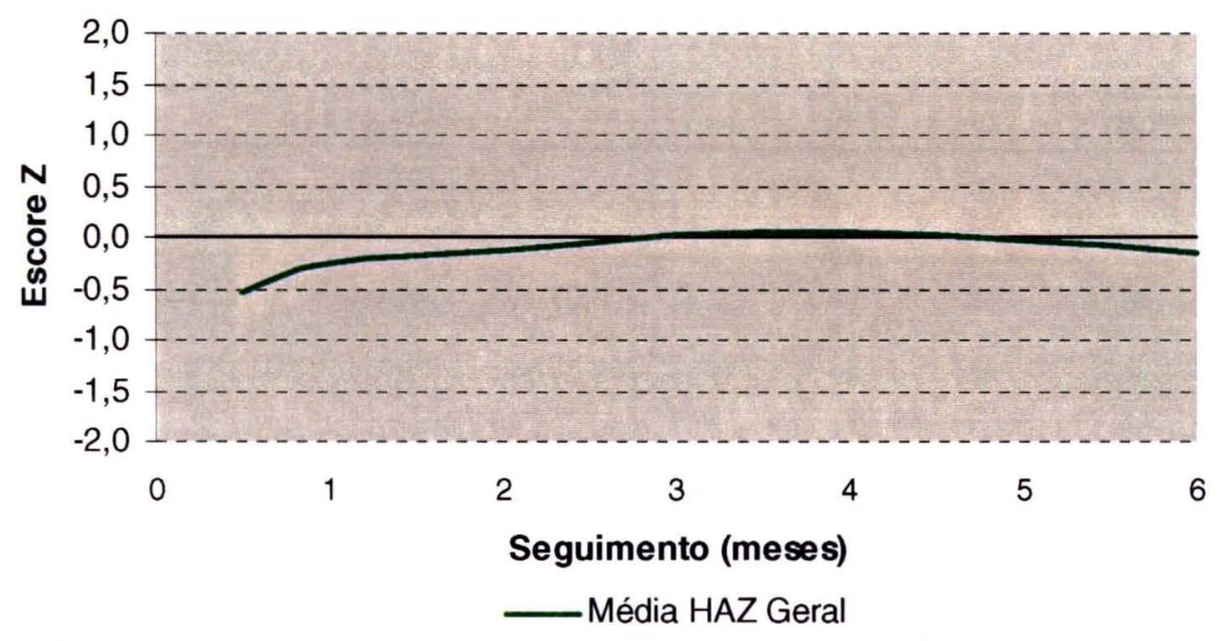

Figura 12: Distribuição das médias de escore $Z$ para $o$ índice estatura [comprimento]/idade (HAZ) das crianças participantes do PROJETO CHIADO nas sete etapas de seguimento, São Paulo, 2005.

De acordo com a figura 12, observa-se em média evolução não tão satisfatória do índice estatura (comprimento)/idade no decorrer do seguimento em relação ao padrão de referência quanto o observado na figura 11, referente ao índice peso/idade.

A curva dos valores das médias de escore $Z$ para o índice estatura (comprimento)/idade no decorrer do seguimento representada na figura 12 apresenta padrão crescente do início do seguimento (consulta de 15 dias 0,53dp) até a consulta de 4 meses, etapa em que alcança valor máximo (+0,04dp). Atinge e supera discretamente a média do padrão de referência do NCHS na consulta de 3 meses, sustentando essa condição até a consulta de 5 meses, etapa em que se inicia o comportamento decrescente atingindo valor não inferior a -0,13dp.

A tabela 5 apresenta a distribuição do índice peso/estatura [comprimento] em escore $Z$ (WHZ), por etapa do seguimento e sexo 
Tabela 5: Distribuição do índice peso/estatura [comprimento] em escore $Z$ (WHZ) para as crianças participantes do PROJETO CHIADO, segundo sexo e etapa do seguimento, São Paulo, 2005.

\begin{tabular}{|c|c|c|c|c|c|c|c|c|c|c|}
\hline \multirow{3}{*}{ Seg. } & \multicolumn{10}{|c|}{ Índice peso/estatura [comprimento] em escore Z (WHZ) } \\
\hline & \multicolumn{2}{|c|}{$\mathbf{n}$} & \multicolumn{2}{|c|}{ Média (dp $\left.{ }^{+}\right)$} & \multicolumn{2}{|c|}{$<-2 d p$} & \multicolumn{2}{|c|}{$-2 d p a+2 d p$} & \multicolumn{2}{|c|}{$>+2 d p$} \\
\hline & $M^{*}$ & $F^{*}$ & $M^{*}$ & $F^{*}$ & $\mathbf{n}$ & $\%$ & $\mathbf{n}$ & $\%$ & $\mathbf{n}$ & $\%$ \\
\hline 15 dias & 60 & 63 & $0,15(0,75)$ & $-0,10(0,81)$ & 2 & 1,62 & 120 & 97,56 & 1 & 0,81 \\
\hline 1 mês & 69 & 72 & $0,42(0,73)$ & $0,48(0,74)$ & 0 & 0,00 & 139 & 98,58 & 2 & 1,42 \\
\hline 2 meses & 65 & 72 & $0,57(0,67)$ & $0,62(0,80)$ & 0 & 0,00 & 136 & 99,28 & 1 & 0,73 \\
\hline 3 meses & 53 & 60 & $0,21(0,75)$ & $0,56(0,92)$ & 0 & 0,0 & 107 & 94,68 & 6 & 5,30 \\
\hline 4 meses & 43 & 52 & $0,28(0,96)$ & $0,31(0,96)$ & 1 & 1,05 & 83 & 91,58 & 7 & 7,34 \\
\hline 5 meses & 38 & 52 & $0,11(1,00)$ & $0,39(1,16)$ & 2 & 2,22 & 82 & 91,12 & 6 & 6,66 \\
\hline 6 meses & 33 & 41 & $0,21(1,42)$ & $0,26(1,21)$ & 1 & 1,32 & 68 & 89,47 & 7 & 9,21 \\
\hline
\end{tabular}

'desvio padrão.

* sexo masculino.

" sexo feminino.

A tabela 5 apresenta, em consonância com o observado para os outros dois indices previamente apresentados e discutidos, em todas as etapas do seguimento, valores médios de escore $Z$, para ambos os sexos, próximos à média do padrão de referência do NCHS e os desvios-padrão, de maneira geral, com valores próximos a 1,0. Apenas a média feminina na consulta de15 dias apresenta valor menor que zero $(-0,1 \mathrm{dp})$.

A freqüência de crianças com déficit de peso (índice pesolestatura (comprimento) inferior a -2dp) observada em todo o periodo de seguimento é próxima do esperado, segundo o padrão de referência do $\operatorname{NCHS}(2,3 \%)$.

A partir dos 3 meses a freqüência de $W H Z>+2 d p$ torna-se expressiva, identificando casos de obesidade. Nota-se que, já nessa etapa, a freqüência observada é maior que o dobro do esperado, atingindo, aos 6 meses, valor 4 vezes maior que o esperado segundo o padrão de referência do NCHS.

A figura 13 apresenta a distribuição em relação ao padrão NCHS das médias de escore $Z$ para 0 índice pesolestatura [comprimento] (WHZ) nas sete etapas de seguimento para crianças com informação disponivel em cada etapa. 


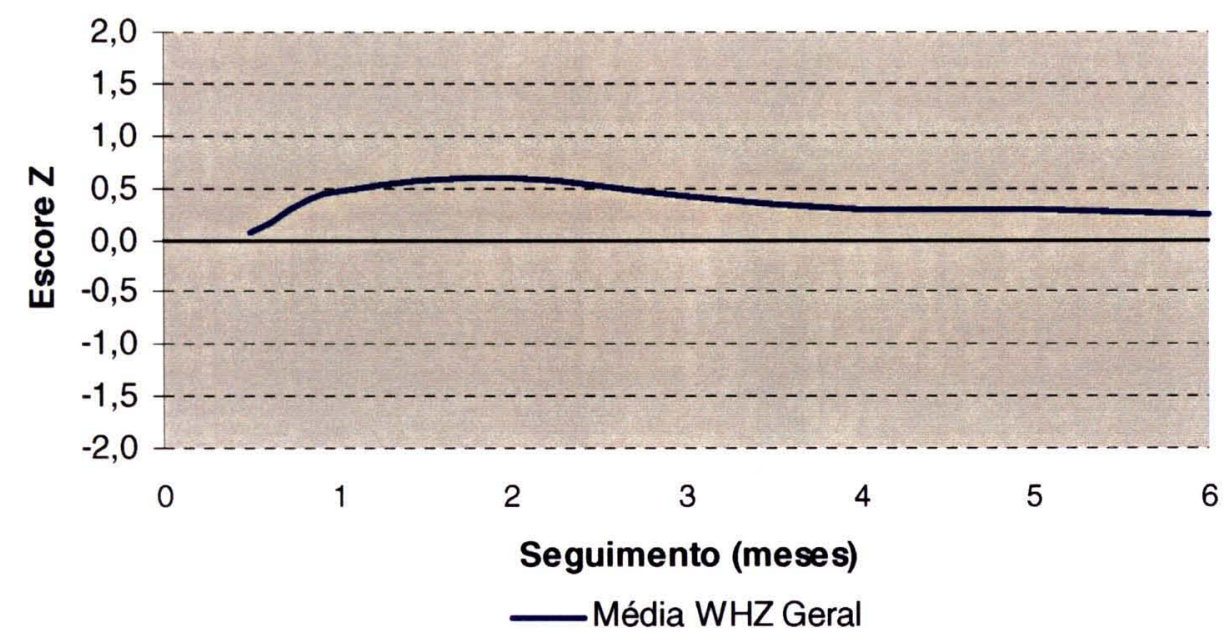

Figura 13: Distribuição das médias de escore $Z$ para o índice peso/estatura [comprimento] (WHZ) das crianças participantes do PROJETO CHIADO nas sete etapas de seguimento, São Paulo, 2005.

Segundo a figura 13, observa-se em média bom desempenho do índice peso/estatura (comprimento) no decorrer do seguimento em relação ao padrão de referência. Nota-se que, em todas as etapas do seguimento, as crianças participantes do estudo apresentaram, em média, padrão de peso para estatura (comprimento) superior à média do padrão NCHS.

A curva dos valores das médias de escore $Z$ para 0 índice peso/estatura (comprimento) no decorrer do seguimento representada na figura 13 apresenta padrão crescente do início do seguimento (consulta de 15 dias +0,07dp) até a consulta de 2 meses, etapa em que alcança valor máximo (+0,6dp). A partir deste momento observa-se um comportamento decrescente extremamente sutil até atingir, na consulta de 6 meses, valor médio $+0,24 \mathrm{dp}$.

A figura 14, com o objetivo de proporcionar uma visualização comparativa do que fora discutido, apresenta a distribuição das médias de escore $Z$ para os três índices avaliados previamente (WAZ, HAZ e WHZ) nas sete etapas de seguimento para crianças com informação disponível em cada etapa. 


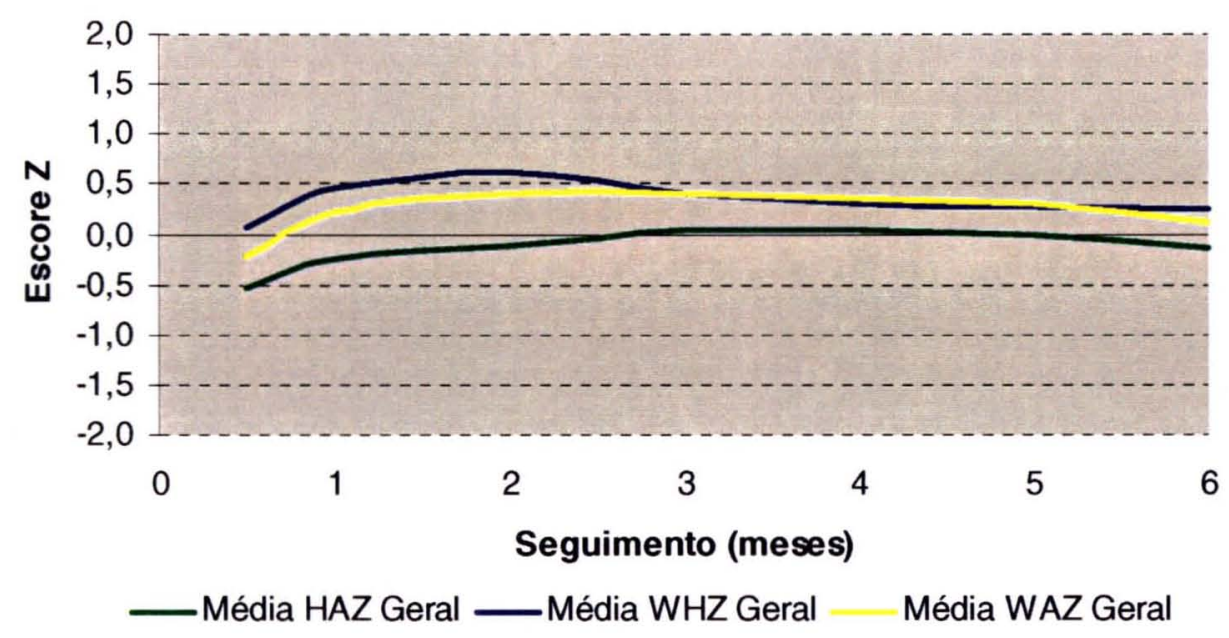

Figura 14: Distribuição das médias de escore $Z$ para os índices peso/idade (WAZ), estatura [comprimento]/idade (HAZ) e peso/estatura [comprimento] (WHZ) das crianças participantes do PROJETO CHIADO nas sete etapas de seguimento, São Paulo, 2005.

Observa-se na figura 14 o comportamento, no decorrer do seguimento, das médias dos três índices antropométricos avaliados. Como já discutido previamente, nota-se em média uma boa evolução dos três índices em relação ao padrão de referência, sendo 0 índice estatura (comprimento)/idade o de perfil menos satisfatório.

Os três índices apresentam seus menores valores médios de escore $Z$ na consulta de 15 dias (etapa inicial do estudo).

A abordagem seguinte apresenta os dados de escore $Z$ para os três índices avaliados considerando três etapas específicas do seguimento: a consulta de 15 dias, a consulta de 3 meses e a consulta de 6 meses; em relação ao padrão do NCHS.

Para a consulta de 15 dias, a figura 15 apresenta a distribuição dos valores de escore $Z$ para o índice peso/idade (WAZ) das crianças com informação disponível nessa etapa do seguimento $(n=144)$ versus o padrão de referência do $\mathrm{NCHS}$. 


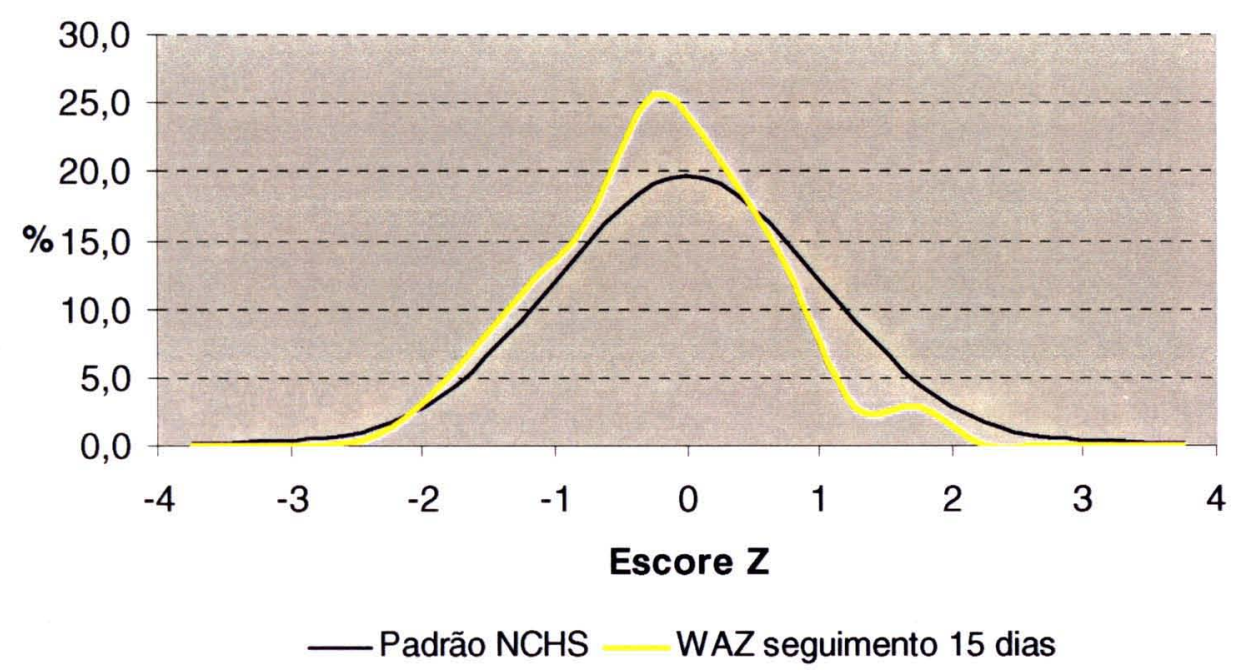

Figura 15: Distribuição dos valores de escore $Z$ para o índice peso/idade (WAZ) das crianças participantes do PROJETO CHIADO na consulta de 15 dias versus o padrão de referência do NCHS, São Paulo, 2005.

Observa-se na figura 15 um discreto deslocamento da curva WAZ consulta de 15 dias para a esquerda em relação ao padrão NCHS, ou seja, nessa etapa do seguimento as crianças apresentaram peso para a idade ligeiramente inferior ao esperado segundo o padrão de referência.

A figura 16 apresenta a distribuição dos valores de escore $Z$ para o índice estatura [comprimento]/idade (HAZ) das crianças com informação disponível na consulta de 15 dias $(n=142)$ versus o padrão de referência do NCHS. 


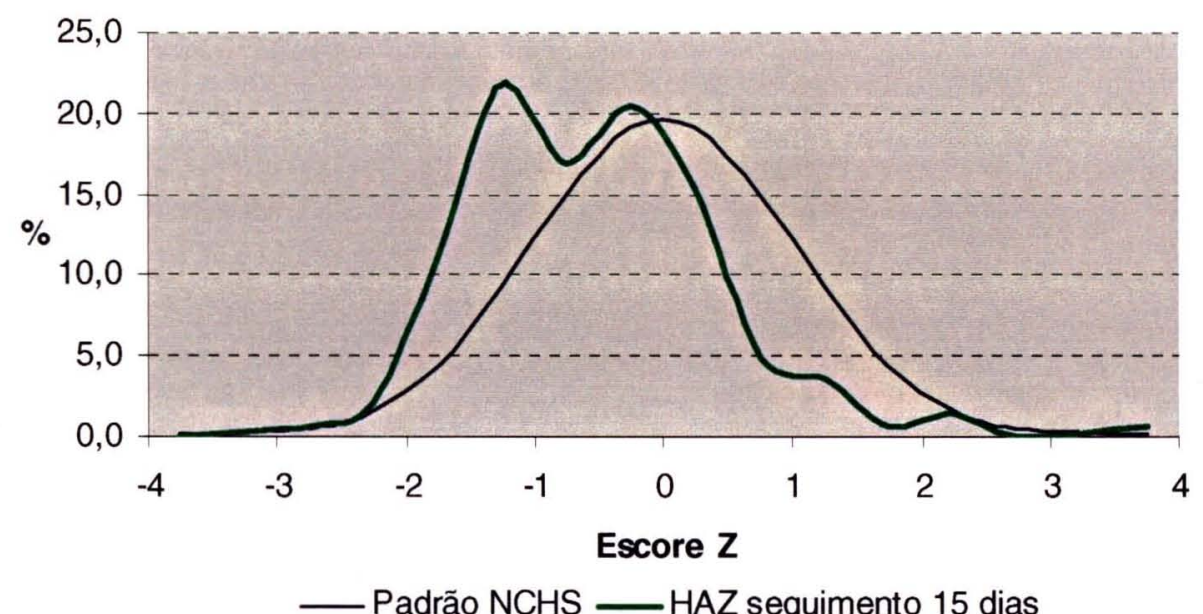

Figura 16: Distribuição dos valores de escore $Z$ para o índice estatura [comprimento]/idade (HAZ) das crianças participantes do PROJETO CHIADO na consulta de 15 dias versus o padrão de referência do NCHS, São Paulo, 2005.

Segundo a figura 16, a curva HAZ consulta de 15 dias apresenta deslocamento considerável à esquerda em relação ao padrão $N C H S$, ou seja, nessa etapa do seguimento as crianças apresentaram evolução do índice estatura para a idade inferior ao esperado segundo o padrão de referência.

Finalizando a análise da etapa inicial do seguimento (consulta de 15 dias), a figura 17 apresenta a distribuição dos valores de escore $Z$ para o índice peso/estatura [comprimento]/ (WHZ) das crianças com informação disponível para a etapa em questão $(n=123)$ versus o padrão de referência do NCHS. 


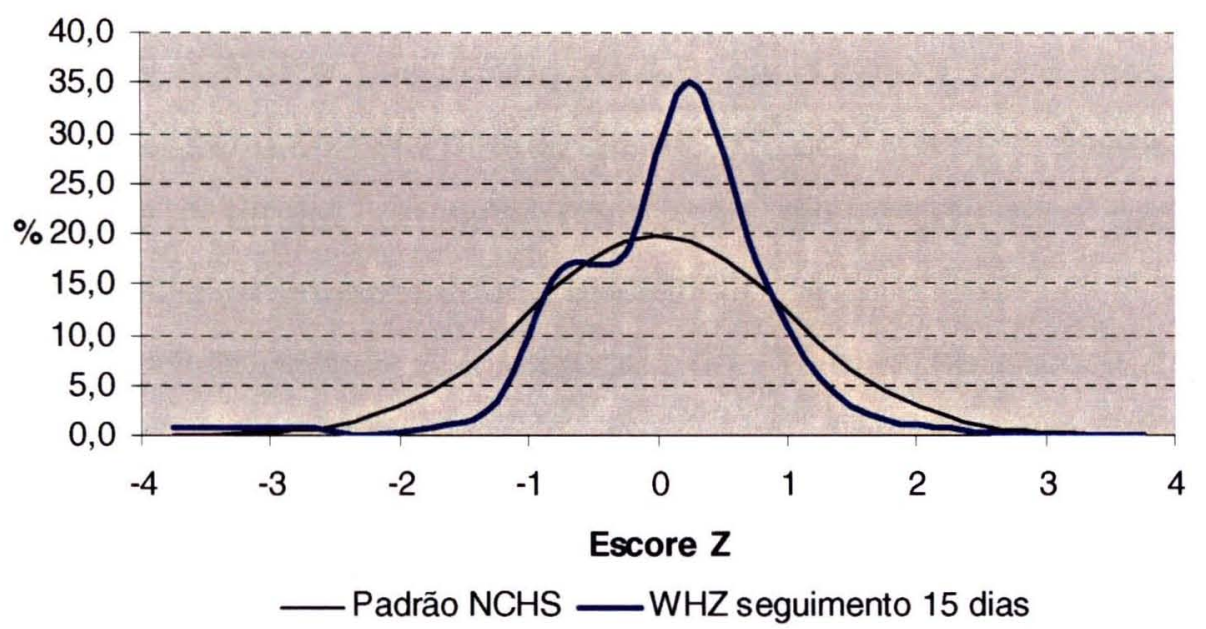

Figura 17: Distribuição dos valores de escore $Z$ para o índice peso/estatura [comprimento] (WHZ) das crianças participantes do PROJETO CHIADO na consulta de 15 dias versus o padrão de referência do NCHS, São Paulo, 2005.

Verifica-se, na figura 17 , bom desempenho em relação ao padrão de referência.

Para a consulta de 3 meses, inicialmente temos a figura 18 apresentando a distribuição dos valores de escore $Z$ para 0 índice peso/idade (WAZ) das crianças com informação disponível nessa etapa do seguimento $(n=113$ ) versus o padrão de referência do NCHS.

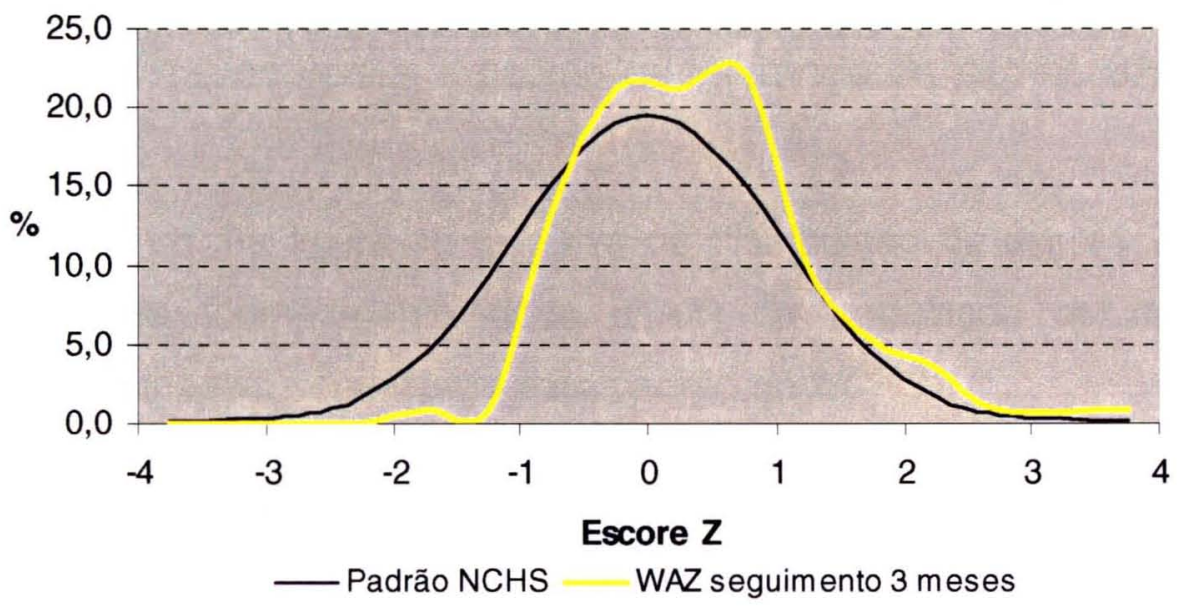

Figura 18: Distribuição dos valores de escore $Z$ para $o$ índice peso/idade (WAZ) das crianças participantes do PROJETO CHIADO na consulta de 3 meses versus o padrão de referência do NCHS, São Paulo, 2005. 
Segundo a figura 18, observa-se que a distribuição dos valores de escore Z para o índice peso/idade (WAZ) na consulta de 3 meses está próxima do apresentado pelo padrão do $\mathrm{NCHS}$, com discreto deslocamento da curva para a direita, ou seja, população em estudo com padrão de peso/idade discretamente superior à referência.

A figura 19 apresenta a distribuição dos valores de escore $Z$ para o índice estatura [comprimento]/idade ( $\mathrm{HAZ}$ ) das crianças com informação disponível na consulta de 3 meses $(n=113)$ versus o padrão de referência do NCHS.

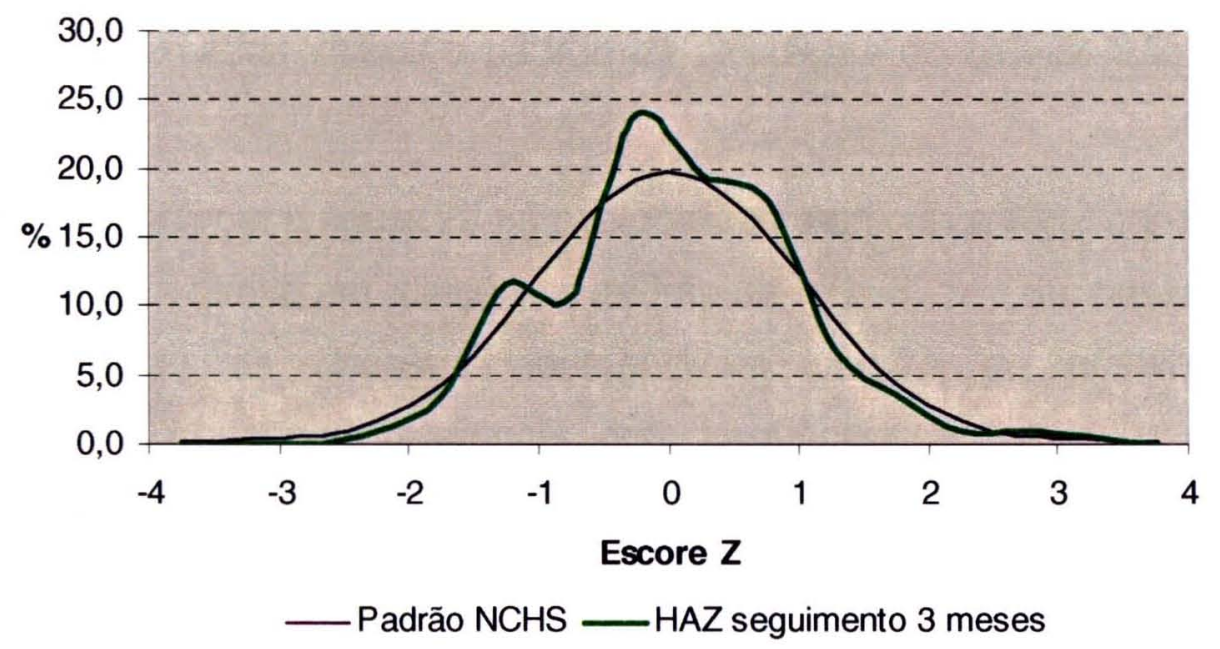

Figura 19: Distribuição dos valores de escore $Z$ para o índice estatura [comprimento]/idade (HAZ) das crianças participantes do PROJETO CHIADO na consulta de 3 meses versus o padrão de referência do NCHS, São Paulo, 2005.

Observa-se, na figura 19, a curva de distribuição de escore $Z$ para o índice estatura [comprimento]/idade (HAZ) da população estudada, na consulta de 3 meses, semelhante à do padrão do NCHS.

A figura 20 apresenta a distribuição dos valores de escore $Z$ para o índice peso/estatura [comprimento]/ ( $\mathrm{WHZ}$ ) das crianças com informação disponivel para a consulta de 3 meses $(n=113)$ versus o padrão de referência do $\mathrm{NCHS}$. 


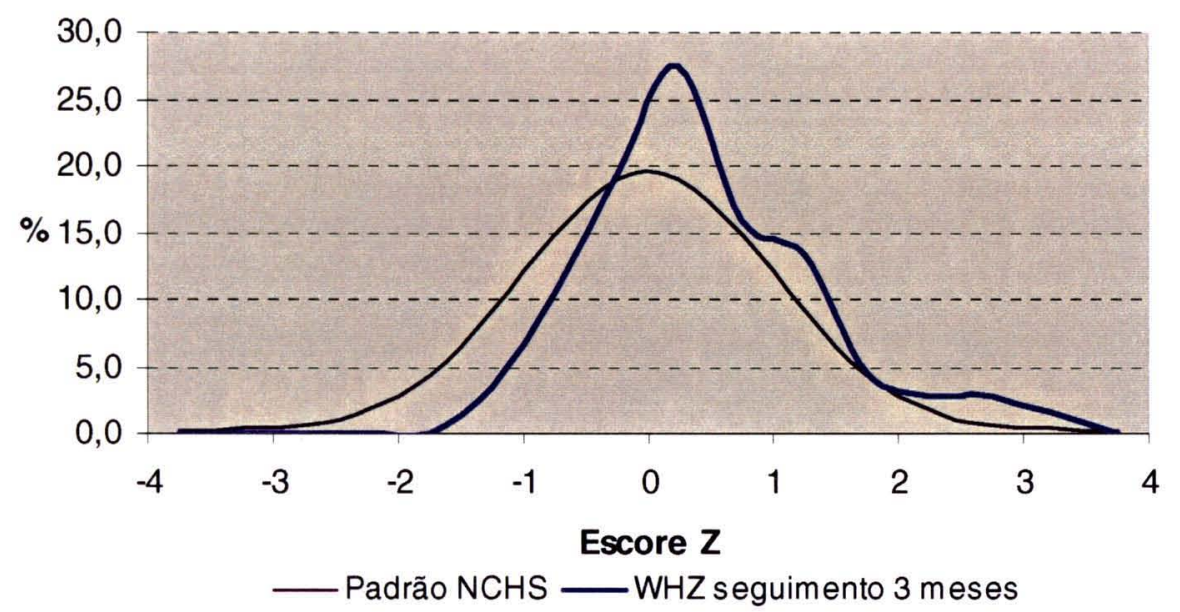

Figura 20: Distribuição dos valores de escore $Z$ para o índice peso/estatura [comprimento] (WHZ) das crianças participantes do PROJETO CHIADO na consulta de 3 meses versus o padrão de referência do NCHS, São Paulo, 2005.

De acordo com a figura 20 há deslocamento da curva WHZ consulta de 3 meses para a direita em relação ao padrão do $N C H S$, ou seja, nessa etapa do seguimento as crianças apresentaram padrão de peso/estatura [comprimento] superior à referência, com freqüência de indivíduos obesos ( $\mathrm{WHZ}>+2 \mathrm{dp}$ ) consideravelmente maior que o esperado segundo o padrão de referência.

Concluindo a visualização por etapa do seguimento das distribuições dos valores de escore $Z$ para os três índices antropométricos estudados apresenta-se a figura 21 , referente à distribuição dos valores de escore $Z$ para o índice peso/idade (WAZ) das crianças com informação disponível na consulta de 6 meses $(n=76$ ) versus o padrão de referência do NCHS. 


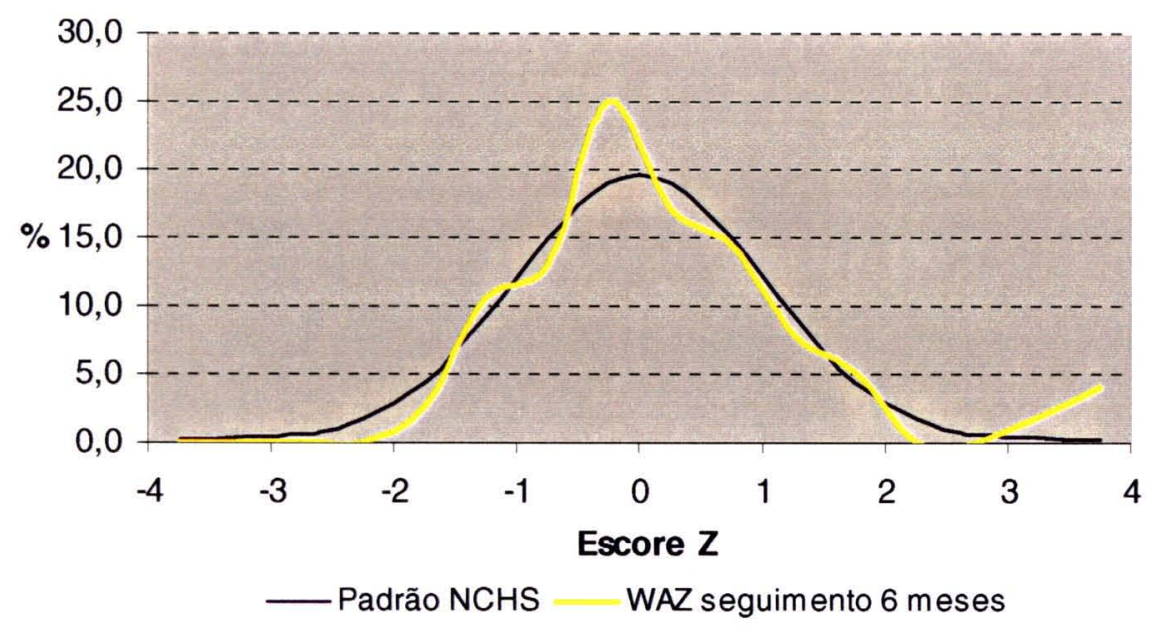

Figura 21: Distribuição dos valores de escore $Z$ para o índice peso/idade (WAZ) das crianças participantes do PROJETO CHIADO na consulta de 6 meses versus o padrão de referência do NCHS, São Paulo, 2005.

Segundo a figura 21, a curva de distribuição dos valores de escore $Z$ para o índice peso/idade (WAZ), aos 6 meses de idade, apresenta padrão semelhante à referência do NCHS.

Destaca-se a baixa freqüência de indivíduos localizados no extremo esquerdo da curva (WAZ < -2dp), indicativo de baixa freqüência de desnutridos nessa etapa do seguimento e, freqüência maior que o esperado de indivíduos com WAZ > +2dp, indicativo de obesidade maior que o esperado segundo o padrão de referência do NCHS.

A figura 22 apresenta a distribuição dos valores de escore $Z$ para 0 índice estatura [comprimento]/idade (HAZ) das crianças com informação disponível na consulta de 6 meses $(n=76)$ versus o padrão de referência do NCHS. 


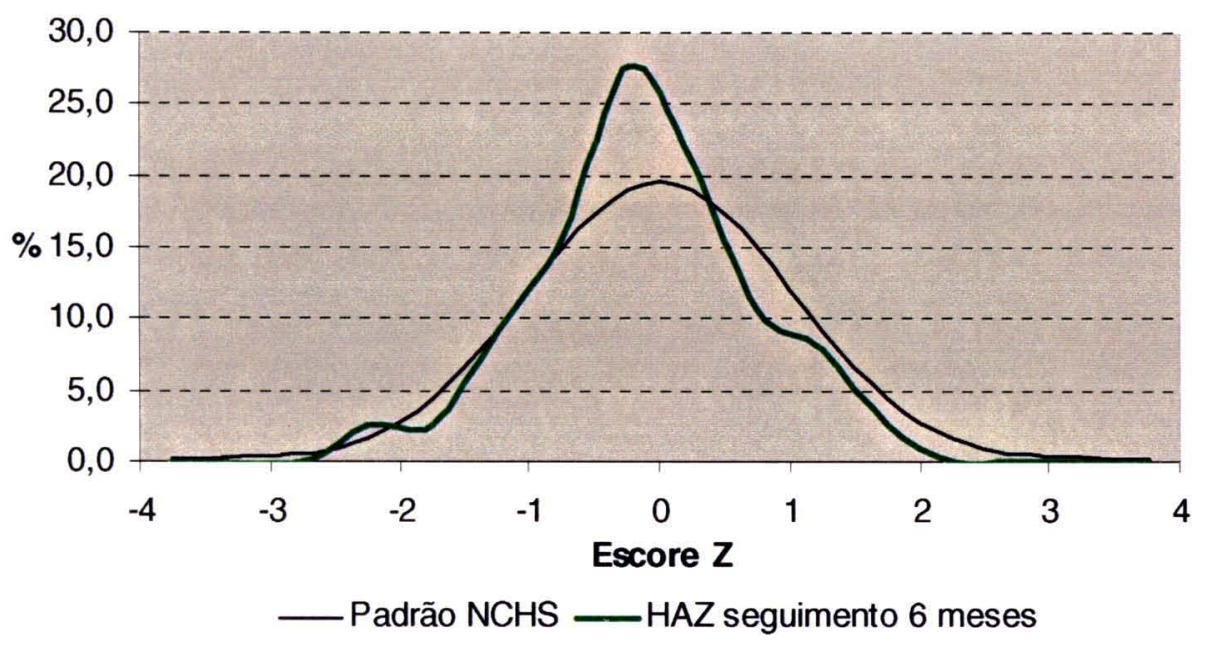

Figura 22: Distribuição dos valores de escore $Z$ para o índice estatura [comprimento]/idade (HAZ) das crianças participantes do PROJETO CHIADO na consulta de 6 meses versus o padrão de referência do NCHS, São Paulo, 2005.

Há distribuição do índice estatura/idade em escore Z (HAZ), na consulta de 6 meses, semelhante ao padrão de referência do NCHS, com discreto desvio da curva para a esquerda em relação à referência, como pode ser observado na figura 22.

Nota-se, para HAZ < -2dp (déficit estatural), freqüência discretamente maior na população estudada que o esperado segundo o padrão de referência

A figura 23 apresenta a distribuição dos valores de escore $Z$ para 0 índice peso/estatura [comprimento]/ (WHZ) das crianças com informação disponível para a consulta de 6 meses $(n=76)$ versus o padrão de referência do NCHS. 


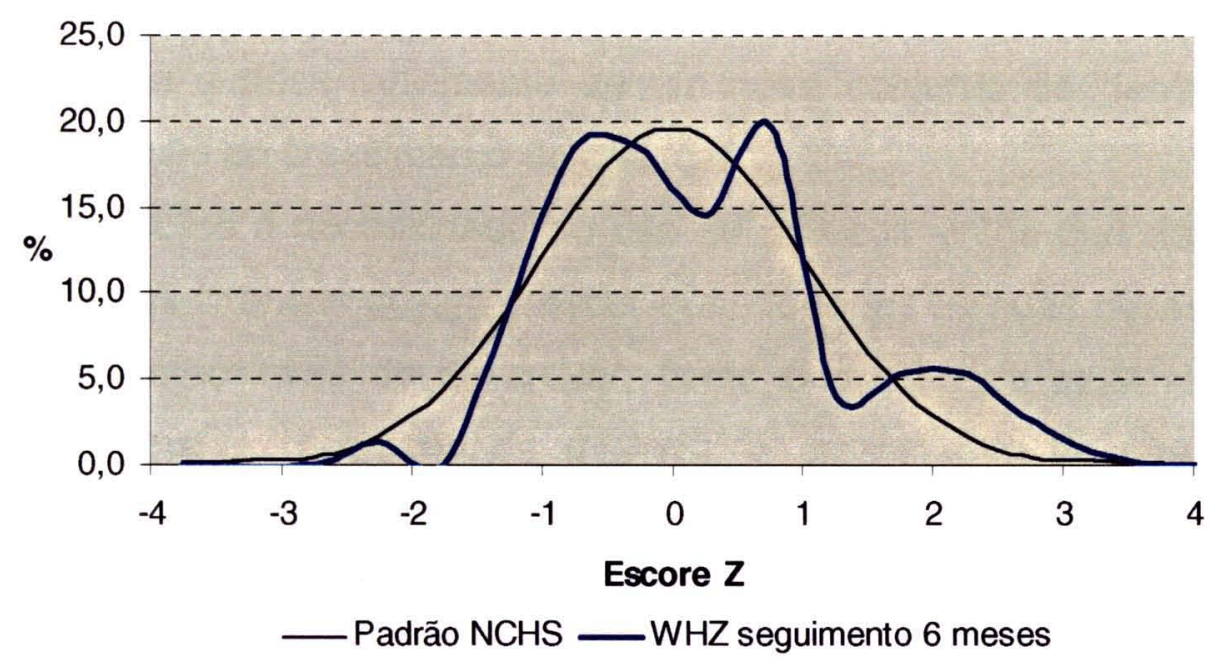

Figura 23: Distribuição dos valores de escore $Z$ para o índice peso/estatura [comprimento] (WHZ) das crianças participantes do PROJETO CHIADO na consulta de 6 meses versus o padrão de referência do NCHS, São Paulo, 2005.

A figura 23 apresenta uma curva de distribuição dos valores de escore $Z$ para o índice peso/estatura [comprimento] (WHZ), na consulta de 6 meses, com flutuações aleatórias em torno da distribuição normal (padrão de referência do $\mathrm{NCHS}$ ), coerentes com o baixo valor de $\mathrm{n}(\mathrm{n}=76)$. Nota-se, porém, maior freqüência de crianças na extremidade direita da curva em relação à da referência, indicativo de maior freqüência de sobrepeso/obesidade $(\mathrm{WHZ}>+2 \mathrm{dp}$ ) na população do presente estudo que o esperado em relação ao padrão de referência.

Como citado anteriormente, são reconhecidas algumas limitações referentes ao padrão do NCHS. Embora entre a maioria das populações de crianças avaliadas para tal referência haja pequenas diferenças no crescimento médio em estatura ou na distribuição em torno da média, o fato de serem incluídas tanto crianças sadias quanto enfermas e crianças em aleitamento materno junto de crianças em aleitamento artificial merece atenção, particularmente ao se comparar indivíduos ou grupos específicos com essa referência (WHO 1995, MICHAELSEN 2000).

Segundo ANNAN (2004), sob a liderança da Organização Mundial da Saúde (OMS) a Organização das Nações Unidas (ONU) iniciou uma revisão detalhada acerca da utilização e interpretação de referências 
antropométricas. Como resultado desse processo, a Assembléia Mundial da Saúde apoiou o desenvolvimento de um novo conjunto de "ferramentas" para a avaliação do crescimento de crianças.

Enfatizou-se a necessidade do uso de procedimentos que descrevam como todas as crianças devem crescer quando todas as suas necessidades são supridas, ao invés de descrever, como é o caso da atual referência internacionalmente recomendada (NCHS), o crescimento de crianças de uma região especifica em determinado periodo de tempo. A Assembléia Mundial da Saúde recomendou a construção de uma referência (instrumento para agrupamento e análise de dados) e posterior desenvolvimento de um padrão, ou o mais próximo possivel de um (instrumento que incorpora o conceito de norma ou alvo, possibilitando, inclusive, julgamento de valores) (ANNAN 2004, GARZA e ONIS, 2004).

A Organização Mundial da Saúde (OMS) e seu principal parceiro, a United Nations University, iniciaram o Estudo Multicêntrico de Referência de Crescimento (Multicentre Growth Reference Study - MGRS), que tem como característica central recrutar crianças que estejam em situação adequada a rigorosos padrões de saúde. Tais crianças não apenas devem estar livres de doenças debilitantes como também devem pertencer a famílias com perfil coerente com as recomendações de saúde quanto ao aleitamento materno e à proposta antitabagismo. Fortalecido pelo comprometimento da Assembléia Mundial da Saúde, esse esforço obteve duas conquistas expressivas: recrutou crianças de todas as principais regiões do mundo, enfatizando que todas elas, independentemente de caracteristicas étnicas ou regionais, crescem de forma semelhante quando suas necessidades são supridas e associou as medidas antropométricas a avaliação do desenvolvimento motor (ANNAN 2004).

No que se refere à substituição da atual referência internacional, esses elementos diferenciais incorporados (amostragem internacional para reforçar a similaridade do crescimento infantil entre diversos grupos étnicos, exploração de métodos analiticos modernos e associações entre medidas antropométricas e dados sobre desenvolvimento funcional) proporcionam um 
instrumento muito melhor para o uso nos esforços a atenção das necessidades das crianças de todo o mundo (ANNAN 2004, GARZA e ONIS 2004).

Em revisão sobre os fatores que embasaram a decisão da Organização Mundial da Saúde (OMS) em construir uma nova referência para a avaliação do crescimento infantil, GARZA e ONIS (2004) destacam três desses fatores, a saber: o crescimento da amostra de crianças em aleitamento materno exclusivo estudada apresentou desvio negativo em relação à atual referência, com magnitude suficientemente grande para interferir no manejo nutricional; examinando dados de peso para idade de uma sub amostra de crianças no primeiro ano de vida em aleitamento materno exclusivo ou predominante de estudo conduzido pelo WHO Human Reproduction Programme (HRP) em 5 países, incorporando, portanto, crianças de diferentes origens geográficas e em condiçōes sócio-econômicas mais diversas que as daquelas crianças pertencentes tanto à atual referência internacional quanto à amostra em aleitamento materno exclusivo, observouse que essa sub amostra apresentara valores de WAZ decrescentes quando comparados à atual referência, ao passo que apresentaram bom desempenho e, até mesmo incremento, quando confrontados com a amostra de crianças em aleitamento materno exclusivo e; a variabilidade do crescimento das crianças da amostra em aleitamento materno exclusivo parece ser significativamente menor do que a apresentada pela atual referência internacional.

A partir dessas observações a abordagem seguinte avalia as médias de escore $Z$ para cada índice antropométrico considerando-se dois grupos estratificados a partir do padrão de aleitamento a saber: "AME" - crianças que mantiveram aleitamento materno exclusivo por todo 0 periodo de seguimento (da consulta de 15 dias à consulta de 6 meses) - e "não AME" demais crianças com classificação da alimentação diferente de AME por todo o periodo de seguimento, ou seja, crianças cuja classificação da alimentação apresentara oscilações no decorrer do seguimento entre AME e as demais ou vice-versa não estão incluídas nos grupos citados. 
Trata-se da avaliação do crescimento das crianças segundo o apresentado na figura 10, que ilustra a dinâmica do padrão de alimentação das crianças a partir da situação inicial (consulta de 15 dias).

A figura 24 ilustra a distribuição das médias de escore $Z$ para o índice peso/idade (WAZ) nas sete etapas de seguimento para crianças com informação disponível, segundo estratificação por padrão de aleitamento, em relação ao padrão $N C H S$.

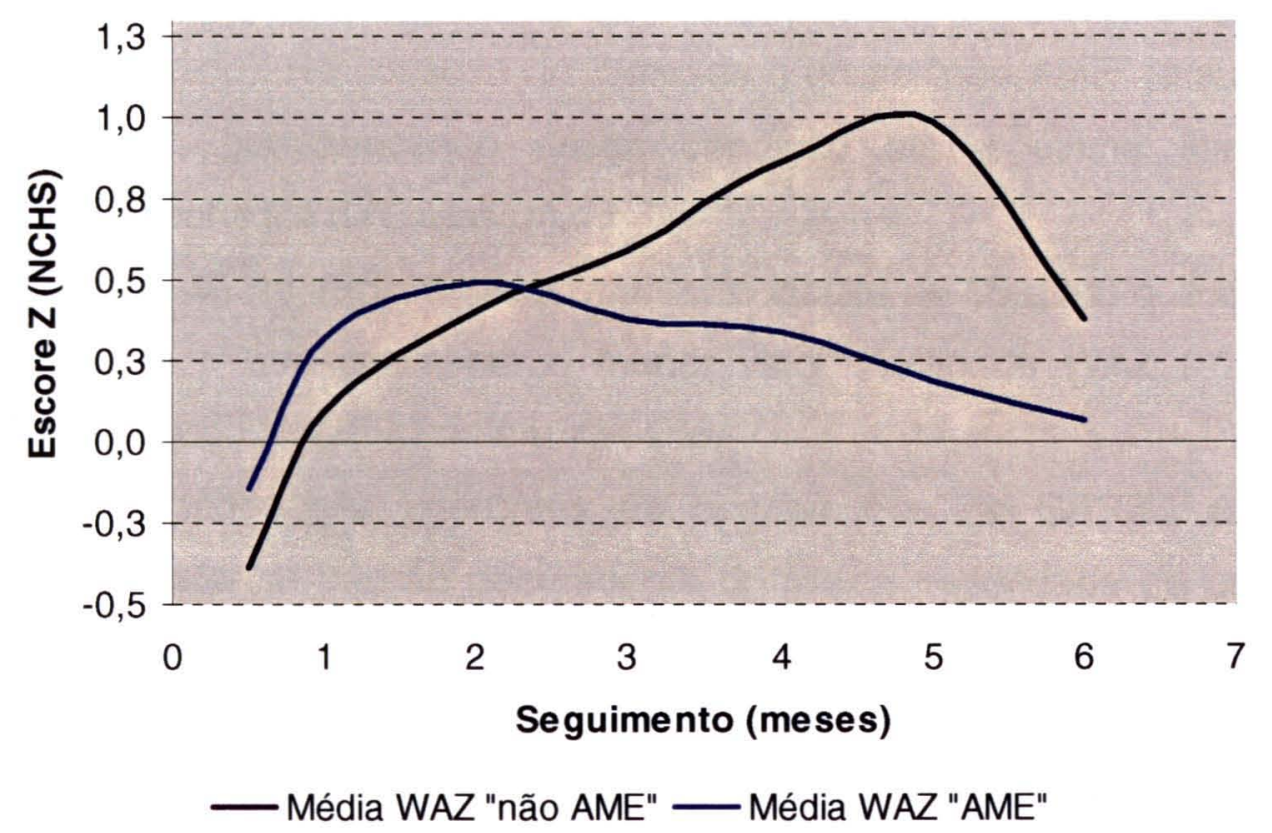

Figura 24: Distribuição das médias de escore $Z$ para o índice peso/idade (WAZ) das crianças participantes do PROJETO CHIADO, nas sete etapas de seguimento, segundo estratificação por padrão de aleitamento, São Paulo, 2005.

Na figura 24, a curva de distribuição das médias de WAZ para o padrão "AME" apresenta desempenho satisfatório do peso para idade em relação ao padrão NCHS. Mantém, em relação à curva do grupo "não AME", as maiores médias de escore $Z$ até a consulta de 2 meses, etapa em que inicia um padrão decrescente. A partir da consulta de 3 meses o grupo "AME" é o que apresenta as menores médias de WAZ em relação às crianças "não AME", embora com bom desempenho em relação ao padrão do NCHS. 
MARQUES et al. (2004), concluiram que crianças em aleitamento materno exclusivo até 0 sexto mês de vida apresentaram ganho de peso satisfatório quando comparados com os padrões de referência disponiveis (NCHS, Murahovschi e Chaves) e esse ganho fora acentuado durante os 4 primeiros meses, sofrendo uma desaceleração do quarto mês em diante.

Destaca-se o comportamento da curva de distribuição das médias de WAZ para o padrão "não AME", que se apresenta em tendência crescente da consulta de 15 dias à consulta de 5 meses, etapa em que atinge valor máximo (+1,09dp). Na consulta de 3 meses o grupo "não AME" já supera o grupo "AME", permanecendo nessa condição até a última etapa do seguimento (consulta de 6 meses).

Observa-se no início do seguimento (consulta de 15 dias) que o grupo "não $A M E$ " é o que apresenta o menor valor médio de $\operatorname{WAZ}(-0,38 \mathrm{dp})$, enquanto o grupo "AME" inicia em -0,14dp.

Tais achados são coerentes as observações de GARZA e ONIS (2004), que referem padrão decrescente do indice peso/idade de crianças em aleitamento materno exclusivo (AME) quando comparados a atual referência internacional (NCHS).

A figura 25 ilustra a distribuição das médias de escore $Z$ para 0 índice estatura [comprimento]/idade ( $\mathrm{HAZ}$ ) nas sete etapas de seguimento para crianças com informação disponivel, segundo estratificação por padrão de aleitamento, em relação ao padrão NCHS. 


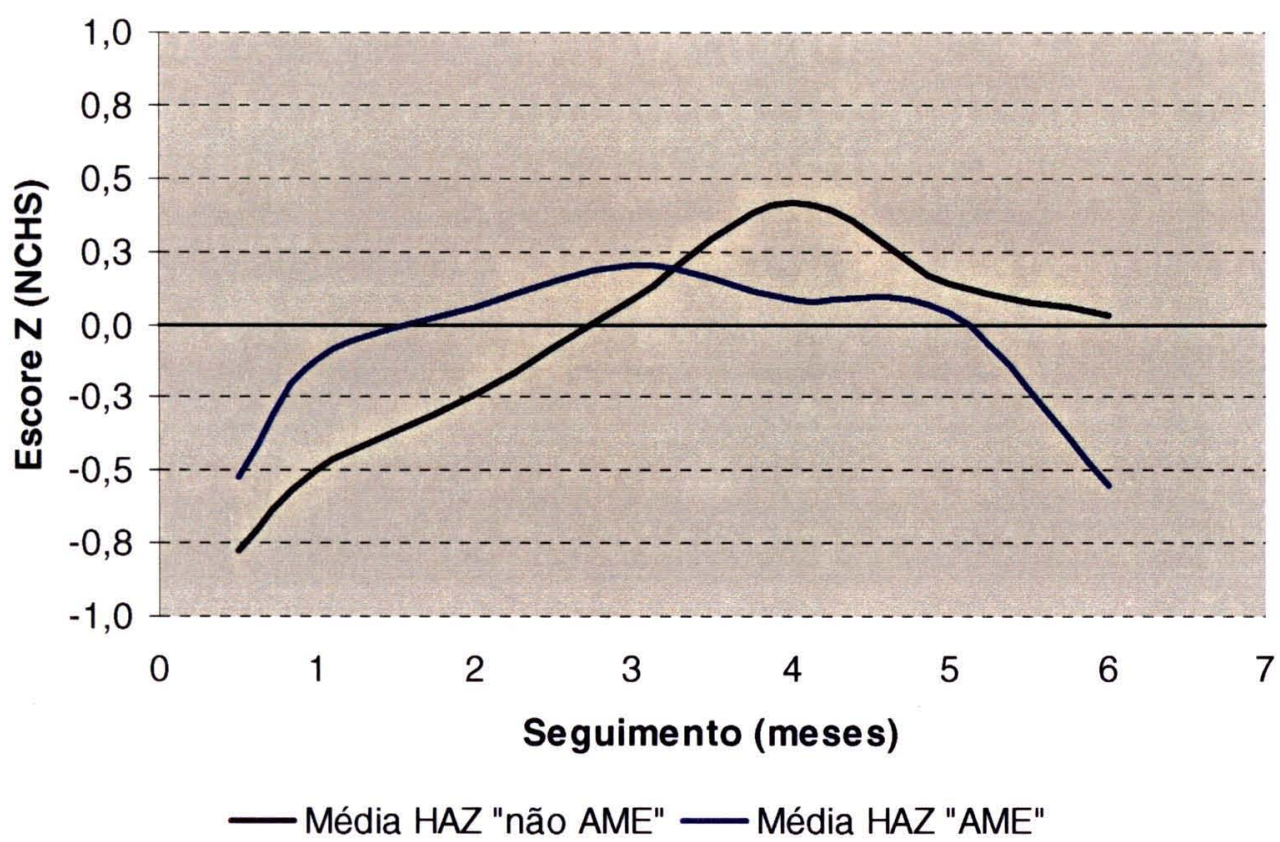

Figura 25: Distribuição das médias de escore $Z$ para o índice estatura [comprimento]/idade (HAZ) das crianças participantes do PROJETO CHIADO, nas sete etapas de seguimento, segundo estratificação por padrão de aleitamento, São Paulo, 2005.

Observa-se na figura 25, para a distribuição das médias de HAZ no decorrer do seguimento, o grupo "AME" apresentando as maiores médias de HAZ da consulta de 15 dias à consulta de 3 meses, sendo superado a partir de então pelo grupo "não AME" e apresentando, a partir desse momento, tendência decrescente até a consulta de 6 meses.

MARQUES et al. (2004), observaram crescimento em comprimento satisfatório, desacelerando após o quarto mês de vida e com diferença entre os sexos detectável apenas após o sexto mês, sendo os lactentes do sexo masculino maiores que as meninas.

A figura 26 ilustra a distribuição das médias de escore $Z$ para o índice peso/estatura [comprimento] (WAZ) nas sete etapas de seguimento para crianças com informação disponível, segundo estratificação por padrão de aleitamento, em relação ao padrão NCHS. 


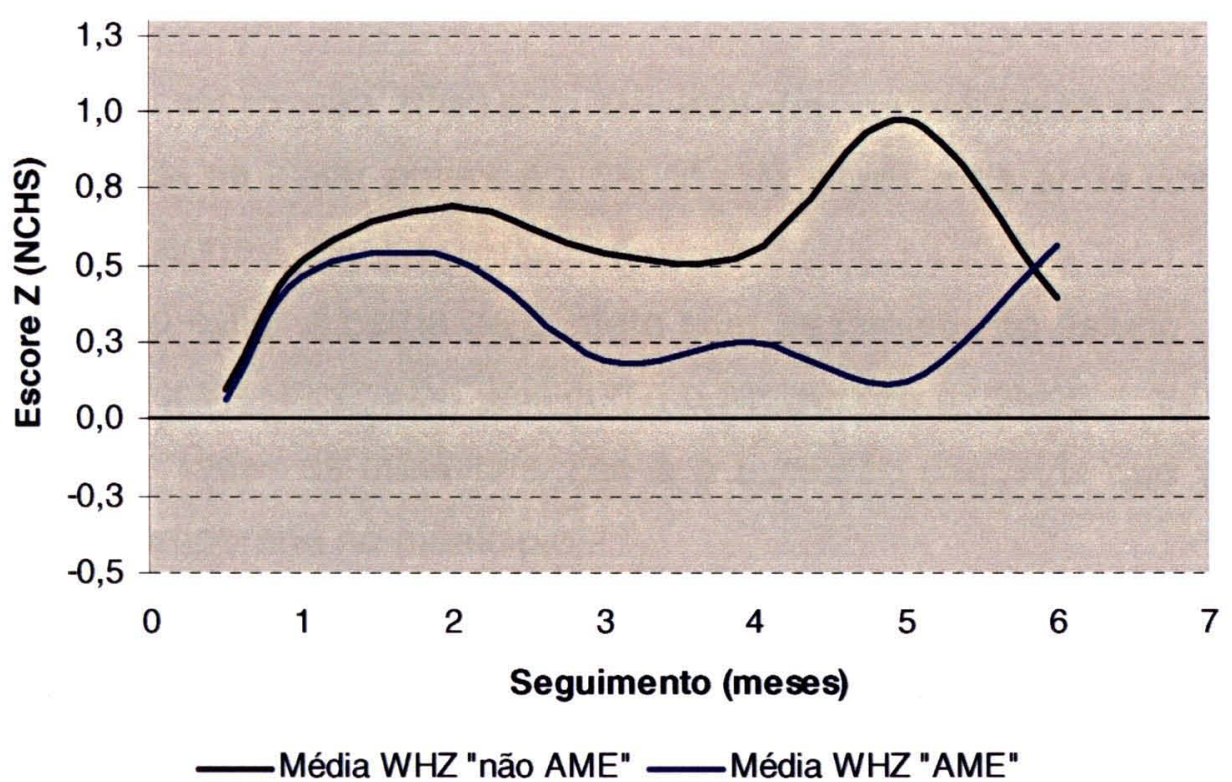

Figura 26: Distribuição das médias de escore $Z$ para o índice peso/estatura [comprimento] (WHZ) das crianças participantes do PROJETO CHIADO, nas sete etapas de seguimento; geral e segundo estratificação por padrão de aleitamento, São Paulo, 2005.

De acordo com a figura 26, as curvas de ambos os grupos têm início em valores muito próximos e apresentam comportamento semelhante da consulta de 15 dias à consulta de 3 meses. A partir da consulta de 1 mês a curva do grupo "não AME" passa a desenvolver seu padrão acima da curva do grupo "AME", mantendo valores superiores até que, na última etapa do seguimento (consulta de 6 meses), o grupo "AME" supera o grupo "não AME".

Nota-se através do exposto pela avaliação do crescimento das crianças participantes do Projeto ChIADO, estratificadas segundo o padrão de aleitamento, coerência com o observado em estudos sobre alimentação e crescimento infantis: o padrão diferenciado de crescimento apresentado pelos lactentes de acordo com a alimentação oferecida $e$ a inadequação do padrão de referência atualmente recomendado em âmbito internacional para a avaliação do crescimento de crianças em aleitamento materno exclusivo (AGOSTONI et al.1999, ECKHARDT et al. 2001, GARZA e ONIS 2004, KRAMER et al. 2002, VICTORA et al. 1998b). 


\subsection{Fontes de erros/vícios e limitações do estudo}

Essa investigação (PROJETo ChIADO) foi cuidadosamente delineada com intuito de se evitar potenciais causas de vícios e de erros comuns em estudos de coorte.

Visando evitar a perda de contato com as famílias do estudo, algumas estratégias foram planejadas, tais como o registro de endereços de parentes e amigos de todas as mães/crianças e a exclusão daquelas que possuem residência temporária no municipio.

Os questionários desenvolvidos para o registro das informaçōes alimentares estão coerentes com questionários utilizados em outros estudos que avaliam o consumo alimentar de crianças nessa faixa de idade, sendo, inclusive, mais completos.

Alguns estudos de coorte se utilizam do questionário recordatório de $24 \mathrm{~h}$ para a coleta de informações alimentares, instrumento que tem uso consagrado nesse tipo de estudo. No presente estudo, os instrumentos utilizados apresentam componentes com características recordatórias e, por haver um seguimento intensivo com consultas periódicas, conseguimos a informação com boa qualidade, das datas de introdução dos diferentes tipos de alimentos.

Uma limitação importante seria a falha de informação da mãe com relação ao consumo alimentar de seus filhos, o que neste estudo acredita-se que foi minimizado devido ao acompanhamento intensivo durante 0 seguimento e à possibilidade de contato telefônico com as mães a qualquer momento, recurso que se mostrou bastante útil para a recuperação de informações de crianças cujas mães eventualmente não passavam na nutrição ou quando da necessidade de esclarecimento sobre alguma informação considerada duvidosa encontrada no questionário na fase de codificação ou crítica.

Embora a porcentagem de perdas até o momento seja coerente com o previsto no planejamento do estudo (aproximadamente $20,0 \%$ ), houve um número considerável $e$ inconstante de perdas para diferentes variáveis analisadas, o que se deveu à falta de um monitoramento mais rigoroso da 
aplicação de alguns questionários. Cabe ressaltar também que o Projeto CHIADO enfrenta limitações de orçamento, desenvolvendo-se apenas com verba parcial, o que limita o número de pessoal agregado para as diversas atividades previstas.

O fato das crianças serem acompanhadas em consultas ambulatoriais, na instituição hospitalar, apresenta certo equilibrio entre aspectos favoráveis e desfavoráveis. Dentre os favoráveis pode-se destacar a infra-estrutura disponivel para 0 atendimento e para eventuais necessidades complementares do ponto de vista de saúde (realização de exames, encaminhamento para outras especialidades, farmácia, assistência social e pronto-socorro). Por outro lado, pôde-se notar que a localização do Instituto da Criança Prof. Pedro de Alcântara do Hospital das Clínicas - FMUSP em relação às casas de algumas familias, o tempo de espera para atendimento no dia da consulta e a necessidade de realização de um atendimento dinâmico devido ao número de pacientes atendidos (com implicaçōes nos procedimentos de coleta de medidas antropométricas) se mostraram como aspectos desfavoráveis do modelo de acompanhamento adotado.

Um dos critérios de elegibilidade adotado no Projeto ChIADO para cerca de $80 \%$ das crianças que compōem a amostra é a confirmação de história materna de asma. Como conseqüência, a inferência dos resultados do estudo e de todos os outros trabalhos que se utilizarem dessa amostra, com precisão estatística adequada, está restrita à população que apresenta tal característica. 


\section{CONCLUSÃO}

O presente trabalho proporcionou subsídios para o direcionamento geral das análises sob o ponto de vista nutricional no PROJeto CHIADO. Como uma primeira exploração dos dados possibilitou a visualização de algumas características da amostra estudada que devem e serão melhor exploradas em trabalhos posteriores.

O padrão alimentar apresentado pelas crianças participantes do Projeto ChIADO foi descrito e caracterizado, evidenciando uma realidade extremamente distante do que é preconizado pelas entidades de saúde mundiais acerca da alimentação de recém-nascidos e lactentes, mesmo estando essas crianças em seguimento intensivo com orientação nutricional periódica em consultas ambulatoriais e possibilidade de contato telefónico dos pais e/ou responsáveis com a equipe do PROJETO CHIADO sempre que necessário.

Em termos de aleitamento (variável referente única e exclusivamente ao tipo de leite consumido), observou-se duração média do aleitamento materno de 96,32 dias (13,76 semanas), sendo a duração mediana de 91,2 dias (13 semanas). Já em relação ao padrāo alimentar (classificaçăo da alimentação), verificou-se duração média do aleitamento materno exclusivo (AME) de 60,26 dias (8,6 semanas) e duração mediana 30,4 dias $(4,34$ semanas).

Quanto ao crescimento (estado nutricional) das crianças participantes do Projeto Chiado verificou-se prevalência de desnutrição aos 6 meses de vida de $1,32 \%$, abaixo, portanto, do esperado segundo o padrão de referência do $\mathrm{NCHS}(2,3 \%)$. Para obesidade foi encontrada prevalência de $9,21 \%$ na consulta de 6 meses. A prevalência de retardo de crescimento (déficit estatural) foi de $2,63 \%$, freqüência semelhante ao esperado segundo o padrão de referência do NCHS e não se observaram casos de baixo peso para idade, desnutrição aguda, ao final do seguimento. A prevalência de índice pesolidade maior que $+2 \mathrm{dp}(\mathrm{WAZ}>+2 \mathrm{dp}$ ), indicativo de obesidade, aos 6 meses, foi de $3,95 \%$. 
Os valores de escore $Z$ encontrados para 0 indice pesolestatura [comprimento] (WHZ), referentes a obesidade, confirmam o apresentado pelo índice pesolidade (WAZ).

Em relação ao padrão de referência do $\mathrm{NCHS}$ e ao grupo de crianças pertencentes à categoria "não AME", as crianças em aleitamento materno exclusivo (AME) apresentaram, de maneira geral, desempenho de crescimento insatisfatório, o que confirma a inadequação do referido padrão para a avaliação do crescimento de crianças nessa condição alimentar. 


\section{REFERÊNCIAS BIBLIOGRÁFICAS}

Annan KA. "A future of sustainable development begins with safeguarding the health of every child" [preface]. Food Nutr Bull 2004; 25 (1 Suppl 1): S34.

Agostoni C, Grandi F, Gianni ML, Silano M, Torcoletti M, Giovannini M, et al. Growth patterns of breast fed and formula fed infants in the first 12 months of life: an Italian study. Arch Dis Child 1999; 81: 395-9.

Audi CAF, Corrêa AMS, Latorre MRDO. Alimentoscomplementares e fatores associados ao aleitamento materno esclusivo em lactentes até 12 meses de vida em Itapira, São Paulo, 1999. Rev Bras Saúde Matern Infant 2003; 3 (1): 85-93.

Barros FC, Victora CG. Epidemiologia da saúde infantil, um manual para diagnósticos comunitários. $3^{a}$ ed. São Paulo: HUCITEC-UNICEF; 1998.

Booth I. Does the duration of breastfeeding matter? Maybe, but not enough to counter support for breast feeding [editorial]. BMJ 2001; 322: 625-6.

Bourroul MLM, Ranña W, Rodrigues D, Hayashida. Anemias. In: Sucupira ACSL, Bresolin AMB, Marcondes E, Saito MI, Dias MHP, Zuccolotto SMC, coordenadores. Pediatria em consultório. $4^{a}$ ed. São Paulo: Sarvier; 2000 p. 194-207.

Brasil. Ministério da Saúde - Instituto Nacional de Alimentação e Nutrição INAN/MS, Programa Nacional de Incentivo ao Aleitamento materno PNIAM/INAN/MS, Coordenação Materno Infantil COMIN/MS. Promoção do Aleitamento Materno, texto básico para apoio ao ensino do aleitamento materno nas escolas de saúde. Brasilia (DF); 2001. 
Brasil. Ministério da saúde - Secretaria de Políticas de Saúde, Departamento de Atenção Básica. Saúde da criança: acompanhamento do crescimento e desenvolvimento infantil. Brasilia (DF); 2002 (Série Cadernos de Atenção Básica, n. 11 - Série A. Normas e Manuais técnicos, n. 173).

Breslow NE, Day NE. Statistical Methods in Cancer Research. The design and analysis of cohort studies. Vol. II. IARC Scientific Publications no.82 (International Agency for Research on Cancer), Lyon, 1987.

Bresolin AMB, Issler $H$, Bricks LF, de Lima IN. Alimentação da criança normal. In: Sucupira ACSL, Bresolin AMB, Marcondes E, Saito MI, Dias MHP, Zuccolotto SMC, coordenadores. Pediatria em consultório. $4^{\mathrm{a}}$ ed. São Paulo: Sarvier; 2000 p. 67-85.

Bronfman M, Tuirán R. La desigualdad ante la muerte: clases sociales y mortalidad en la niñez. Cuad Méd-soc 1988; (29/30): 53-75.

Brown KH, Kanashiro HC, Dewey KG. Optimal complementary feeding practices to prevent childhood malnutrition in developing countries. Food Nutr Bull 1995; 16 (4): 320-39.

Bueno MB, Souza JMP de, Souza SB de, Paz SMRS da, Gimeno SGA, Siqueira AAFde. Riscos associados ao processo de desmame entre crianças nascidas em hospital universitário de São Paulo, entre 1998 e 1999: estudo de coorte prospectivo do primeiro ano de vida. Cad Saúde Pública 2003; 19 (5): $1453-60$.

Carvalhaes MABL, Benício MHD'A. Capacidade materna de cuidar e desnutrição infantil. Rev. Saúde Pública. [periódico on-line] 2002; 36 (2): [16 telas]. Disponivel em:

<URL:http://www.scielo.br/scielo.php?script=sci_arttext\&pid=S0034-

$89102002000200011 \&$ Ing=pt\&nrm=iso $>$ [2004 abr]. 
[CDCMHO] Centers for Disease Control and Prevention - Division of Nutrition, World Health Organization - Department of Nutrition for Health and Development. ANTHRO software for calculating anthropometry. [software]. Version 1.02 Y2K compliant. Atlanta (USA)/Geneva (SWZ): CDCMHO, 1999.

Dewey KG, Cohen RJ, Brown KH, Rivera LL. Age of introduction of complementary foods and growth of term, low birth weight, breast-fed infants: a randomized intervention study in Honduras. Am J Clin Nutr 1999; (69): 679-86.

Eckhardt CL, Rivera J, Adair LS, Martorell R. Full breast-feeding for at least four months has differential effects on growth before and after six months of age among children in a Mexican community. J Nutr 2001; 131: 2304-9.

Garcia GCB. Avaliação do estado nutricional de crianças matriculadas em creches do município de São Paulo. São Paulo; 2003. [Dissertação de Mestrado - Faculdade de Saúde Pública - USP].

Garza C, Onis M de [for the WHO Multicentre Growth Reference Study Group]. Rationale for developing a new international growth reference. Food Nutr Bull 2004; 25 (1 Suppl 1): S5 -14.

Greiner T. Research based in poor infant feeding definitions is unworthy of our attention [letter]. BMJ [serial online] 2002; 325. Available from: <URL: http://bmj.bmijournals.com/cgi/eletters/325/7366/675/b> [2004 dec].

Heath AM, Tuttle CR, Simons MSL, Cleghorn CL, Parnell WR. A longitudinal study of breastfeeding and weaning practices during the first year of life in Dunedin, New Zealand. J Am Diet Assoc. 2002; 102: 937-43. 
Hörnell A, Hofvander $Y$, Kylberg $E$. Solids and formula: association with pattern and duration of breastfeeding. Pediatrics 2001; 107 (3): [7 screens] Available from: <URL:http://www.pediatrics.org/cgi/content/full/107/3/e38> [2003 Aug].

Kramer MS, Guo T, Platt RW, Shapiro S, Collet JP, Chalmers B et al. Breastfeeding and infant growth: biology or bias? Pediatrics 2002; 110 (2): 343-7.

Kummer SC, Giugliani ERJ, Susin LO, Folletto JI, Lermen NR, Wu VYJ, et al. Evolução do padrão de aleitamento materno. Rev Saúde Pública 2000; 34 (2): $143-8$.

Lauer JA, Betrán AP, Victora CG, Onis M de, Barros AJD. Breastfeeding patterns and exposure to suboptimal breastfeeding among children in developing countries: review and analysis of nationally representative surveys. BMC medicine [serial online] 2004; 2 (26): [29 screens]. Available from: <URL: http://www.biomedcentral.com/1741-7015/2/26> [2004 Nov].

Leeson CPM, Katternhorn M, Deanfield JE, Lucas A. Duration of breastfeeding and arterial distensibility in early adult life: population based study. BMJ 2001; 322: 643-7.

Levy-Costa RB. Consumo de leite de vaca e anemia na infância no municipio de São Paulo. São Paulo; 2002. [Dissertação de mestrado Faculdade de Saúde Pública - USP].

Lombardi C, Bronfman M, Facchini LA, Victora CG, Barros FC, Béria JU et al. Operacionalização do conceito de classe social em estudos epidemiológicos. Rev Saúde Pública 1988; 22 (4): 253-65. 
Marchioni DML. Alimentação no primeiro ano de vida: prevalência de consumo de alimentos em dois centros de saúde do municipio de Săo Paulo. São Paulo; 1999. [Dissertação de mestrado - Faculdade de Saúde Pública - USP].

Marcondes EY, organizador. Pediatria Básica. $9^{\text {a }}$ ed. São Paulo: Sarvier; 2002/2003. 3v.

Marques NM, Lira PIC, Lima MC, Silva NL, Filho MB, Huttly SRA et al.. Breastfeeding and early weaning practices in northeast Brazil: a longitudinal study. Pediatrics [serial on line] 2001; 108 (4): [7 screens]. Available from: <URL: http://www. pediatrics.org/cgi/content/full/108/4/e66> [2003 Aug].

Marques RFSV, Lopez FA, Braga JAP. Growth of exclusively breastfed infants in the first 6 months of life. J Pediatr 2004; 80 (2): 99 -105.

Martins M. A orientação alimentar e a deficiência de ferro em lactentes. São Paulo; 2002. [Tese de doutorado - Faculdade de Saúde Pública - USP].

Mayor S. Breast feeding does not protect against atopy [letter]. BMJ 2002; 325: 675 .

Michaelsen KF, Weaver L, Branca F, Robertson A. Feeding and nutrition of infants and young children: guidelines for the WHO European Region, with emphasis on the former Soviet countries. Copenhagen: World Health Organization, Regional Office for Europe; 2000. (WHO - Regional publications, European series; 87).

Microsoft Corporation. Microsoft Excel [programa de computador]. Versão 2000. Microsoft Corporation; 1999. 
Monteiro CA, Benicio MHD'A, lunes RF, Gouveia NC, Cardoso MAA. Evolução da desnutrição infantil. In: Monteiro CA, organizador. Velhos e novos males da saúde no Brasil: a evolução do país e suas doenças. São Paulo: Hucitec; 1995. 93 - 114.

Monteiro CA, Conde WL. Tendência secular do crescimento pós-natal na cidade de São Paulo (1974-1996). Rev. Saúde Pública. [periódico on-line]. dez. 2000; 34 (6 Supl.): [11telas]. Disponivel em: <URL:http://www.scielo.br/scielo.php?script=sci_arttext\&pid=S0034$89102000000700007 \&$ Ing=pt\&nrm=iso $>$ [2004 fev 18].

Moura C. Ruido urbano: niveis de pressão sonora na cidade de São Paulo. São Paulo; 2002. [Dissertação de mestrado - Faculdade de Saúde Pública - USP].

[MS/OPAS/OMS] Ministério da Saúde - Secretaria de Políticas de Saúde Coordenação Geral de Políticas de Alimentação e Nutrição, Organização Pan-americana da Saúde, Organização Mundial da Saúde. Dez passos para uma alimentação saudável: guia alimentar para crianças menores de 2 anos. Brasilia - DF;2002.

Myr R. Something does not protect against atopy [letter]. BMJ [serial online] 2002; 325. Available from:

<URL: http://bmj.bmijournals.com/cgi/eletters/325/7366/675/b> [2004 dec].

O'Sullivan E. Long-term atopy study in Lancet 1995 [letter]. BMJ [serial online] 2002; 325. Available from:

<URL: http://bmj.bmijournals.com/cgi/eletters/325/7366/675/b> [2004 dec].

Murahovschi J, Miranda AC. Alimentação na infância. Pediatria Moderna 2003; 39 (6): 169-80. 
Oddy WH, Sly PD, de Klerk NH, Landau LI, Kendall GE, Holt PG et al. Breast feeding and respiratory morbidity in infancy: a birth cohort study. Arch Dis Child 2003; 88: 224-8.

Palma D, Sarni RS, Oliveira FLC, Valverde MA. Alimentação da criança nos primeiros anos de vida. Rev Paul Pedriatr. 1998; 16:112-7.

Richards CE. Peer reviewers with relevant experience needed [letter]. BMJ [serial online] 2002; 325. Available from:

<URL: http://bmj.bmijournals.com/cgi/eletters/325/7366/675/b> [2004 dec].

Sarni RS, relatora. Avaliação da condição nutricional: crianças e adolescentes/método antropométrico. In: Sociedade Brasileira de Pediatria, Departamento de Nutrição. Temas em Pediatria. Edição especial 2001; 2: 28-30.

Sears MR, Greene JM, Willian AR, Taylor DR, Flannery EM, Cowan JO, et al. Long-term relation between breastfeeding and development of atopy and asthma in children and young adults: a longitudinal study. Lancet 2002; 360: 901-7.

Spolidoro JVN, Müller DP. Alimentação no primeiro ano de vida. Rev Bras Nutr Clin 2001; 16: 175-9.

Stata Corporation. Intercooled Stata for Windows 98/95 NT [software]. 7.0. College Station (TX USA): 2002.

Sterken E. Atopy study conclusions seriously flawed [letter]. BMJ [serial online] 2002; 325. Available from:

<URL: http://bmj.bmijournals.com/cgi/eletters/325/7366/675/b> [2004 dec]. 
[UN-SCN] United Nations System - Standing Committee on Nutrition. Nutrition for improved development outcomes. Geneva; 2004. ( $5^{\text {th }}$ Report on the World Nutrition Situation).

Venâncio SI, Monteiro CA. A evolução da prática da amamentação nas décadas de 70 e 80. Rev Bras Epidemiologia 1998; 1 (1): 40-9.

Vianna, RPT. Consumo alimentar, amamentação e saúde infantil. Campinas; 2002. [Tese de doutorado - Faculdade de Ciências Médicas UNICAMP]

Victora CG., Barros FC, Lima RC, Behague DP, Gonçalves H, Horta BL, et al.. The Pelotas birth cohort study, Rio Grande do Sul, Brazil, 1982 - 2001. Cad Saúde Pública 2003, 19 (5): 1241-56.

Victora CG., Gigante DP., Barros AJD, Monteiro CA, Onis M de. Estimativa da prevalência de déficit de altura/idade a partir da prevalência de déficit de peso/idade em crianças brasileiras. Rev. Saúde Pública [periódico online] ago 1998a; 32 (4): [6 telas]. Disponivel em: <URL:http://www.scielo.br/scielo.php?script=sci_arttext\&pid=S00348910199 $8000400003 \&$ Ing=pt\&nrm=iso [2004 fev 18].

Victora CG, Morris SS, Barros FC, Horta BL, Weiderpass E, Tomasi E. Breast-feeding and growth in Brazilian infants. Am J Clin Nutr 1998b; 67: 452-8.

[WHO] World Health Organization Expert Committee. Physical status: the use and interpretation of anthopometry. Geneva; 1995 (WHO - Technical Report Series, 854). 
[WHO] World Health Organization. The optimal duration of exclusive breastfeeding. Results of a WHO systematic review - note for the press n. 7. Geneva; 2001.

Wilson AC, Forsyth JS, Greene AS, Irvine L, Hau C, Howie PW. Relation of infant diet to childhood health: seven year follow up of cohort of children in Dundee infant feeding study. BMJ 1998; 316: 21-5. 


\section{BIBLIOGRAFIA COMPLEMENTAR}

Jenkins MA, Hopper JL, Flander LB, Carlin JB, Giles GG. The association between childhood asthma and atopy, and parental asthma, hayfever and smoking. Paediatr Perinat Epidemiol 1993; 7(1): 67-76.

Post CLA, Victora CG. The low prevalence of weight-for-height deficits in Brazilian children is related to body proportions. J Nutr 2001; 131: 1290-96.

Universidade de São Paulo. Faculdade de Saúde Pública. Biblioteca/CIR. Guia de apresentação de teses. São Paulo: A Biblioteca; 2001.

Ventura RN, Puccini RF, Silva EMK. Avaliação nutricional de crianças portadoras de "chiado no peito" atendidas nas Unidades Básicas de Saúde do Jardim Santo Eduardo e do Jardim Santa Emilia, município do Embu, no período de maio/88 a julho/93. Rev Paul Pediatria 1998; 16 (4): 201-7.

Shrimpton R, Victora CG, Onis M de, Lima RC, Blössner M, Clugston G. Worldwide timing of growth falteringÇ implications for nutritional interventions. Pediatrics [serial online] May 2001; 107 (5): [7 screens]. Available from: <URL:http://www.pediatrics.org/cgi/content/full/107/5/e75> [2004 feb]. 
ANEXOS 
ANEXO 1

\section{Composição da amostra PRojeto Chiado}

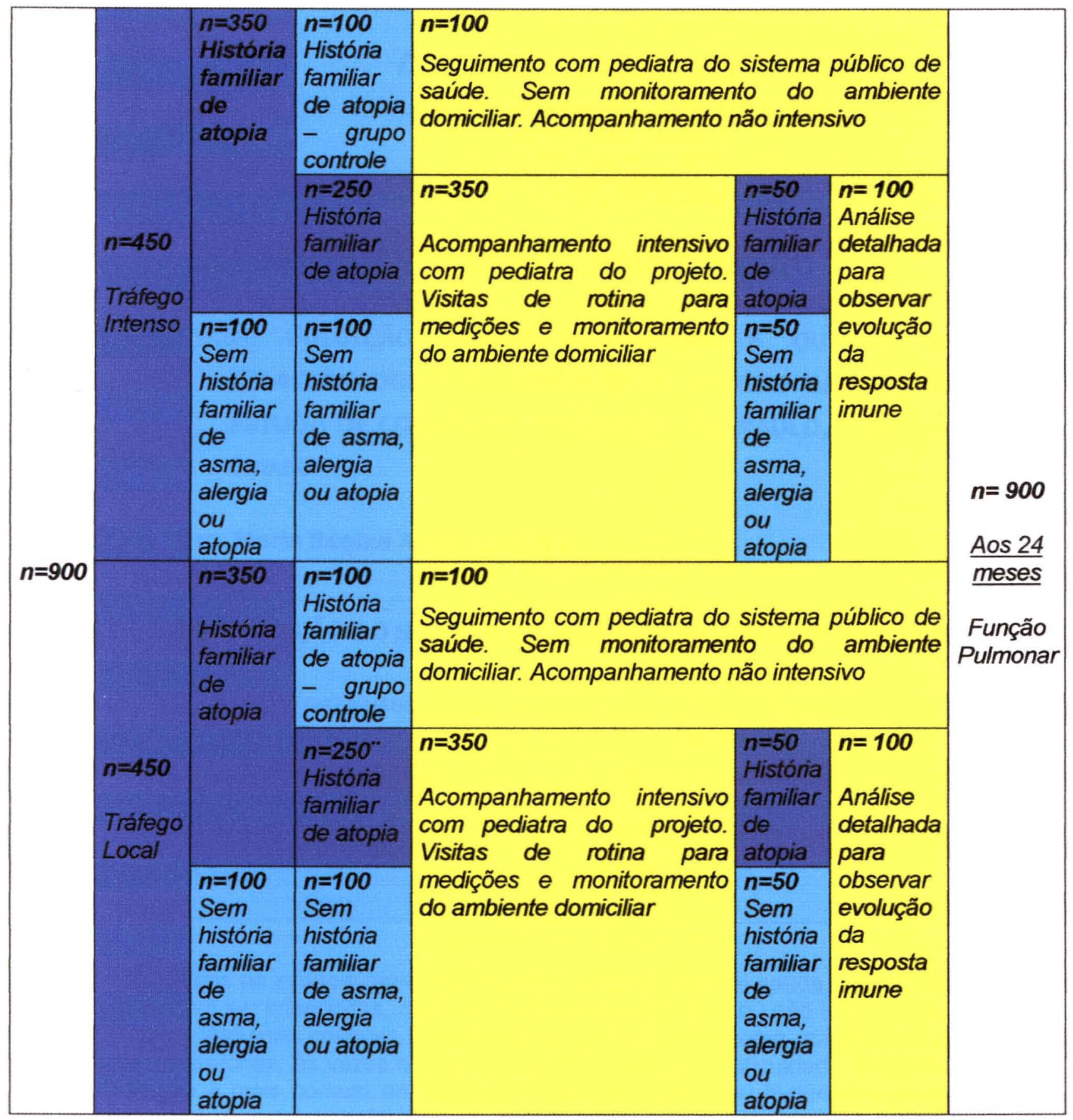


ANEXO 2

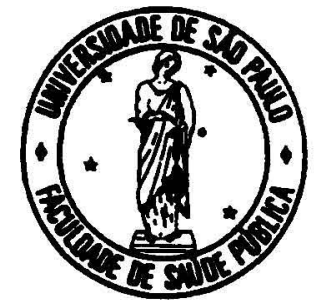

\section{UNIVERSIDADE DE SÃO PAULO \\ FACULDADE DE SAÚdE PÚBLICA \\ DEPARTAMENTO DE EPIDEMIOLOGIA}

Av. Dr. Arnaldo, 715 - CEP: 01246-904

Brasil - Săo Paulo/SP

Fone: 3083.5738 ou 3066.7777

Fax: (011) 3082-2920

\section{CONSENTIMENTO LIVRE E ESCLARECIDO}

\section{TÍTULO DA PESQUISA: POLUIÇÃO AMBIENTAL URBANA E OUTROS FATORES RELACIONADOS À OCORRÊNCIA DE CHIADO NA INFÂNCIA: UM ESTUDO DE COORTE NA CIDADE DE SÃO PAULO, BRASIL-PROJETO CHIADO}

COORDENADORA: Dra. Maria Regina Alves Cardoso

DADOS DE IDENTIFICAÇÃO DO SUJETTO DA PESQUISA OU RESPONSÁVEL LEGAL

1. NOME DA CRIANÇA

SEXO: $M \square \quad F \square$

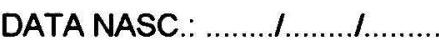

2. NOME DA MÃE

NOME DO PAI

ENDERECO:

No APTO:

BAIRRO:

CEP: TELEFONE

TELEFONE PARA CONTATO

As doenças respiratórias na infância representam um grave problema de saúde pública. As causas destas doenças podem ser infecciosas, como as gripes e pneumonias, ou não infecciosas, como a asma (ou bronquite). Algumas crianças apresentam chiado no peito como manifestação de uma destas doenças respiratórias, às vezes acompanhado de cansaço ou dificuldade respiratória. Este tipo de manifestação é mais comum em filhos de mães com asma ou história de alergia (rinite alérgica, por exemplo). Apesar de todos os avanços da medicina, pouco se sabe sobre os motivos que levam algumas crianças a apresentar episódios de chiado, enquanto outras nunca apresentam este tipo de sintoma.

Este estudo tem por objetivo investigar a ocorrência de chiado em filhos de mães com história de asma, com intuito de avaliar os fatores associados (poluição ambiental, infecções virais, etc.) ao aparecimento de sintomas respiratórios em crianças.

\section{ACOMPANHAMENTO MÉDICO:}

Para a realização do estudo será necessário um acompanhamento de perto de todas as crianças 
participantes através de consultas médicas periódicas, visitas domiciliárias e exames. Todas as crianças serão acompanhadas por um pediatra em atendimentos regulares no Instituto da Criança do Hospital das Clinicas - FMUSP. Os pais receberäo auxilio transporte para freqüentar estas consultas, que serão feitas para o acompanhamento rotineiro da saúde, como habitualmente é recomendado para todas as crianças nos primeiros anos de vida.

\section{VISITAS DOMICILIÁRIAS:}

Além deste acompanhamento médico rotineiro, serão feitas visitas às casas das crianças uma vez por mês e nestas ocasiōes serão feitas perguntas sobre a saúde delas. Além disso, serão realizadas nas casas medições de fatores ambientais como poluição, umidade e temperatura. Todos os resultados das medições realizadas serão fornecidos aos pais.

\section{EXAMES:}

Alguns exames complementares serão necessários para a investigação dos motivos que levam as crianças a terem chiado no peito. Serão pedidos dois tipos de exame para a mãe e quatro para as crianças como explicado abaixo:

\section{Para a mãe:}

(1) exame de fezes: uma amostra de fezes na primeira semana após o parto. Para colher este material a mãe receberá o recipiente adequado e as instruções de como proceder para a coleta e o armazenamento.

(2) exame de leite materno: uma amostra do leite matemo durante o primeiro mês de vida da criança. Para fazer esta coleta a mãe receberá um recipiente adequado e as instruçōes de como proceder para a coleta e o armazenamento.

\section{Para a crianca:}

(1) exame de fezes: amostras de fezes das crianças quando elas estiverem nas faixas de idade 4 a 6 meses, 7 a 9 meses, 10 a 12 meses, 16 a 18 meses e 22 a 24 meses (total de 5 amostras). Para colher este material a mãe receberá o recipiente adequado e as instruçöes de como proceder para a coleta, o armazenamento e transporte das amostras;

(2) exame de sangue: amostras de sangue das crianças quando elas completarem 3, 612 e 24 meses de idade (total de 4 amostras de $6 \mathrm{ml}$ de sangue cada uma). Para colher o sangue da sua criança nós vamos contar com uma enfermeira especializada e com materiais apropriados e descartáveis. Este procedimento não influenciará o desenvolvimento da sua criança e não causará nenhum problema, exceto a dor da picadinha da agulha no local da coleta;

(3) exame de lavado nasal: para detectar os vírus que causam resfriado e gripe e que podem causar chiado nas crianças é preciso colher secreção do nariz. Para isso, faz-se uma lavagem das duas narinas com soro e colhe-se o material com um "tubinho" coletor (cateter) colocado nas narinas para aspirar o conteúdo com uma seringa sem agulha. Este procedimento pode ser um pouco desconfortável e causar tosse ou espirros durante a coleta mas não oferece risco para a criança;

(4) prova de função pulmonar: serão realizadas no primeiro mês de vida e ao completar um e dois anos de idade. O exame em si é seguro e consiste da colocação de uma máscara sobre o rosto da criança para efetuar medidas da respiração

Antes de realizar ou coletar material para qualquer dos exames acima os pediatras da pesquisa explicarão os motivos e modo de realização dos mesmos. As crianças só serão submetidas aos exames após autorização (individual, por exame) dos pais, lembrando-se que a participação é VOLUNTÁRIA. Todos os resultados de exames poderão ser fornecidos aos pais. 


\title{
BENEFÍcIOS:
}

A participação nesta pesquisa è TOTALMENTE VOLUNTÁRIA. O benefício oferecido aos participantes consiste na realização de um acompanhamento pediátrico especializado, por equipe altamente qualificada, a ser prestado no Instituto da Criança do Hospital das Clínicas - FMUSP. Além disso, será oferecido apoio emocional em relação ao cuidado da criança para os familiares que assim o desejarem. Serão fornecidos vales transporte para as consultas rotineiras de acompanhamento pediátrico ou psicológico. Os participantes podem desistir, a qualquer momento, da participação na pesquisa bem como recusar a realização de qualquer um dos procedimentos listados acima, sem que isso resulte na interrupção do seguimento pediátrico rotineiro. A identidade das crianças participantes bem como dados de endereço domiciliar serão de absoluto sigilo e não poderão ser divulgados sem o prévio consentimento dos participantes.

\section{CONTATO COM OS PESQUISADORES:}

O pediatra responsável pelo acompanhamento das crianças neste estudo é o Dr. Luiz Vicente e ele poderá ser contatado para qualquer esclarecimento ou necessidade de encaminhamento para atendimento no endereço abaixo:

\section{Dr. Luiz Vicente R. F. da Silva Filho}

Instituto da Criança - FMUSP

Av. Dr. Enéas Carvalho de Aguiar 647

Tel: 30698566 ou 30698579

A coordenadora deste estudo é a Dra. Maria Regina e ela poderá ser contatada para qualquer dúvida ou esclarecimento sempre que necessário no endereço abaixo:

\author{
Dra. Maria Regina Alves Cardoso \\ Faculdade de Saúde Pública \\ Departamento de Epidemiologia \\ Av. Dr. Amaldo 715 CEP: 01246-904 São Paulo, SP \\ Tel: 30835738 ou 30667777 \\ Fax: 30812108 ou 30822920 \\ E-mail: rcardoso@usp.br
}

\section{CONSENTIMENTO PÓS-ESCLARECIDO}

Declaro que li e compreendi todas as informações enumeradas acima, e autorizo a participação do meu filho(a) nesta Pesquisa, o que implica no atendimento pediátrico, na realização de visitas domiciliárias periódicas para avaliação ambiental e aplicação de um questionário e na realização de exames de fezes, leite materno, sangue, lavado nasal e prova de função pulmonar. Os exames propostos não são de realização obrigatória.

Posso, a qualquer momento, como responsável pela criança, solicitar a interrupção da realização de procedimentos desta pesquisa, e nesta situação fica garantida a continuidade do atendimento pela equipe pediátrica da Pesquisa no Instituto da Criança do Hospital das Clínicas-FMUSP.
São Paulo,
de
de 200

assinatura do sujeito da pesquisa ou responsável legal 
UNIVERSIDADE DE SÃO PAULO

FACULDADE DE SAÚDE PÚBLICA

DEPARTAMENTO DE EPIDEMIOLOGIA

Av. Dr. Arnaldo, 715 - CEP: 01246-904

Brasil - São Paulo/SP

Fone: 3083.5738 ou 3066.7777

Fax: (011) 3082-2920

\section{CONSENTIMENTO LIVRE E ESCLARECIDO}

TÍTULO DA PESQUISA: POLUIÇÃO AMBIENTAL URBANA E OUTROS FATORES RELACIONADOS À OCORRÊNCIA DE CHIADO NA INFÂNCIA: UM ESTUdO DE COORTE NA CIDADE DE SÃO PAULO, BRASIL-PROJETO CHIADO

COORDENADORA: Dra. Maria Regina Alves Cardoso

\section{DADOS DE IDENTIFICAÇÃO DO SUJEITO DA PESQUISA OU RESPONSÁVEL LEGAL}

1. NOME DA CRIANÇA
SEXO: $M \square \quad F \square$
DATA NASC.
I....................

2. NOME DA MÃE

NOME DO PAI

ENDEREÇO

$\mathrm{N}^{\mathrm{O}}$

APTO:

BAIRRO:

CEP: TELEFONE:

TELEFONE PARA CONTATO

As doenças respiratórias na infância representam um grave problema de saúde pública. As causas destas doenças podem ser infecciosas, como as gripes e pneumonias, ou não infecciosas, como a asma (ou bronquite). Algumas crianças apresentam chiado no peito como manifestação de uma destas doenças respiratórias, às vezes acompanhado de cansaço ou dificuldade respiratória. Este tipo de manifestação é mais comum em filhos de mães com asma ou história de alergia (rinite alérgica, por exemplo). Apesar de todos os avanços da medicina, pouco se sabe sobre os motivos que levam algumas crianças a apresentar episódios de chiado, enquanto outras nunca apresentam este tipo de sintoma.

Este estudo tem por objetivo investigar a ocorrência de chiado em filhos de mães com história de asma, com intuito de avaliar os fatores associados (poluição ambiental, infecções virais, etc.) ao aparecimento de sintomas respiratórios em crianças.

\section{ACOMPANHAMENTO DAS CRIANÇAS:}

Para a realização do estudo, será necessário acompanhar a saúde e o desenvolvimento de um grupo de crianças através de visitas domiciliárias periódicas e de uma prova de função pulmonar. 
VISTTAS DOMICILIÁRIAS:

As visitas ocorrerão na primeira semana de vida destas crianças e depois aos 6, 12 e 24 meses de idade. Nestas ocasiōes será aplicado um questionário para a mãe com perguntas relativas à saúde da criança.

\title{
PROVA DE FUNÇÃO PULMONAR:
}

Será realizada uma prova de função pulmonar quando a criança completar dois anos de idade. $O$ exame em si é seguro e consiste da colocação de uma máscara sobre o rosto da criança para efetuar medidas da respiração. Antes desta prova, porém, os pais receberão uma explicação sobre os motivos e modo de realização da mesma. As crianças só serão submetidas a este exame após autorização especifica fornecida pelos pais, lembrando-se que a participação é VOLUNTÁRIA. Os resultados desta prova serão fornecidos aos pais.

\section{BENEFÍcIOS:}

A participação nesta pesquisa é TOTALMENTE VOLUNTÁRIA. O benefício oferecido pelos pesquisadores aos participantes consiste no encaminhamento das crianças para serviços de saúde adequados sempre que houver necessidade e/ou for solicitado pelos pais. Os participantes podem desistir, a qualquer momento, da participação na pesquisa bem como recusar a realização da prova de função pulmonar, sem que isso resulte em qualquer constrangimento. A identidade das crianças participantes bem como dados de endereço domiciliar serão de absoluto sigilo e não poderão ser divulgados sem o prévio consentimento dos participantes.

\section{CONTATO COM OS PESQUISADORES:}

O pediatra responsável pela pesquisa é o Dr. Luiz Vicente e ele poderá ser contatado para qualquer esclarecimento ou necessidade de encaminhamento para atendimento no endereço abaixo:

\author{
Dr. Luiz Vicente R. F. da Silva Filho \\ Instituto da Criança - FMUSP \\ Av. Dr. Enéas Carvalho de Aguiar 647 \\ Tel: $\mathbf{3 0 6 9} 8566$ ou 30698579
}

A coordenadora geral deste estudo é a Dra. Maria Regina e ela poderá ser contatada para qualquer dúvida ou esclarecimento sempre que necessário no endereço abaixo:

\author{
Dra. Maria Regina Alves Cardoso \\ Faculdade de Saúde Pública \\ Departamento de Epidemiologia \\ Av. Dr. Arnaldo 715 CEP: 01246-904 São Paulo, SP \\ Tel: 30835738 ou 30667777 \\ Fax: 30812108 ou 30822920 \\ E-mail: rcardoso@usp.br
}




\section{CONSENTIMENTO PÓS-ESCLARECIDO}

Declaro que li e compreendi todas as informações enumeradas acima, e autorizo a participação do meu filho(a) nesta Pesquisa, o que implica na realização de visitas domiciliárias periódicas para aplicação de um questionário e na realização de uma prova de função pulmonar. O exame proposto não é de realização obrigatória.

Posso, a qualquer momento, como responsável pela criança, solicitar a interrupção da realização de procedimentos desta pesquisa sem que isto resulte em qualquer constrangimento ou prejuízo.

São Paulo, de de 200 


\section{ANEXO 3}

UNIVERSIDADE DE SÃO PAULO

PROGRAMA DE INFORMAÇÃO EM SAÚDE E AMBIENTE

PROISAUSP

PROJETO CHIADO

\section{GUIA DE ELEGIBILIDADE}

Identificação: $\{$ ID $\}$

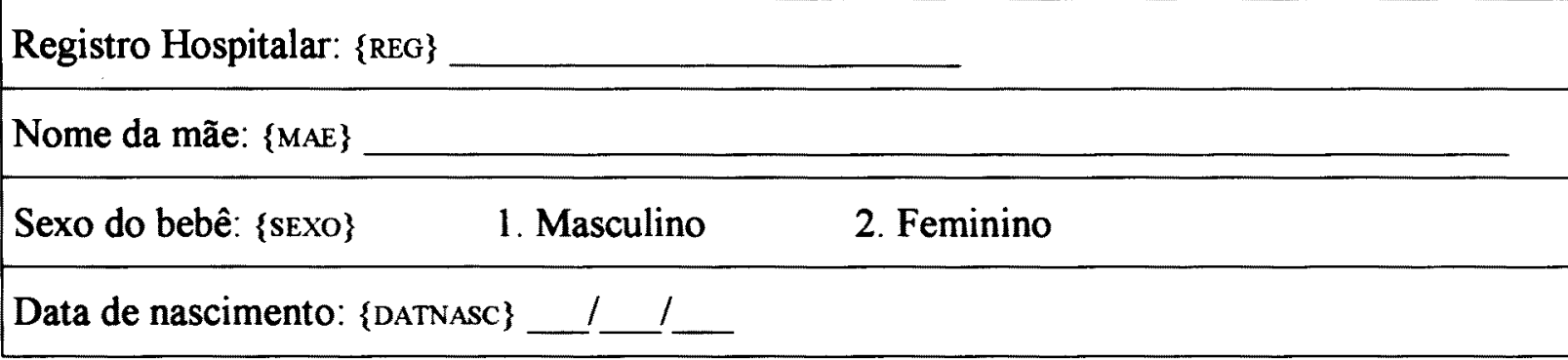

Endereço: $\{$ END $\}$

Bairro: \{BAIRRO\}

Telefone: $\{$ FONE $\}$

Ponto de Referência:

Data: $\{$ EDATENTR $\}$

Entrevistador: \{EENTREV\}

Observações:

\begin{tabular}{|c|c|c|c|}
\hline & CRÍTICA & CODIFICAÇÃO & DIGITAÇÃO \\
\hline NOME & & & \\
\hline DATA & -1 & 1 & 1 \\
\hline
\end{tabular}


CARACTERIZAÇÃO DO DOMICÍLIO:

O domicílio é:

Térrea

Sobrado

Apartamento

Térrea, favela

Sobrado, favela

Cortiço

Somente parte de baixo

Somente parte de cima

Somente parte de baixo, favela

Somente parte de cima, favela

Outros (especificar):

\section{INFORMAÇÕES DO RECÉM-NASCIDO:}

\begin{tabular}{|l|c|c|}
\hline & Não & Sim \\
\hline 1. Idade gestacional <35 semanas. \{EIDGEST\} & 1 & 2 \\
\hline $\begin{array}{l}\text { 2. Necessidade de oxigenoterapia de ventilação por pressão } \\
\text { positiva (VPP). \{EVP\} }\end{array}$ & 1 & 2 \\
\hline 3. Necessidade de entubação traqueal ou CPAP nasal. \{ECPAP\} & 1 & 2 \\
\hline 4. Necessidade de drogas cardiotônicas. \{EDROGA\} & 1 & 2 \\
\hline 5. Presença de má-formação. \{EMAFORM\} & 1 & 2 \\
\hline $\begin{array}{l}\text { 6. Presença de sinais sugestivos de síndrome genética. } \\
\text { \{ESINDGEN\} }\end{array}$ & 1 & 2 \\
\hline $\begin{array}{l}\text { 7. Sinais clínicos sugestivos de infecção materno-fetal. } \\
\text { \{ENFEMA\} }\end{array}$ & 1 & 2 \\
\hline 8. Mãe soropositiva para HIV. \{EHIV\} & 1 & 2 \\
\hline$\Rightarrow$ EXcluir a criança Caso haja alguma resposta SIM. & \\
\hline
\end{tabular}


INFORMAÇÕES DA FAMÍLIA:

\begin{tabular}{|l|l|c|c|c|l|}
\hline $\begin{array}{l}\text { 9. Diagnóstico médico de asma ou bronquite ou bronquite alérgica ou bronquite } \\
\text { asmática em algum momento da vida? }\end{array}$ \\
\hline & Não & Sim & NSA & NS/NR & \\
\hline Mãe \{EASMAM\} & 1 & 2 & 8 & 9 & \\
\hline Pai \{EASMAP\} & 1 & 2 & 8 & 9 & \\
\hline Irmãos \{EASMAI\} & 1 & 2 & 8 & 9 & \\
\hline
\end{tabular}

10. Já teve episódios de chiado ou aperto no peito ou tosse ou falta de ar em situações como:

10.1 Exercícios físicos (caminhada, corrida).

\begin{tabular}{|l|c|c|c|c|l|}
\hline & Não & Sim & NSA & NS/NR & \\
\hline Mãe \{EEXFISM & 1 & 2 & 8 & 9 & \\
\hline Pai $\{$ EEXXISP\} & 1 & 2 & 8 & 9 & \\
\hline Irmãos \{EEXFIII & 1 & 2 & 8 & 9 & \\
\hline \hline
\end{tabular}

10.2 Risadas.

\begin{tabular}{|l|c|c|c|c|c|}
\hline & Não & Sim & NSA & NS/NR & \\
\hline Mãe \{ERISM $\}$ & 1 & 2 & 8 & 9 & \\
\hline Pai \{ERISP\} & 1 & 2 & 8 & 9 & \\
\hline Irmãos \{ERISI\} & 1 & 2 & $\mathbf{8}$ & 9 & \\
\hline \hline
\end{tabular}

10.3 Mudanças climáticas.

\begin{tabular}{|l|c|c|c|c|c|}
\hline & Não & Sim & NSA & NS/NR & \\
\hline Mãe \{EMUDCLIM & 1 & 2 & 8 & 9 & \\
\hline Pai $\{$ EMUDCLIP\} & 1 & 2 & 8 & 9 & \\
\hline Irmãos \{EMUDCLI\} & 1 & 2 & 8 & 9 & \\
\hline \hline
\end{tabular}

10.4 Associado a perfumes e/ou cheiros fortes.

\begin{tabular}{|l|c|c|c|c|c|}
\hline & Não & Sim & NSA & NS/NR & \\
\hline Mãe \{EPERFM\} & 1 & 2 & 8 & 9 & \\
\hline Pai \{EPERFP\} & 1 & 2 & 8 & 9 & \\
\hline Irmãos \{EPERFI\} & 1 & 2 & 8 & 9 & \\
\hline \hline 10.5 Gripes ou resfriados. & \multicolumn{5}{|l|}{} \\
\hline \multicolumn{7}{|l|}{ Não } & Sim & NSA & NS/NR & \\
\hline Mãe \{EGRIPEM & 1 & 2 & 8 & 9 & \\
\hline Pai \{EGRIPEP\} & 1 & 2 & 8 & 9 & \\
\hline Irmãos \{EGRIPEI\} & 1 & 2 & 8 & 9 & \\
\hline
\end{tabular}


Identificação: $\{\mathrm{DD}\}$

\begin{tabular}{|l|c|c|c|c|c|}
\hline 10.6 Pó. & Não & Sim & NSA & NS/NR & \\
\hline Mãe \{EPOM\} & 1 & 2 & 8 & 9 & \\
\hline Pai \{EPOP\} & 1 & 2 & 8 & 9 & \\
\hline Irmãos \{EPOI\} & 1 & 2 & 8 & 9 & \\
\hline \hline 10.7 Mofo. & Não & Sim & NSA & NS/NR & \\
\hline & 1 & 2 & 8 & 9 & \\
\hline Mãe \{EMOFOM\} & 1 & 2 & 8 & 9 & \\
\hline Pai \{EMOFOP\} & 1 & 2 & 8 & 9 & \\
\hline Irmãos \{EMOFOI\} & & & & \\
\hline
\end{tabular}

11. Os sintomas melhoram com inalação ou broncodilatador como Aerolin, Berotec, Bricanyl, Salbutamol, Aminofilina?

\begin{tabular}{|l|c|c|c|c|l|}
\hline & Não & Sim & NSA & NS/NR & \\
\hline Mãe \{EINALM\} & 1 & 2 & $\mathbf{8}$ & 9 & \\
\hline Pai \{EINALP\} & 1 & 2 & $\mathbf{8}$ & 9 & \\
\hline Irmãos \{EINALI\} & 1 & 2 & 8 & 9 & \\
\hline
\end{tabular}

12. Nariz entupido, com coceira e/ou espirros em série:

12.1 Pela manhã.

\begin{tabular}{|l|c|c|c|c|c|}
\hline & Não & Sim & NSA & NS/NR & \\
\hline Mãe \{EENTUPMM\} & 1 & 2 & 8 & 9 & \\
\hline Pai \{EENTUPMP\} & 1 & 2 & 8 & 9 & \\
\hline Irmãos \{EENTUPMI & 1 & 2 & 8 & 9 & \\
\hline \hline
\end{tabular}

12.2 Associado a mudanças climáticas.

\begin{tabular}{|l|c|c|c|c|c|}
\hline & Não & Sim & NSA & NS/NR & \\
\hline Mãe \{EENTUPCM & 1 & 2 & 8 & 9 & \\
\hline Pai \{EENTUPCP\} & 1 & 2 & 8 & 9 & \\
\hline Irmãos $\{$ EENTUPCI & 1 & 2 & 8 & 9 & \\
\hline
\end{tabular}

12.3 Associado a perfumes e/ou cheiros fortes, pó ou mofo.

\begin{tabular}{|l|c|c|c|c|c|}
\hline & Não & Sim & NSA & NS/NR & \\
\hline Mãe \{EENTUPPM\} & 1 & 2 & 8 & 9 & \\
\hline Pai \{EENTUPPP\} & 1 & 2 & 8 & 9 & \\
\hline Irmãos \{EENTUPPI\} & 1 & 2 & 8 & 9 & \\
\hline
\end{tabular}


13. Coceira, vermelhidão e/ou lacrimejamento dos olhos freqüentemente.

\begin{tabular}{|l|c|c|c|c|c|}
\hline & Não & Sim & NSA & NS/NR & \\
\hline Mãe \{ECOCEIM\} & 1 & 2 & 8 & 9 & \\
\hline Pai \{ ECOCEIP\} & 1 & 2 & 8 & 9 & \\
\hline Irmãos \{ECOCEI\} & 1 & 2 & 8 & 9 & \\
\hline
\end{tabular}

14. Quando bebê apresentou lesões na pele do rosto com descamação e vermelhidão?

\begin{tabular}{|l|c|c|c|c|c|}
\hline & Não & Sim & NSA & NS/NR & \\
\hline Mãe \{EDESCM & 1 & 2 & 8 & 9 & \\
\hline Pai $\{$ EDESCP $\}$ & 1 & 2 & 8 & 9 & \\
\hline Irmãos $\{$ EDESCI\} & 1 & 2 & 8 & 9 & \\
\hline
\end{tabular}

15. Teve sintomas respiratórios como chiado no peito, aperto no peito ou tosse na gravidez?

\begin{tabular}{|l|c|c|c|l|}
\hline & Não & Sim & NS/NR & \\
\hline Mãe \{всHIADOM\} & 1 & 2 & 9 & \\
\hline
\end{tabular}

16. Já teve lesões na pele na região da dobra de joelhos, dobra de cotovelos, mãos e pés, com descamação e coceira?

\begin{tabular}{|l|c|c|c|c|c|}
\hline & Não & Sim & NSA & NS/NR & \\
\hline Mãe \{ELESAOM\} & 1 & 2 & 8 & 9 & \\
\hline Pai \{ELESAOP\} & 1 & 2 & 8 & 9 & \\
\hline Irmãos \{ELESAOI\} & 1 & 2 & 8 & 9 & \\
\hline
\end{tabular}

17. Já teve lesões na pele de aparecimento e desaparecimento súbitos, relacionadas à ingestão de alimentos ou medicamentos, caracterizadas por placas avermelhadas e sobrelevadas, com coceira?

\begin{tabular}{|l|c|c|c|c|c|}
\hline & Não & Sim & NSA & NS/NR & \\
\hline Mãe \{EINGM\} & 1 & 2 & 8 & 9 & \\
\hline Pai \{EINGP\} & 1 & 2 & 8 & 9 & \\
\hline Irmãos \{EINGI\} & 1 & 2 & 8 & 9 & \\
\hline
\end{tabular}

18. Residência na área do estudo: \{ERESID\}

\begin{tabular}{|l|c|}
\hline Não & 1 \\
\hline Sim & 2 \\
\hline
\end{tabular}


Identificação: $\{\mathrm{ID}\}$

\section{HISTÓRIA MATERNA POSITIVA:}

Incluir a mãe:

1. Quando houver resposta SIM na questão 9 e pelo menos uma resposta

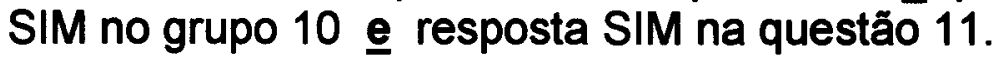
$\underline{\text { OU }}$

2. Quando houver resposta SIM em pelo menos três questões do grupo 12 ao 17.

\section{CONTROLE:}

Quando não houver nenhuma resposta SIM.

19. Termo de consentimento: ECONSENT $\}$

\begin{tabular}{|l|l|l|}
\hline Não & 1 \\
\cline { 1 - 2 } Sim & 2 & \\
\hline
\end{tabular}

20. Criança elegível? \{EELEGI\}

Não

Sim

1

2

\section{Observações:}


ANEXO 4

Número do questionário:

UNIVERSIDADE DE SÃO PAULO

PROGRAMA DE INFORMAÇÃO EM SAÚDE E AMBIENTE

PROISAIUSP

PROJETO CHIADO

\section{ACOMPANHAMENTO NUTRICIONAL I - almentos liquidos, agua 6 cha}

\section{Identificação: $\{\mathrm{ID}\}$}

Idade da criança:

Registro IC:

Nome da criança:

Nome da mãe:

Informante: $\{$ NINFOR__ $\}$ 1. Mãe 2. Pai 3. Outro:

Data da consulta: $\{$ NDIAPC ___

Nutricionista: \{NUTRIC

Observações:

\begin{tabular}{|c|c|c|c|}
\hline & CRÍTICA & CODIFICAÇÃO & DIGITAÇÃO \\
\hline NOME & & & \\
\hline DATA & 1 & 1 & 1 \\
\hline
\end{tabular}




\begin{tabular}{|l|c|c|}
\hline 1. Existe um local definido para a alimentação do bebê? \{NLOCAL__\} \\
\hline Não & 1 & \\
\cline { 1 - 3 } Sim & 2 & \\
\hline Qual? \{NQUALI__a NQUAL___ & & \\
\hline & & \\
\hline
\end{tabular}

\begin{tabular}{|c|c|}
\hline $\begin{array}{l}\text { Não } \rightarrow \text { Data de término: }\{\text { NDTA__ }\} \text { _ } \\
\rightarrow \text { Dirïja-se à questão número } 5\end{array}$ & 1 \\
\hline Sim & 2 \\
\hline
\end{tabular}

\section{Frequiência ( $\mathrm{n}^{0}$ de vezes/dia ou intervalo) e duração (em minutos) das mamadas ao} peito:

Freqüência: \{ NFREP___\}

Duração: \{NDURP__\}

\begin{tabular}{|l|c|}
\hline 4. Uso de medicamento pela mãe: \{NMEDMA___\} & 1 \\
\hline Não $\rightarrow$ Dirija-se à questão número 5 & 2 \\
\hline Sim & \\
\hline Qual (is)? \{NQUME1__a NQUME5__\} & \\
\hline & \\
\hline
\end{tabular}

\begin{tabular}{|l|l|}
\hline 4.1. Quem orientou? \{NORMED __\} & 1 \\
\hline Conta própria & 2 \\
\hline Médico & 3 \\
\hline Outro & 9 \\
\hline NS/NR & \\
\hline
\end{tabular}

\begin{tabular}{|l|c|c|}
\hline 5. Foi introduzido outro tipo de leite que não o materno? \{NOUTLE __\} \\
\hline Não $\rightarrow$ Dirija-se à questão número 6 & 1 & \multirow{2}{*}{} \\
\cline { 1 - 2 } Sim & 2 & \\
\hline
\end{tabular}




\begin{tabular}{|c|c|c|c|c|c|c|}
\hline \multirow[t]{2}{*}{$\begin{array}{c}\text { Qual } \\
\{\text { NQLEIl __ a NQLEI ___ }\}\end{array}$} & \multirow{2}{*}{$\begin{array}{c}\text { Data da } \\
\text { introduçăo } \\
\left\{\mathrm{NDILL}_{--}{ }^{\mathrm{a} \text { NDIL } 3}{ }_{--}\right\}\end{array}$} & \multicolumn{2}{|c|}{$\begin{array}{c}\text { Ainda toma } \\
\text { este leite? } \\
\text { \{NTL }\end{array}$} & \multirow{2}{*}{$\begin{array}{c}\text { Data de término } \\
\text { do uso } \\
\left\{\mathrm{NDTL}_{\ldots}{ }_{-} \text {a NDTL } 3_{\ldots}\right\}\end{array}$} & \multirow[t]{2}{*}{ 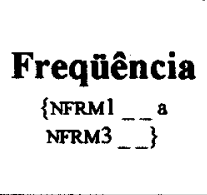 } & \multirow{2}{*}{ 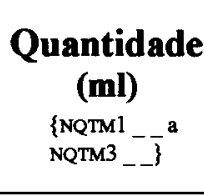 } \\
\hline & & Não & Sim & & & \\
\hline & 1 & 1 & 2 & 1 & & \\
\hline & 1 & 1 & 2 & 1 & & \\
\hline & 1 & 1 & 2 & 1 & & \\
\hline
\end{tabular}

\subsection{Descrever o preparo da mamadeira:}

Descrever todos os ingredientes utilizados e as quantidades

\begin{tabular}{|l|c|}
\hline 5.2. Quem orientou a introdução desse (s) leite (s)? \{NORINT___ \\
\hline Conta própria & 1 \\
\hline Médico/nutricionista & 2 \\
\hline Outro & 3 \\
\hline NS/NR & 9 \\
\hline
\end{tabular}

\section{A criança já recebeu alguma dessas bebidas:}

\begin{tabular}{|c|c|c|c|c|c|}
\hline \multicolumn{6}{|c|}{ Água. \{NBEBA __ $\}$} \\
\hline \multicolumn{4}{|c|}{ Não $\rightarrow$ Dirÿa-se à questão número 6. CHÁS } & 1 & \\
\hline \multicolumn{4}{|l|}{ Sim } & 2 & \\
\hline \multirow{2}{*}{$\begin{array}{c}\text { Data da } \\
\text { introdução } \\
\left\{\text { NDIAG__ }_{-}\right\}\end{array}$} & \multicolumn{2}{|c|}{$\begin{array}{c}\text { Ainda toma água? } \\
\text { \{NTAG__\} }\end{array}$} & \multirow{2}{*}{$\begin{array}{l}\text { Data de término do uso } \\
\text { \{NDTAG }--\}\end{array}$} & \multirow{2}{*}{$\begin{array}{c}\text { Freqüência } \\
\left\{\text { NBEBAF }_{--}\right\}\end{array}$} & \multirow{2}{*}{$\begin{array}{c}\text { Quantidade } \\
\text { (ml) } \\
\left\{\text { NBEBAQ__ }_{-}\right\}\end{array}$} \\
\hline & Não & Sim & & & \\
\hline 1 & 1 & 2 & 1 & & \\
\hline
\end{tabular}

Descrever o preparo:

Chás. \{NBEBC__\}

\begin{tabular}{|l|c|}
\hline Não $\rightarrow$ Dirïa-se à questão número 6. SUCOS & 1 \\
\hline $\operatorname{Sim}$ & 2 \\
\hline
\end{tabular}




\begin{tabular}{|c|c|c|c|c|c|}
\hline \multirow{2}{*}{$\begin{array}{c}\text { Data da } \\
\text { introduçåno } \\
\left\{\mathrm{NDICH}_{--}\right\}\end{array}$} & \multicolumn{2}{|c|}{$\begin{array}{c}\text { Ainda toma chá? } \\
\quad\left\{\mathrm{NTCH}_{-}\right\}\end{array}$} & \multirow{2}{*}{$\begin{array}{c}\text { Data de término do uso } \\
\qquad\left\{\mathrm{NDTCH}_{-}\right\}\end{array}$} & \multirow{2}{*}{$\begin{array}{l}\text { Freqũência } \\
\left\{\text { NBEBCF__- }_{-}\right\}\end{array}$} & \multirow{2}{*}{$\begin{array}{c}\text { Quantidade } \\
\text { (ml) } \\
\left\{\mathrm{NBEBCQ}_{-}\right\}\end{array}$} \\
\hline & Não & Sim & & & \\
\hline 1 & 1 & 2 & 1 & & \\
\hline
\end{tabular}

Descrever o preparo:

$\rightarrow$ Descrever todos os ingredientes utifizados e as quantidades

\begin{tabular}{|c|c|c|c|c|c|c|}
\hline \multicolumn{6}{|c|}{ Sucos. $\{$ NBEBS __ $\}$} & \\
\hline \multicolumn{5}{|c|}{ Não $\rightarrow$ Dirÿa-se à questão número 6. OVTRO } & 1 & \\
\hline \multicolumn{5}{|l|}{ Sim } & 2 & \\
\hline \multirow[t]{2}{*}{$\underset{\{\text { NQSU1 _- a NQSU5 _- }}{\text { Qual }}$} & \multirow{2}{*}{$\begin{array}{c}\text { Data da } \\
\text { introduçåo } \\
\{\text { NDIS1_. a a NISS _. }\}\end{array}$} & \multicolumn{2}{|c|}{$\begin{array}{l}\text { Ainda toma } \\
\text { este suco? } \\
\left\{\mathrm{NTS} 1_{-} \text {a } \mathrm{NTSS}_{\ldots}\right\}\end{array}$} & \multirow{2}{*}{$\begin{array}{c}\text { Data de término } \\
\text { do uso } \\
\left.\{\mathrm{NDTS}\}_{\ldots} \ldots \mathrm{NDTSS} \ldots\right\}\end{array}$} & \multirow[t]{2}{*}{$\begin{array}{c}\text { Freqüêência } \\
\text { \{NBESF } 1 \text {-a } \\
\text { NBESE5 } 5-- \text { \} }\end{array}$} & \multirow{2}{*}{ 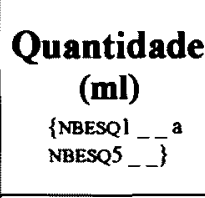 } \\
\hline & & Não & Sim & & & \\
\hline & 1 & 1 & 2 & 1 & & \\
\hline & 1 & 1 & 2 & 1 & & \\
\hline & 1 & 1 & 2 & 1 & & \\
\hline & 1 & 1 & 2 & 1 & & \\
\hline & 1 & 1 & 2 & 1 & & \\
\hline
\end{tabular}

Descrever o preparo:

Descrever todos os ingredientes utifizados e as quantidades

\begin{tabular}{|c|c|}
\hline Outro. $\left\{\right.$ NBEBO $\_-$\} & \\
\hline Não $\rightarrow$ Dirüa-se à questão número 7 & 1 \\
\hline Sim & 2 \\
\hline
\end{tabular}


A18

\begin{tabular}{|c|c|c|c|c|c|c|}
\hline \multirow{2}{*}{$\underbrace{\text { Qual }}_{\{\mathrm{NQOU1}}$} & \multirow{2}{*}{$\begin{array}{c}\text { Data da } \\
\text { introdução } \\
\{\text { NDIOI__ a NDIO3__\} }\end{array}$} & \multicolumn{2}{|c|}{$\begin{array}{l}\text { Ainda toma } \\
\text { esta bebida? } \\
\left\{\mathrm{NTO}_{\text {a }} \text { NTO3__ }\right\}\end{array}$} & \multirow{2}{*}{$\begin{array}{c}\text { Data de término } \\
\text { do uso } \\
\left\{\mathrm{NTO}_{\ldots} \text { a NTO3 }\right.\end{array}$} & \multirow{2}{*}{$\begin{array}{l}\text { Freqūência } \\
\text { \{NBEOF1_a } \\
\text { NBEOF3 } 3 \text { - }\end{array}$} & \multirow{2}{*}{ 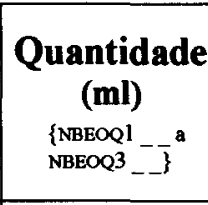 } \\
\hline & & Não & Sim & & & \\
\hline & 1 & 1 & 2 & 1 & & \\
\hline & 1 & 1 & 2 & 1 & & \\
\hline & 1 & 1 & 2 & 1 & & \\
\hline
\end{tabular}

Descrever o preparo:

Descrever todos os ingredientes utilizados e as quantidades

\begin{tabular}{|l|l|}
\hline 7. Tipo de aleitamento: \{NALEIT___ & 1 \\
\hline Materno exclusivo & 2 \\
\hline Misto & 3 \\
\hline Artificial & 4 \\
\hline Materno predominante & \\
\hline
\end{tabular}

Observações: 
ANEXO 5

Número do questionário:

UNIVERSIDADE DE SÃO PAULO

PROGRAMA DE INFORMACÃO EM SAÚDE E AMBIENTE

PROISAUSP

PROJETO CHIADO

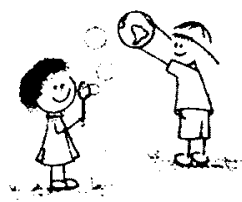

\section{ACOMPANHAMENTO NUTRICIONAL, II - Introduça de allmentos} (allmentacaio de transicaio)

Identificação: $\{\mathrm{ID}\}$

Idade da criança:

Registro IC:

Nome da criança:

Nome da mãe:

\begin{tabular}{|l|l|l|l|}
\hline Informante: $\{$ IINFOR__\} 1. Mãe & 2. Pai 3. Outro: & \\
\hline Data da consulta: $\{$ IDIAPC __ $\}$ & & & \\
\hline Nutricionista: $\{$ INUTRI___ & & & \\
\hline
\end{tabular}

Observações:

\begin{tabular}{|c|c|c|c|}
\hline & CRÍTICA & CODIFICAÇÃO & DIGITAÇÃO \\
\hline NOME & & & \\
\hline DATA & 1 & 1 & 1 \\
\hline
\end{tabular}




\begin{tabular}{|l|c|c|}
\hline 1. O bebê come papa doce? \{IPAPDO ___ & 1 \\
\cline { 1 - 2 } Não $\rightarrow$ Dirija-se à questão número 2 & 2 & \\
\cline { 1 - 2 } & & \\
\hline
\end{tabular}

\begin{tabular}{|c|c|c|c|c|c|}
\hline \multirow[t]{2}{*}{ 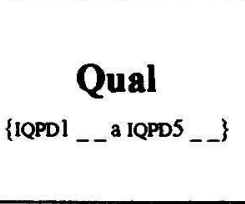 } & \multirow[t]{2}{*}{$\begin{array}{c}\text { Data da introdução } \\
\text { \{mIPDI__a mIPDS __ }\}\end{array}$} & \multicolumn{2}{|c|}{$\begin{array}{l}\text { Ainda come } \\
\text { esta papa? } \\
\text { ([MPD1 }\end{array}$} & \multirow[t]{2}{*}{$\begin{array}{c}\text { Data de término } \\
\text { do uso } \\
\text { \{DTPDI__ a IDTPDS__\} }\end{array}$} & \multirow{2}{*}{ 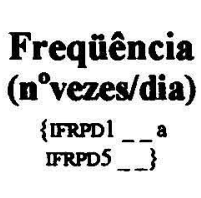 } \\
\hline & & Não & Sim & & \\
\hline & 1 & 1 & 2 & 1 & \\
\hline & 1 & 1 & 2 & 1 & \\
\hline & 1 & 1 & 2 & 1 & \\
\hline & 1 & 1 & 2 & 1 & \\
\hline & 1 & 1 & 2 & 1 & \\
\hline
\end{tabular}

Descrever o preparo da(s) papa(s) doce(s):

Descrever todos os ingredientes utifizados e as quantidades

Quem orientou a introdução da(s) papa(s)? \{IORPAP ___

\begin{tabular}{|l|c|}
\hline Conta própria & 1 \\
\hline Médico / Nutricionista & 2 \\
\hline Outro & 3 \\
\hline NS/NR & 9 \\
\hline
\end{tabular}


2. 0 bebê come papa salgada? \{IPAPSA ___

\begin{tabular}{|c|c|c|c|c|c|}
\hline \multicolumn{4}{|c|}{ Não $\rightarrow$ Termine o questionário. } & 1 & \\
\hline \multicolumn{4}{|l|}{ Sim } & 2 & \\
\hline \multirow[t]{2}{*}{$\begin{array}{c}\text { Qual } \\
\left\{\left.1 \mathrm{QPS}\right|_{--} \text {a IQPSS _-_ }\right\}\end{array}$} & \multirow[t]{2}{*}{$\begin{array}{c}\text { Data da introdução } \\
\{\text { mPPs! __ a DPSS }\}\end{array}$} & \multicolumn{2}{|c|}{$\begin{array}{l}\text { Ainda come } \\
\text { esta papa? } \\
\text { (IIPs! __a arrss __ }\end{array}$} & \multirow[t]{2}{*}{$\begin{array}{c}\text { Data de término } \\
\text { do uso } \\
\{\text { [DTPS1__ a DTPSS __ }\}\end{array}$} & \multirow{2}{*}{ 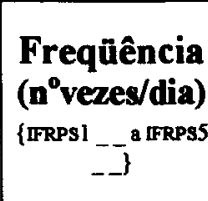 } \\
\hline & & Não & Sim & & \\
\hline & 1 & 1 & 2 & 1 & \\
\hline & 1 & 1 & 2 & 1 & \\
\hline & 1 & 1 & 2 & 1 & \\
\hline & 1 & 1 & 2 & 1 & \\
\hline & 1 & 1 & 2 & 1 & \\
\hline
\end{tabular}

Descrever o preparo da(s) papa(s) salgada(s):

Descrever todos os ingredientes utifizados e as quantidades

Quem orientou a introdução da(s) papa(s)? \{IOPAPS ___ $\}$

Conta própria

Médico / Nutricionista

Outro

3

NS/ NR

9




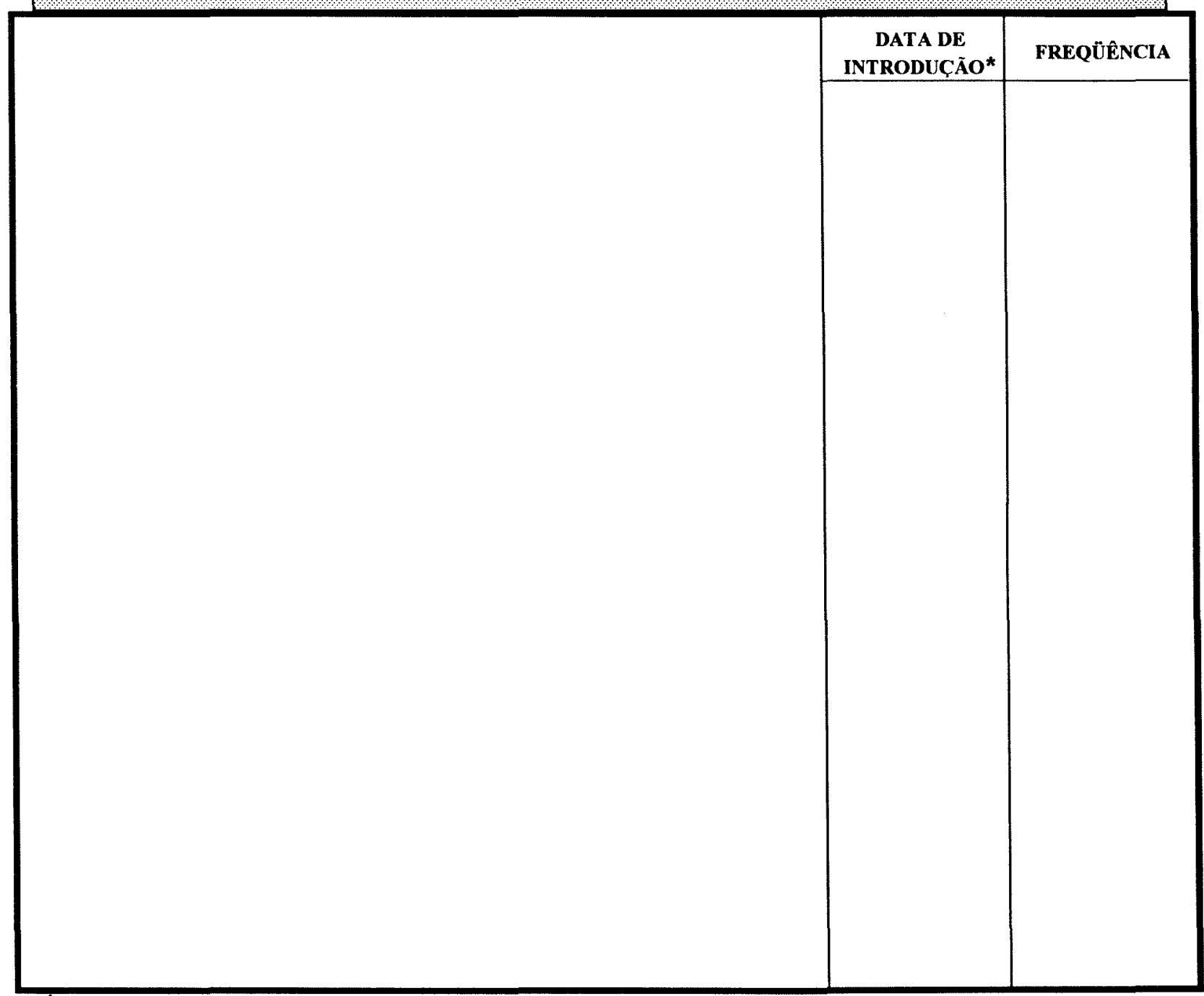

* Para os alimentos: ovo, peixe/frutos do mar, morango, kiwi, amendoim, castanhas, com corantes e/ou conservantes na composição.

\section{OBSERVAÇÕES}




\section{Proposta para classificaçăo da alimentação CLASSIFICAÇÃO DA ALIMENTAÇÃO}

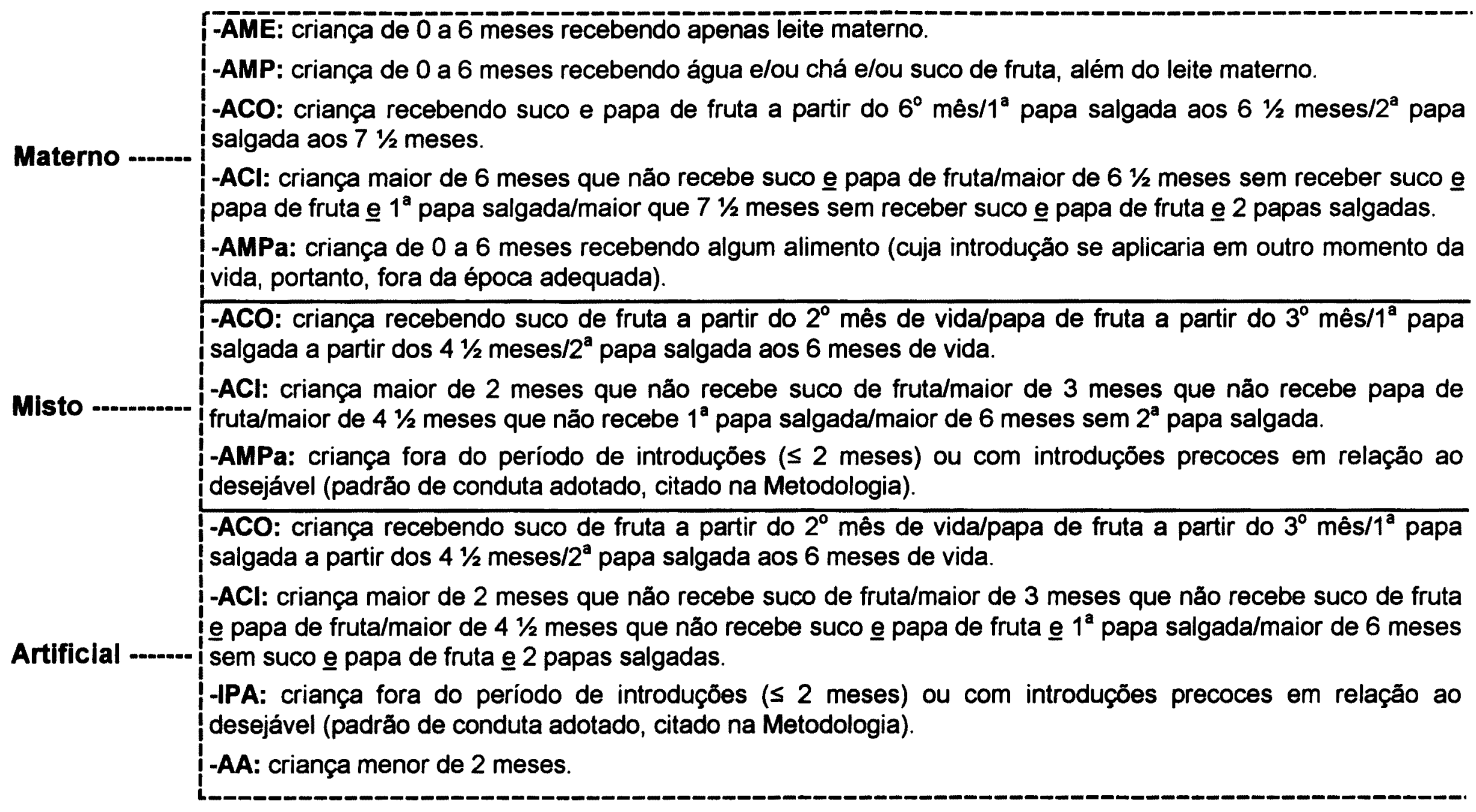




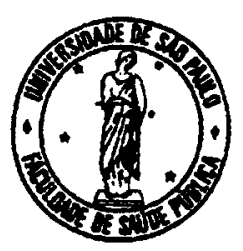

\section{Universidade de São Paulo}

Faculdade de Saúde Pública

\section{Of. COEP/269/01}

19 de dezembro de 2001

Pelo presente, informo que o Comitê de Ética em Pesquisa da Faculdade de Saúde Pública da Universidade de São Paulo-COEP, analisou e aprovou, de acordo com os requisitos da Resolução CNS/196/96, o protocolo de Pesquisa n..$^{\circ} 615$, intitulado: "POLUIÇÃO AMBIENTAL URBANA E OUTROS FATORES RELACIONADOS À OCORRÊNCIA DE CHIADO NA INFÂNCIA: UM ESTUDO DE COORTE NA CIDADE DE SÃO PAULO, BRASIL", apresentado pela pesquisadora Maria Regina Alves Cardoso.

Atenciosamente,

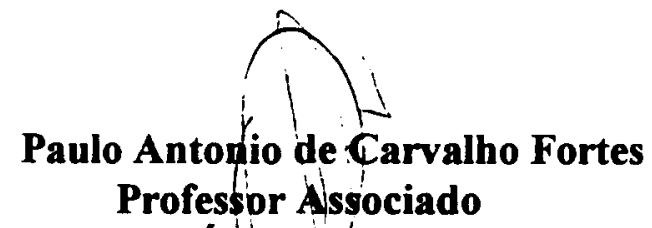

Coordenador do Comitê de Ética end Pesquisa da FSP-COEP 


\section{ANEXO 8}

MINISTÉRIO DA SAÚdE

Conselho Nacional de Saúde

Comissão Naclonal de Éticā om Pesqulsa - CONEP

PARECER $N^{\circ} 300 / 2003$

CAAE : 0141.0.015.000-02

Registro CONEP: 7194 (Esto $n^{\circ}$ deve ger citado nas correspondènclas roforentes a esto projeto )

Registro CEP: 1077/02

Processo $n^{\circ}$ 25000.004343/2003-25

Projeto de Pesquisa: "Poluiçâo ambiental urbana e outros fatores relacionados à ocorrência de chiado na infància : um estudo de coorte na cidade de Sáo Paulo, Brasil ".

Pesqulsador Responsável : Dr. Luiz Vicente Ribeiro Ferreira da Silva Filho Instituição: HCFMUSP

Área Temática Especial : Pesquisa com cooperação estrangeira

RESUMO: Trata-se de pesquisa multicéntrica que envolve participação internacional. Pretende estudar fatores ambientais relacionados à ocorrência de chiado respiratório em crianças. Seráo acompanhados 700 recém-nascidos que realizarăo provas de funçáo pulmonar, exames de fezes e sangüíneos e lavado nasal. Os critérios de inclusaao no estudo sāo compativeis com seus propósitos.

CONSIDERAÇóES: A pesquisa tem relevância social e científica. A ponderaçāo entre riscos e benefícios é positiva, podendo trazer benefícios diretos aos envolvidos, porque os participantes terâo acompanhamento direto de médicos pediatras e realizarăo exames condizentes às necessidades clínicas individuais. $O$ risco de maletícios envolvendo os testes a serem realizados é mínimo. Os termos de consentimento livre e esclarecido trazem os principios éticos para o bom desenvolvimento da pesquisa. A concepção da pesquisa tem a participação importante de pesquisadores brasileiros e é adaptada às necessidades do pais.

As informaçöes enviadas atendem aos aspectos fundamentais das Resoluçōes CNS 196/96 e 292/99, sobre Diretrizes e Normas Regulamentadoras de Pesquisas Envolvendo Seres Humanos;

O projeto foi aprovado pelo Comitê de Ética em Pesquisa - CEP da instituição supracitada.

Diante do exposto, a Comissão Nacional de Ética em Pesquisa CONEP, de acordo com as atribuiçōes deflnidas na Res. CNS 196/96, manifesta - se pela aprovação do projeto de pesquisa proposto.

Situação : Projeto aprovado

Brasilia. 20 de fevereiro de 2003

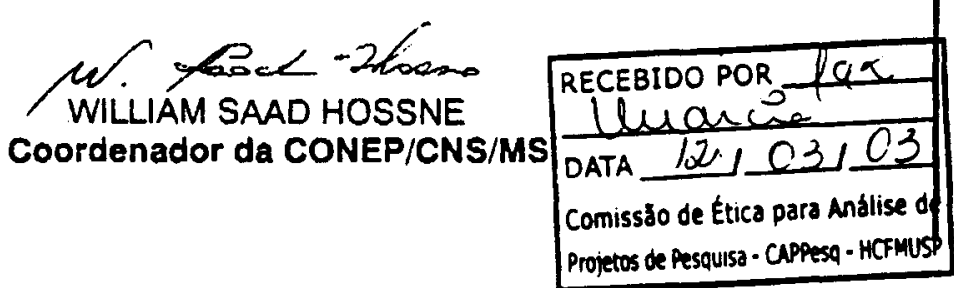




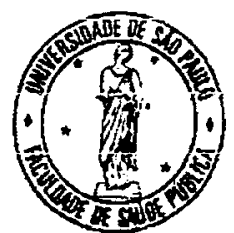

\section{Universidade de São Paulo}

\section{Faculdade de Saúde Pública}

COMITE DE ÉTICA - COEP

\section{Of.COEP $/ 057 / 04$}

Pelo presente, informo que o Comitê de Ética em Pesquisa da Faculdade de Saúde Pública da Universidade de São Paulo-COEP, analisou e aprovou o protocolo de pesquisa n." 1120, intitulado "ALLENT AÇÃO NO PRINEIRO ANO DE VIDA DE CRIANÇAS COM RISCO PARA O DESENVOLVIMENTO DE ASMA E/OU ATOPIA - PROJETO CHIADO", apresentado pelo pesquisador Rafaei de Carvalho Cacavalio.

$O$ projeto faz parte de uma pesquisa mais ampla, intitulada: "POLUTÇÃO AMBIENTAL URBANA E OUTROS FATORES RELACIONADOS A OCORREANCIA DE CHIADO NA INFANCLA: UM ESTUDO DE COORTE NA CIDADE DE SÃO PAULO, BRASI"”, da pesquisadora Maria Regina Alves Cardoso, já analisada e aprovada por este Comitê em reunião reaiizada em 19.12.2001, não havendo modificações relativas ao conteúdo da pesquisa original.

Atenciosamente,
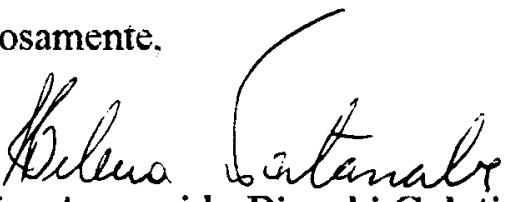

Dunice Aparecida Bianchi Galati

Professora Doutora

Coordenadora do Comitê de Ética em Pesquisa da FSP-COEP 